\title{
Beyond THE RHETORIC Of PARTICIPATION A Case Study of Participatory Practices and Power IN EAST NUSA TENGgaRA, INDONESIA
}

by

Cynthia Monica Ecclestone

A thesis submitted to Victoria University of Wellington in partial fulfilment of the requirements for the degree of Master of Development Studies

School of Geography, Environment and Earth Sciences Victoria University of Wellington

2020 
Figure 1 - Mentoring Local Farmers

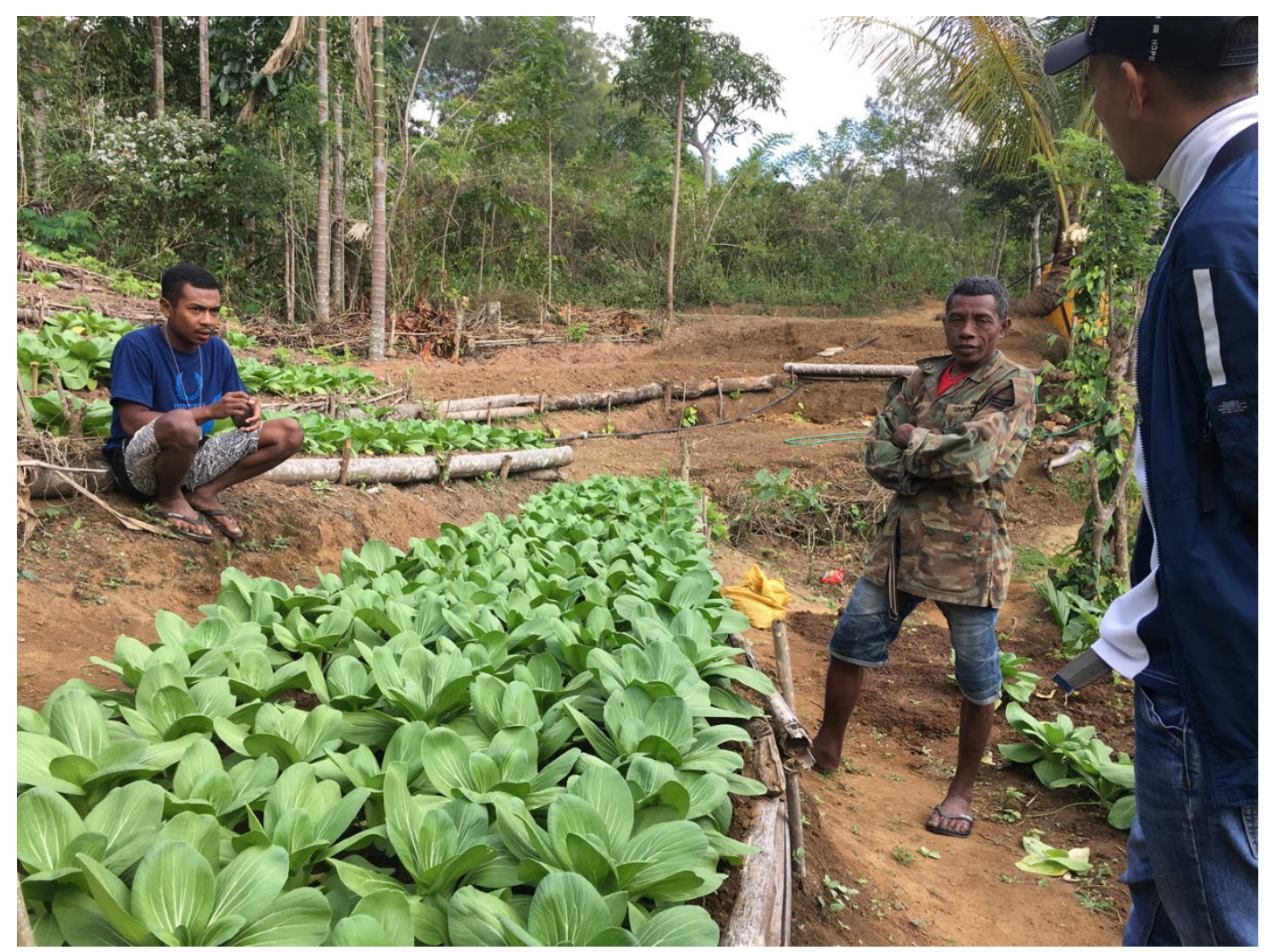

Location: TTS Regency

Date: 25 Jun 2019

Source: Cynthia Ecclestone 


\begin{abstract}
This study looks critically at the practices of participatory development by a local NGO in East Nusa Tenggara, Indonesia. In doing so, the Life Skills Training programme is chosen as a case study of potentially participatory development. By exploring people's experiences, perceptions, and feelings about their participation, the study examines the power dynamics in the programme. To gather data, the study used semi-structured interviews and observations. Interviews were conducted with 14 research participants, who were purposively selected from different backgrounds.
\end{abstract}

The study finds that the approaches of the programme point to lower-level forms of participation, with local people having both minimal involvement and little role in decision-making. Despite the use of the rhetoric of participation, doubts about the quality of participation are raised particularly in relation to gender, age, and religious differences. By scrutinising the ways in which issues of power manifest in the programme, the study demonstrates that issues of power and power relations in participatory development are quite complex. Using the frameworks of power analysis, I argue that issues related to inequalities of power are manifested in the NGO's domination of decision-making processes, and that these issues were also contributed to by a patriarchal culture and filial piety. More importantly, I argue that people's participation in the programme is less likely lead to meaningful outcomes if the issues of power imbalances are not addressed.

The study provides useful insights into ways to improve the practices of participatory development. An increased understanding of various forms of power and their implications will be useful for development practitioners to exercise their power to make a difference. Moreover, efforts to reduce power imbalances in participatory development will be inadequate without critically examining and attending to power and its dynamics. Without a deeper understanding of power, development programmes that make claims about participation may be less effective in achieving transformative goals for the intended beneficiaries. 


\section{DEDICATION}

This thesis is dedicated to my beloved father, mother, and my brother Tony.

You are forever in my heart. 


\section{ACKNOWLEDGEMENTS}

First and foremost, praise and thanks to God for all the blessings and protection throughout my study.

The completion of this thesis would not have been possible without the kind support and help of many people, whom I wish to thank for their invaluable assistance during my study.

I wish to express my deepest gratitude to my supervisor, Professor John Overton, who has believed in me and consistently encouraged me from the beginning of my study. He was always reliable and supportive whenever I came across a problem or had a question during my study. Without his guidance and advice, this thesis would not have become a reality.

I wish to thank Ray Watters through the Asia Pacific Research Award for the financial support towards my field research.

I would like to thank the head and staff of Yayasan Tangan Pengharapan for allowing me to undertake my research about one of the organisation's programmes. I am particularly grateful for the warm welcome and friendly assistance from Frouline Septianingrum, Richi Mboro, Bapak and Ibu Margono, Yermi Manane, Ibu Narti and Pak Gogo.

My grateful thanks are also extended to all of my research participants, especially the local people of Timor Tengah Selatan regency, who have shared their experiences, stories, and realities.

I am also grateful for the help from my friends, family members, and relatives in Indonesia, for supporting and motivating me in many ways during my field research. I wish to acknowledge the help of Wahyu Mahendra in getting the recommendation letter from University of Indonesia for visa purposes. I would like to thank Lina Marliani for the advice, love, and support, especially for letting me stay with her while I was in Jakarta. My sincere thanks go to Adinda Tenriangke Muchtar, Eva Fitrina, and Rania Siahaan for the continuous support, motivation, and beautiful friendship. I would also like to thank Yossie Jacob and her family, who welcomed me with open arms in their home in Kupang. Additionally, I wish to thank Amalia Giri and her family for the genuine love and care during my stay with them in Jakarta.

Finally, I would like to express my profound gratitude to my husband, Andrew Ecclestone, for providing me with unfailing support, useful feedback, 'lively' discussions, and continuous encouragement throughout my years of study and the research process, as well as in the process of writing this thesis. 


\section{CONTENTS}

ABSTRACT

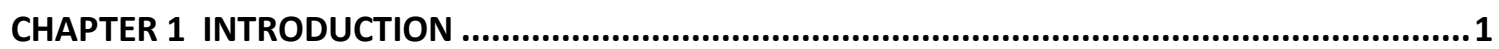

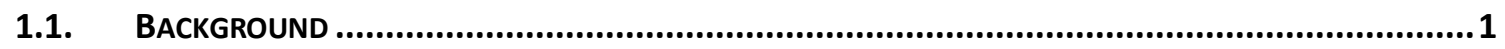

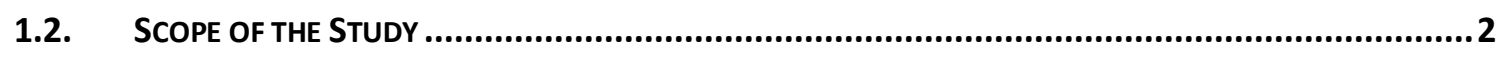

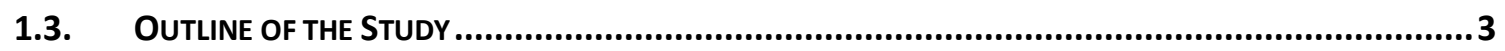

CHAPTER 2 PARTICIPATION AND POWER IN DEVELOPMENT ......................................... 5

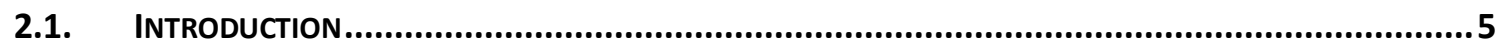

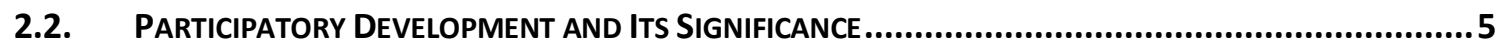

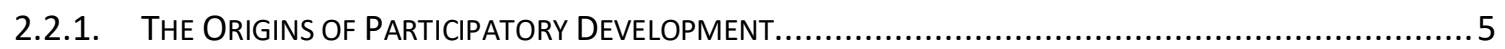

2.2.2. WHAT IS 'PARTICIPATORY DEVELOPMENT'?

2.2.3. Key PRINCIPLES Of A GenUINE PARTICIPATORY DeVELOPMENT PROJeCT..................................... 8

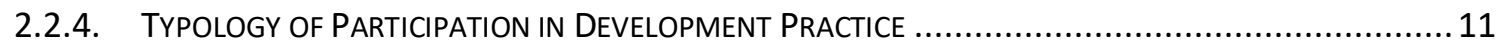

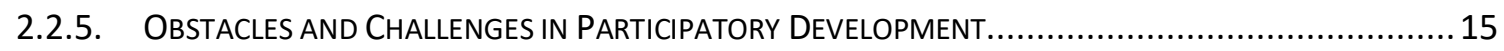

2.2.6. WHY IS IT IMPORTANT TO IMPLEMENT MEANINGFUL PARTICIPATORY DEVELOPMENT? .................... 17

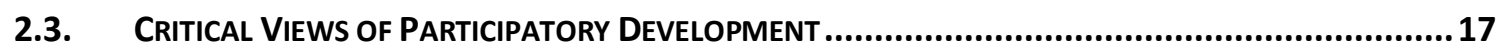

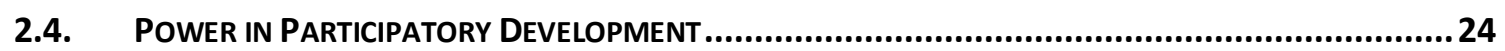

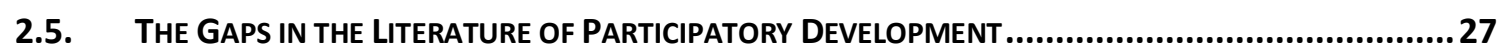

CHAPTER 3 BACKGROUND OF THE LIFE SKILLS TRAINING PROGRAMME ............................29

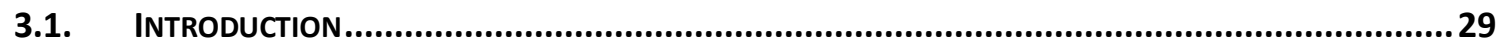

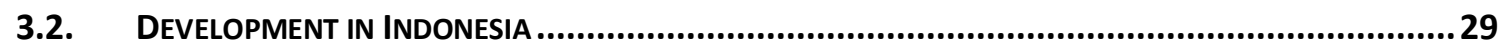

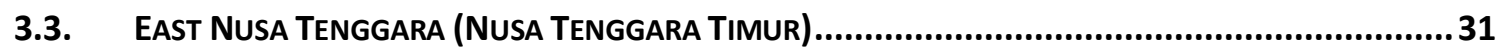

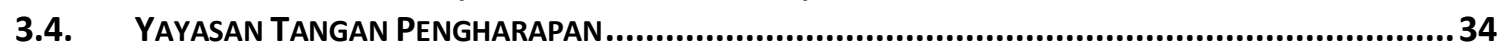

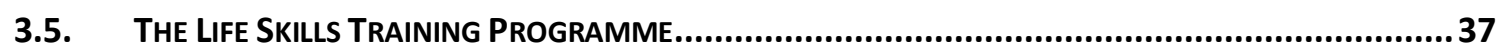

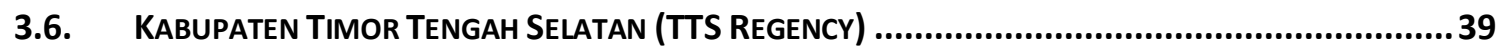

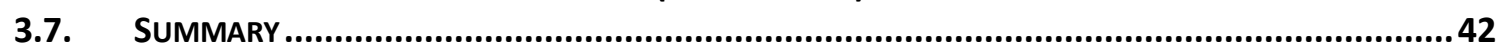

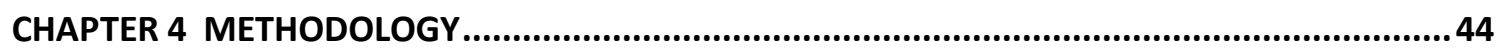

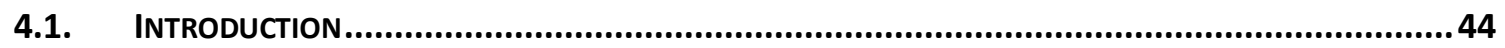

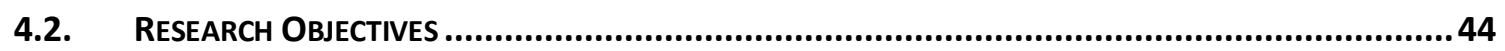

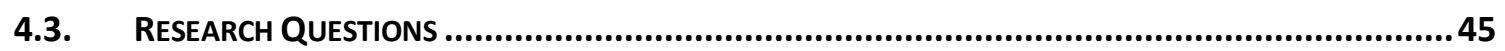

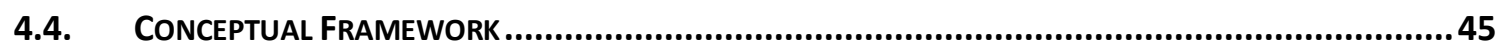

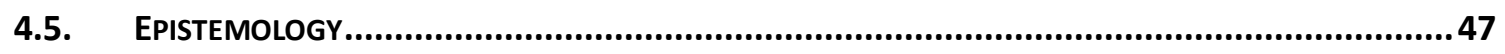

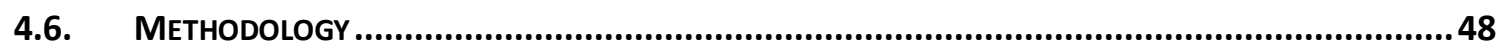

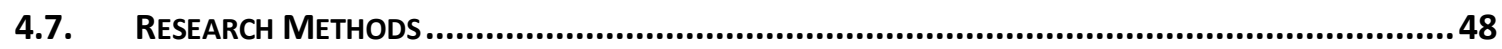




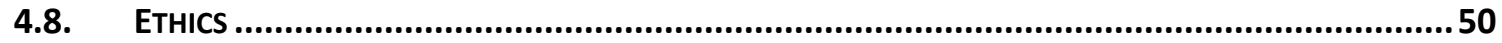

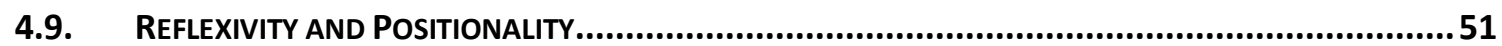

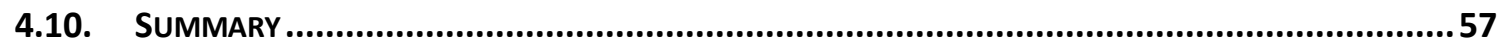

CHAPTER 5 EXPERIENCES, PERCEPTIONS, AND FEELINGS ABOUT PARTICIPATORY PROCESSES OF THE LIFE SKILLS TRAINING PROGRAMME IN EAST NUSA TENGGARA...............................58

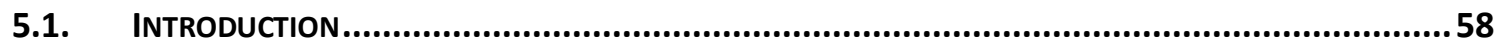

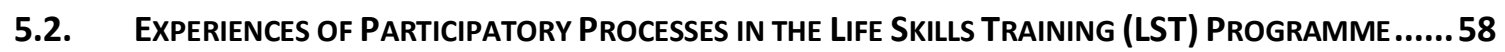

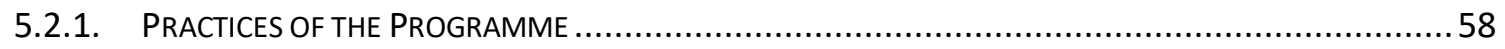

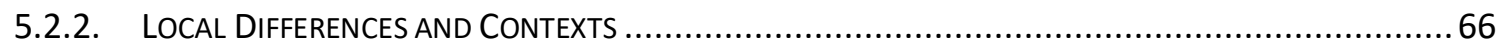

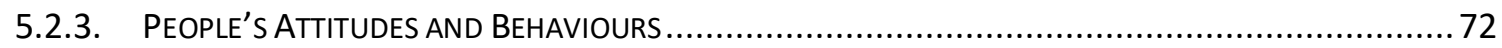

5.3. Perceptions of the Problems, Needs, Capacity, and livelihood of the Local Community 75

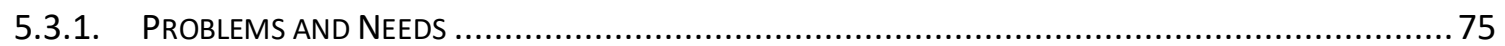

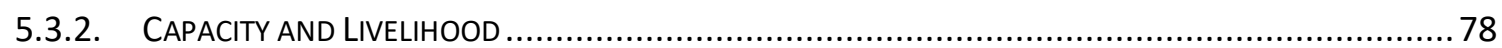

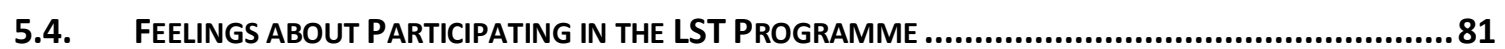

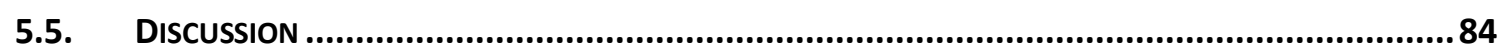

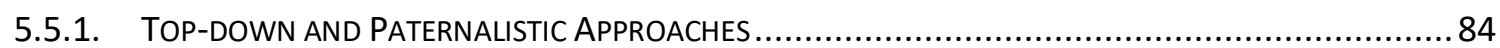

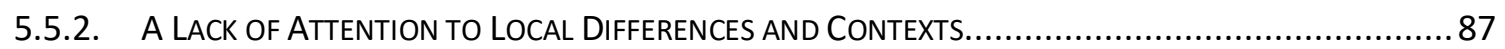

5.5.3. ATTITUdES AND BEHAVIOURS THAT SUPPORT AND INHIBIT PEOPLE'S PARTICIPATION......................8 89

5.5.4. DifFERENT PERCEPTIONS OF THE LOCAL PROBLEMS AND NEEDS................................................ 90

5.5.5. INCREASE IN THE CAPACITY AND IMPROVEMENT OF THE LIVELIHOOD OF THE LOCAL COMMUNITY..... 92

5.5.6. Positive and Negative feelings of People's Participation in the LST Programme ............. 93

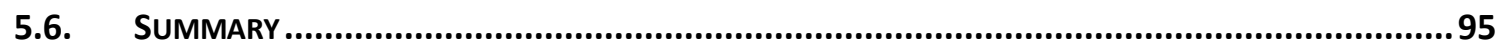

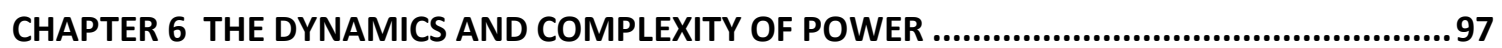

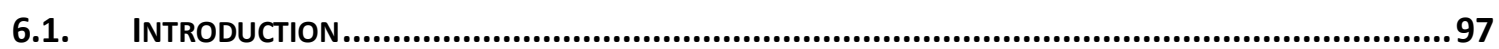

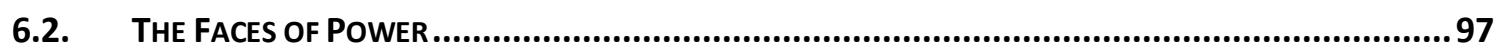

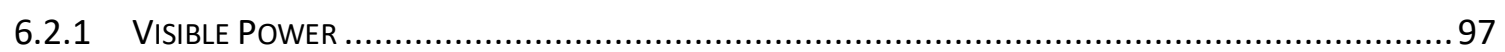

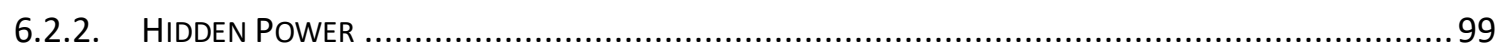

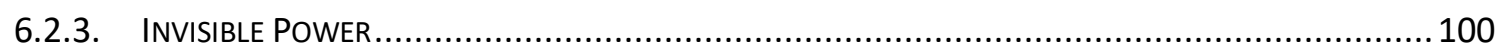

6.3. EXPRESSIONS OF POWER

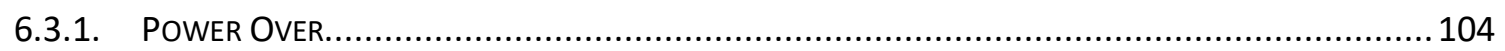

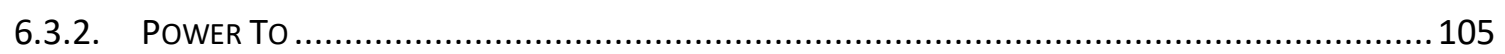

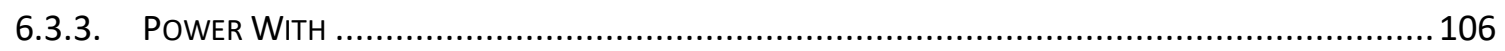

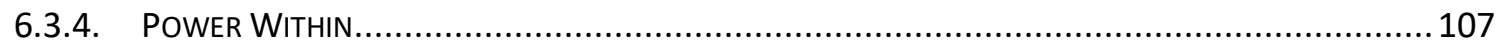

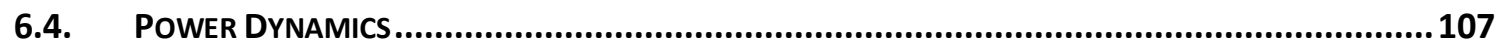

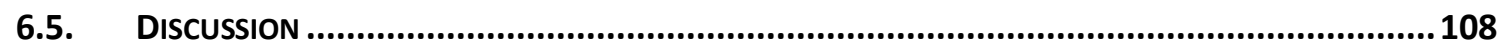

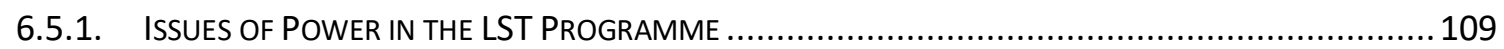

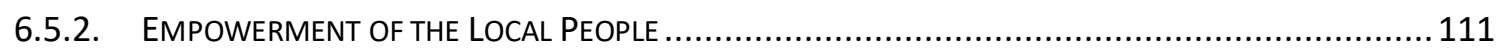

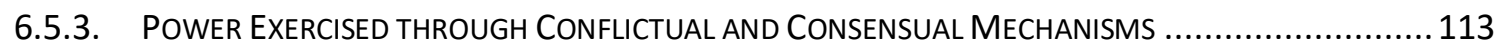

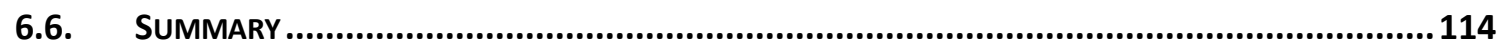

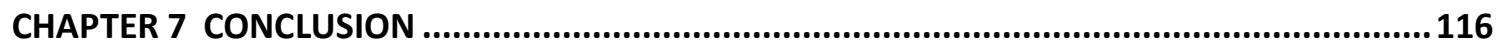

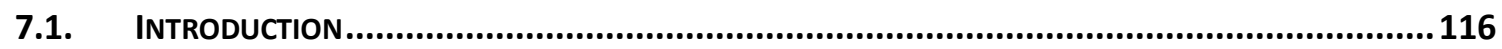

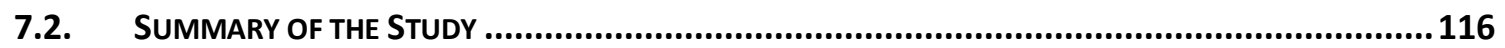

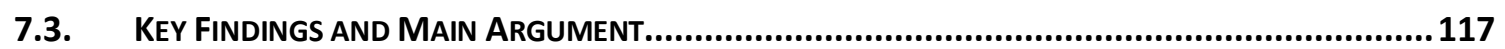

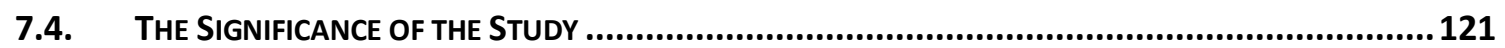

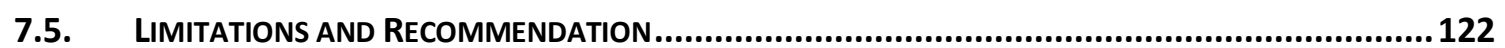

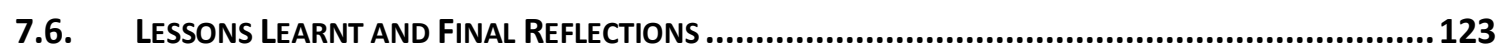

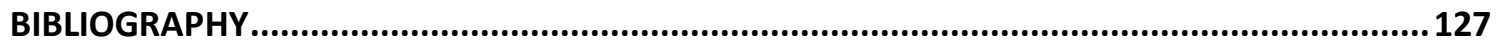




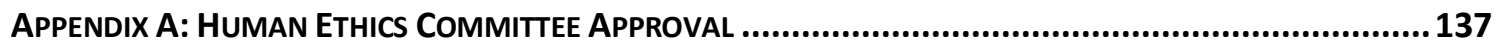

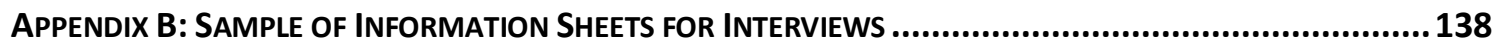

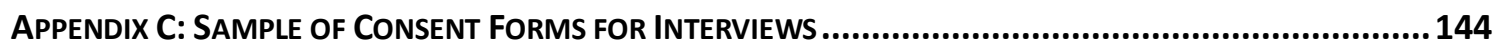

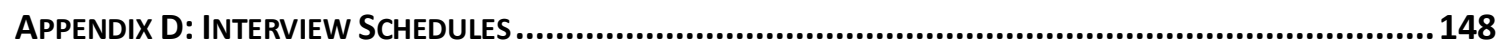

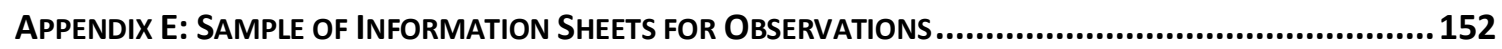

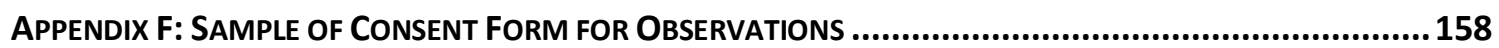

APPENDIX G: THE LIFE SKILLS TRAINING PROGRAMME PROPOSAL..............................................162

APPENDIX H: RULES FOR THE LIFE SKILLS TRAINING PROGRAMME PARTICIPANTS ...................................168 


\section{LIST OF ILLUSTRATIONS}

\section{FIGURES}

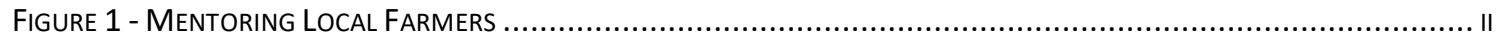

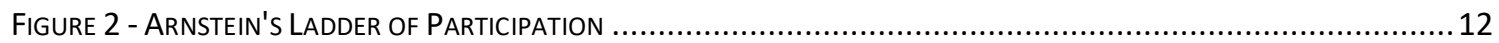

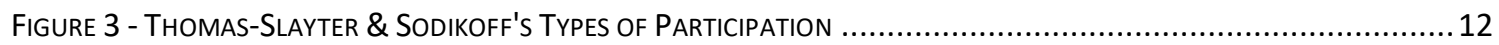

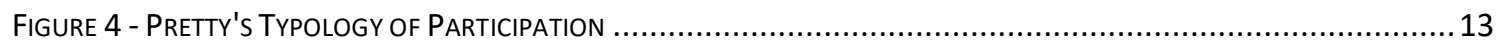

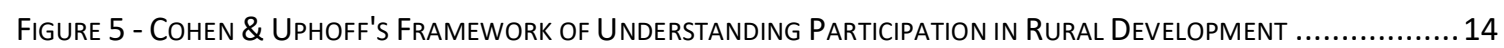

FIgURE 6 - White'S FormS, INTERESTS, AND FUnCTIONS OF PARTICIPATORY DEVELOPMENT ................................... 15

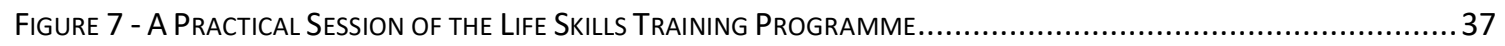

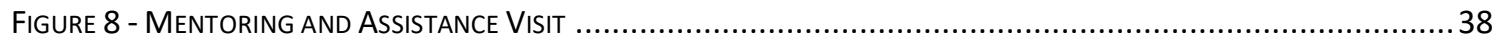

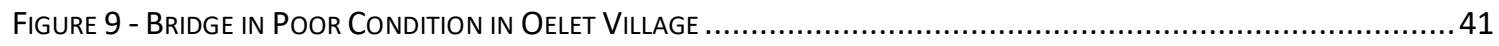

Figure 10 - A Contrast in Road Quality between Oe'Ekam Village and Other Villages...................................4 42

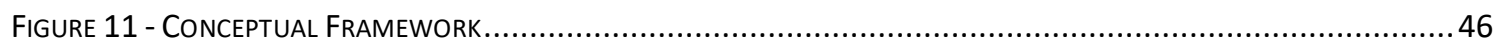

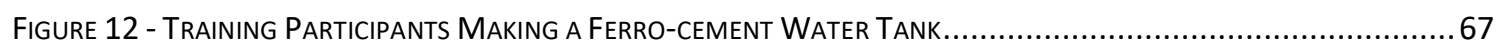

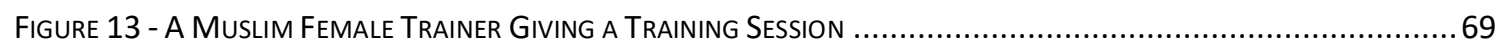

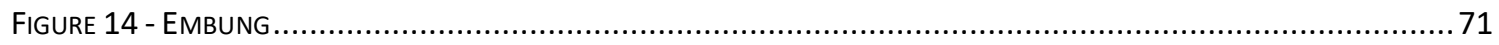

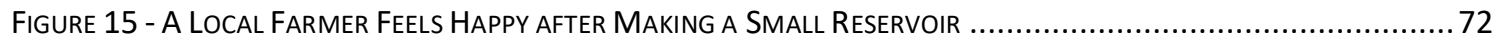

FigURE 16 - THE Most COMMOn WordS MENTIONEd IN INTERVIEWS ......................................................... 78

Figure 17 - The Wife of A Training Participant Attending Their KIOSK ..................................................... 80

Figure 18 - The Wife of A Training Participant Helping to Put Compost on the Field.................................. 100

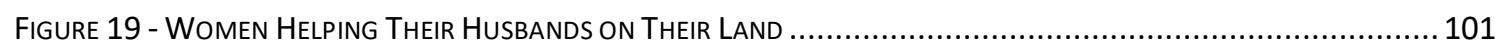

Figure 20 - The Wife of a Training Participant Caring for Her Small Child .......................................... 101

FIGURE 21 - LoCAL FARMERS Working TOGETHER In MAKING COMPOST ................................................. 106

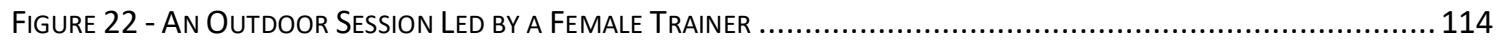

\section{TABLES}

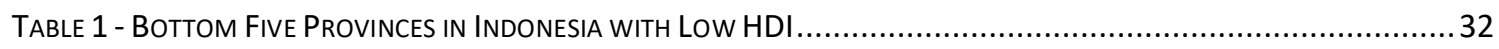

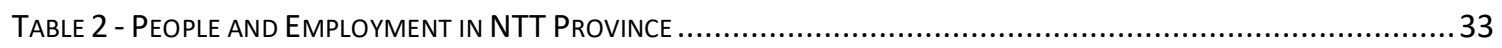

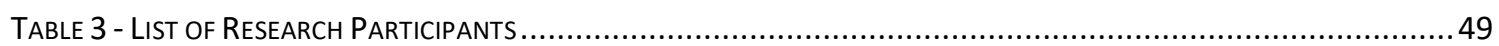

\section{CHARTS}

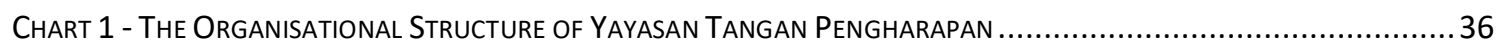

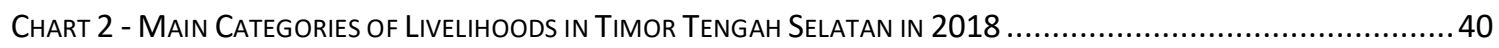

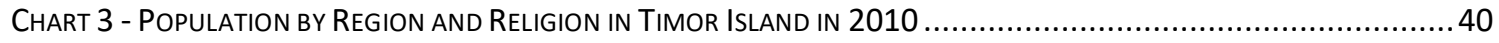

\section{MAPS}

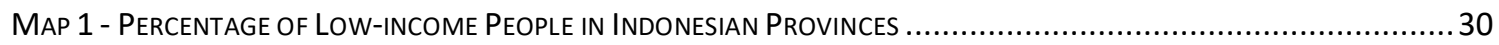

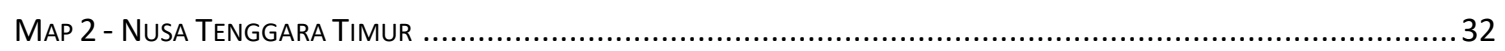

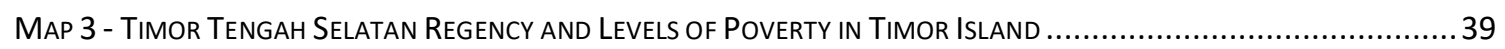




\section{GLOSSARY}

\begin{tabular}{|c|c|}
\hline Term & Definition \\
\hline ANU & The Australian National University. \\
\hline DKP & $\begin{array}{l}\text { Dewan Ketahanan Pangan is part of the Indonesian government } \\
\text { department in Food and Agriculture and responsible for food } \\
\text { security. }\end{array}$ \\
\hline Embung & The Indonesian term for a catchment reservoir. \\
\hline Ibu & $\begin{array}{l}\text { The Indonesian term for mother. However, ibu can also be used } \\
\text { to greet older and/or married women, and is a way of conveying } \\
\text { respect for the person. }\end{array}$ \\
\hline Kabupaten & The Indonesian term for a regency (sub-district). \\
\hline LST & $\begin{array}{l}\text { The Life Skills Training programme (a training programme for } \\
\text { rural farmers in East Nusa Tenggara, which is examined in this } \\
\text { thesis). }\end{array}$ \\
\hline NGO & Non Governmental Organisation \\
\hline NTT & $\begin{array}{l}\text { Nusa Tenggara Timur (East Nusa Tenggara) is the name of the } \\
\text { Indonesian province, where part of the field research was } \\
\text { conducted. }\end{array}$ \\
\hline Provinsi & The Indonesian term for a province. \\
\hline Provinsi NTT & East Nusa Tenggara Province. \\
\hline TTS & Timor Tengah Selatan (South Central Timor). \\
\hline TTS Regency & $\begin{array}{l}\text { Timor Tengah Selatan (South Central Timor) regency is the name } \\
\text { of the regency in East Nusa Tenggara province, where part of } \\
\text { the field research was conducted. }\end{array}$ \\
\hline TTU & Timor Tengah Utara (North Central Timor). \\
\hline TTU Regency & Timor Tengah Utara (North Central Timor) regency. \\
\hline Uang Duduk & $\begin{array}{l}\text { A form of financial incentive, which is normally given for people } \\
\text { in exchange for their attendance in training activities, meetings, } \\
\text { or workshops that are held by government agencies or NGOs. }\end{array}$ \\
\hline UN-WFP & United Nations World Food Programme. \\
\hline YTP & $\begin{array}{l}\text { Yayasan Tangan Pengharapan (Tangan Pengharapan } \\
\text { Foundation) is the Indonesian NGO examined in this thesis. }\end{array}$ \\
\hline
\end{tabular}




\section{CHAPTER 1 \\ INTRODUCTION}

\subsection{Background}

Whose voice counts in development programmes? Although this question has been posed before (see Cornwall, 2003; Holland \& Blackburn, 1998), it is still a relevant and important question for all who hold power and seek to reduce inequalities in development processes. In attempting to reduce inequalities, the participation of local, poor, and marginalised people in development has been encouraged since the 1970s (e.g. Chambers, 1983). Their participation is believed to be an effective way to reduce power inequalities, to empower them, and to bring greater effectiveness to development programmes.

However, participation can be interpreted differently, either as a means to achieve something, or as an end in itself: a process of empowerment (Nelson \& Wright, 1995). The different interpretations of participation involve different power dynamics between various development actors, which can lead to problems related to power differentials and reduce the effectiveness of a development programme.

While there have been many studies of participatory development (e.g. critiques and benefits of participatory development), there are few studies that explore people's perceptions, experiences, and feelings about their participation in development programmes, particularly those of the intended beneficiaries of the participatory approaches. Moreover, studies that look at the participatory practices of local NonGovernmental Organisations (NGOs) from the 'South' are uncommon. Thus, there is a need for exploring people's experiences, perceptions, and feelings about their participation in development programmes designed and delivered by a Southern NGO, to understand the issue better, and to unpack the underlying issues of power. 


\subsection{Scope of the Study}

Against the above backdrop, this study intends to help to fill the gap by focusing its analysis on the practices of a development programme that is delivered by a local NGO in Indonesia. The programme analysed in this study is the 'Life Skills Training' programme, which has been delivered in Kupang, East Tenggara Timur, Indonesia since 2016. The programme is designed and implemented by Yayasan Tangan Pengharapan with the intention of helping and empowering low-income people, who live in rural and remote areas in West Timor. In doing so, the programme provides various training activities (in agriculture, horticulture, water harvesting, poultry, and aquaculture) to meet the needs, expand the capacity, and improve the livelihood of the local community. This programme has been selected for this study because it shares the same ideals that Chambers' participatory approaches try to achieve, in which it emphasises the importance of targeting the poor in rural areas, who were often overlooked, and of prioritising them in the process of development (Chambers, 1983).

To help guide the study, three research questions were devised. The main question of the study is 'how are issues of power manifested in the Life Skills Training programme?' Additionally, two sub-questions were added to help answer the main question, they are:

1. What experiences, perceptions, and feelings of the participatory processes are held by the various stakeholders involved, particularly the targeted beneficiaries, in the Life Skills Training programme?

2. How does the application of a participatory process in the Life Skills Training programme relate to the needs, capacity, and livelihood of the local community?

In this thesis, I argue that issues related to imbalances of power occur in the Life Skills Training programme through the domination of the NGO's leadership in the decisionmaking processes, and that these were also contributed to by patriarchy and filial piety, two socio-cultural norms within the local community and in Indonesian society in general. More importantly, I argue that people's participation in the programme is less 
likely lead to meaningful outcomes if the issues of power imbalances are not addressed.

\subsection{Outline of the Study}

In the following chapter, I first review the literature on participatory development and power. The review of participatory development provides the information regarding the main debates in participatory development, both at the theoretical and practical levels. The thorny debates in participatory development centre around its transformative potential. They point to the significance of attending to issues related to power. Hence, in the next chapter, I briefly review the different understandings of power and frameworks for analysing power in the practices of participatory development. This chapter also sets out the gaps in the literature that this study seeks to address.

In Chapter 3, I provide the background information about the study. I first briefly explain the history of the increased public participation in development processes in Indonesia. Then, I outline the current situation of development in East Nusa Tenggara and various aspects that affect the development of the region. I then provide a brief introduction about Yayasan Tangan Pengharapan, the Life Skills Training programme, and the regency (administrative district) where the study was mainly conducted.

Chapter 4 outlines the methodological approach used in this study. Based on social constructivism, the study used a series of semi-structured interviews with, and observation of, fourteen purposively selected research participants. I then briefly set out the frameworks used in this study. In addition, I point out and reflect on issues related to ethics and positionality in conducting the study. 
Chapter 5 of this thesis focuses on discussing people's participation in the Life Skills Training programme. I present the findings before relating the findings to the literature on participatory development. The findings are divided into three broad areas:

1. People's experiences in the programme

2. People's perceptions of their participation in the programme

3. People's feelings about their participation in the programme

Chapter 6 concentrates on power dynamics in the Life Skills Training programme. Using the framework of 'faces of power' and 'expressions of power', I explain how various forms of power were exercised by different actors involved in the programme. I then summarise and discuss the findings of the study in relation to the literature on power in participatory development.

Finally, a conclusion is provided in Chapter 7. I summarise the findings of the two main topics covered in this study: people's participation and power dynamics in the Life Skills Training programme. I then outline the significance of the study for development practitioners. I also point out the limitations of the study and provide a recommendation for further research. Lastly and most importantly, I draw some insights that can be learned by development practitioners from this study to improve the practices of participatory development. 


\section{CHAPTER 2 PARTICIPATION AND POWER IN DEVELOPMENT}

\subsection{Introduction}

This chapter has multiple purposes. First, it is intended to provide readers with a general overview of participatory development by briefly explaining its origins, meanings and applications. Then, three key principles of a genuinely participatory development project will be presented, followed by a description of a number of commonly found typologies of participation. Subsequently, it sets out the barriers to, and the benefits of, conducting meaningful participatory development. Finally, it provides critiques to participation, before turning to an explanation of power in development.

Second, this chapter aims to establish the significance of examining power dynamics in participatory development. Given that power relations are inherent in participatory development and have become one of the major concerns in the debate on participatory development, it is important to analyse power dynamics in participatory development.

Finally, this chapter is intended to provide a justification for my research study. In doing so, I will conclude with a brief explanation of the gaps in the literature of participatory development.

\subsection{Participatory Development and Its Significance}

\subsubsection{The Origins of Participatory Development}

Participatory approaches in the development field have been born out of various contributing factors. Firstly, from the mid-1970s, there was a growing critique of both mainstream and radical development theories and practices that predominantly focused on economic growth and top-down policies, instead of putting people at the centre of development. Friedman and Weaver (1979) put forward an important argument that the top-down approaches to development prioritised economic 
development and largely ignored the needs of people living in rural areas. In his book, Rural Development: Putting the Last First, Chambers (1983) pointed out that little attention had been paid to low-income people in rural areas. He called for a different approach that seeks to apply bottom-up approaches in development and for greater participation of rural people in development projects. Later on, Chambers (1997) argued for the need to recognise the views and needs of poor and marginalised people in development, and to encourage their participation in development through the disempowerment of more powerful people. In doing so, he encouraged the use of participatory methods, known as the Rural Rapid Appraisal (RRA) and especially Participatory Rural Appraisal (PRA).

At the same time, there was a recognition among development practitioners of the failure of top-down development practices. Although economic growth was achieved by a number of developing countries, this achievement had gone hand in hand with increasing poverty in these countries (Hettne, 1990). Development was perceived as failing to improve the living conditions of the poorest segment of society in these countries. The failures of top-down development policies and practices encouraged practitioners to reflect on their practices. Those, who carefully looked at the design of their development projects, realised that there was a lack of participation of local people in their projects. Local people were not involved from the beginning of development projects and solutions to their problems were decided by outsiders. Consequently, local people not only felt a lack of ownership of development projects, but often projects did not address their main difficulties. In response to this problem, interest in participatory development has grown significantly, seeking to encourage local people's engagement in development projects.

Another contributing factor for the growing interest in participatory development was because public participation is no longer perceived as a threat by government and development institutions (Rahnema, 2011). People's participation has become an attractive approach to achieve greater effectiveness and efficiency of development projects. These contributing factors have led to the growth in the use of participatory practices. 


\subsubsection{What is 'participatory development'?}

Despite its ascendancy, the concept of participatory development has been interpreted differently by different people in different contexts. People's perception of the concept of participatory development has been divided into two main categories: participation as a 'means', or as an 'end' (Nelson \& Wright, 1995; Oakley, 1991).

As a means, participatory development refers to the involvement of a significant number of people in decision-making processes in the design and implementation of development projects, in order to achieve the objectives of the projects with greater efficiency and effectiveness. This interpretation was largely adopted by development organisations at the beginning of the period when development organisations tried to mainstream participatory approaches in development. For example, the 1991 report of the Chairman of the OECD's Development Assistance Committee defined participatory development as approaches that "combine effective economic policies, equitable access to basic social and economic services and broader popular participation in decision-making, on the orientation of government policies and programmes" (OECD, 1991, as cited in Nelson \& Wright, 1995, p. 4).

However, the value of participatory development can be reduced when people's participation in development only serves its instrumental purposes. As Saxena (2011, p. 31) points out, participatory development can also be used for "getting people to agree to and go along with a project that has already been designed for them, or to get support of a few leaders". In other words, participatory development is used merely as a means to mobilise people into a development process that is pre-determined by other powerful actors, such as government or development agencies (Rahnema, 2011). In addition, it can be used as a means to get people to 'buy into' a development project to ensure its sustainability and to share the costs.

Nevertheless, participatory development can also be viewed as an end, which broadly refers to a process of empowerment and social transformation (Chambers, 1983, 1997; Freire, 2018; Friedmann, 1992; Nelson \& Wright, 1995). The notion of empowerment in participatory development entails a process that enhances people's capability, by 
involving them to make their own decisions and to take control of the processes that affect their lives (Cleaver, 1999). As Cohen and Uphoff (1977, as cited in Oakley) point out

With regard to rural development ... participation includes people's involvement in decision-making processes, in implementing programmes, their sharing in the benefits of development programmes and their involvement in efforts to evaluate such programmes.

As an end, participatory development also aims to transform the targeted beneficiaries from passive recipients into participants who engage actively throughout the project cycle. Over time, through this process of active participation, they can increase their ability to exercise their agency and re-negotiate their power within existing power relations.

However, it is possible to see participatory development as both a means and an end. People's participation in development can evolve from a means to achieve the objectives of a project through participating in all stages of development process, to a transformative process that displays aspects of empowerment, such as greater confidence and ability to make a difference. The Gwembe Valley Agricultural Mission (GVAM) in Zambia is an example of this interpretation of participatory development. The GVAM project stresses that the participation of the targeted beneficiaries at all stages of development process is essential (Hussein, 1995). However, the project was also intended to help their participants to be self-reliant in their own development without continuous support from outsiders, as reflected in the GVAM publicity material in relation to the project's long-term objective.

\subsubsection{Key Principles of a Genuine Participatory Development Project}

Regardless of the multiple conceptions of participatory development, there are, at least, three key principles that underpin the theoretical framework of an ideal participatory development project. 


\section{The first principle: bottom-up and people-centred}

The bottom-up and people-centred principle mean that participatory development should include greater participation of the people that are targeted by the project in all stages of the project. As Oakley (1991, p. 161) states “... participatory development must be consciously based on the people, their needs, their analysis of issues and their decisions". It involves greater recognition of and respect towards the views and knowledge of the local people (Chambers, 1983, 1997). Moreover, participatory development should encourage rural and local people to move from being 'passive' to 'active' participants, and from being 'objects' to 'subjects' of development projects (Oakley, 1991, p. 161). Greater recognition of people's needs should also mean that participatory development will ensure those who are powerless and had been marginalised within a community, such as young people, women, and elderly, can have a greater role in development (Oakley, 1991, p. 162). This bottom-up and peoplecentred principle should be the starting point in participatory development, in response to the failures of both mainstream and radical development policies and practices, which have mainly relied on a top-down approach and focused on economic growth.

\section{The second principle: empowerment}

The concept of empowerment is intrinsically linked with the concept of power. Power itself is a complex subject and can be understood in various ways (Eyben, Harris, \& Pettit, 2006; McGee \& Pettit, 2019; Mosse, 2005). Broadly speaking, power can be perceived as a 'finite resource' that involves politics to determine its distribution; or as something that is inherent within individuals (the capacity and capability to act, change, sustain, or resist) (Eyben et al., 2006). VeneKlasen and Miller (2002, p. 39) state that "In reality, power is both dynamic and multidimensional, changing according to context, circumstance and interest". As power manifests in relationships, a better understanding of power relations can help us to see how different forms of power operate in society and their implications. 
Empowerment is viewed as a process that requires a transfer or devolution of power, and is a fundamental aspect of participatory development (Friedmann, 1992; Nelson \& Wright, 1995, p. 160). McArdle (1989) defines empowerment as a decision-making process by the people whose lives are affected by those decisions. However, McArdle's definition of empowerment may be too narrow, since it implies that participation in decision-making is the only important thing for empowerment to occur. In practice, it may involve consultation with the person or community in identifying their needs and choice of options, while the implementation or monitoring and evaluation of the programme is controlled by outsiders. Such practices are criticised for tokenism, as they fall short of recognising that "as long as the process is controlled by others who have access to resources, then the process is actually disempowering." (Onyx \& Benton, 1995, p. 51).

A broader understanding of empowerment has been contributed by feminist theorists, as they incorporate the full range of human abilities and potential in their interpretations of empowerment (Rowlands, 1995). As a result, empowerment is now increasingly viewed as a process that opens up access to decision-making, but also involves some degree of personal development, which include self-confidence, selfreliance, and the feeling of being in control of the things that affect their lives (Burkey, 1993; Marsden, 1994, p. 90; Rowlands, 1995). Additionally, any efforts to empower the intended beneficiaries of a development programme require practitioners and professionals to not only reflect on their practices and seek better understanding of the reality of local people, but also to 'hand over the stick' of development projects to the local people (Chambers, 1983, 1997). I will examine the issue of power in development in more depth below.

\section{The third principle: transformation}

Another important aspect of participatory development is social transformation (Freire, 2018). The principle of transformation seeks to change the unequal power relations, between the people who have been alienated from the process of development and those who are more powerful due to their socio-economic, educational, or professional 
backgrounds (Chambers, 1983, 1997). Through their participation, the powerless can be transformed into more powerful actors in development, by developing and using their newly acquired skills and knowledge with greater confidence to solve their problems and to exercise their agency to make a difference (Nelson \& Wright, 1995, p. 13; Saxena, 2011, p. 31; White, 1996, pp. 61-62).

\subsubsection{Typology of Participation in Development Practice}

Sometimes, gaps between the theoretical framework of the ideal participatory development and its practices can be found. Some of these gaps may be a result of the ambiguity of the concept of participation in development. This has led development organisations and actors to use the term 'participation' in a variety of ways or for different purposes. The various forms of participation further reveal the different levels or degrees of people's participation in development (Arnstein, 1969; Cohen \& Uphoff, 1980; Pretty, 1995; Thomas-Slayter \& Sodikoff, 2001; White, 1996).

There are a number of commonly found typologies of participation in the development field. One of the most used typologies of participation is Sherry Arnstein's ladder of participation (Figure 2 on page 12). The ladder of participation is divided into eight levels of participation to show the forms of people's involvement in development (Arnstein, 1969). The five rungs at the bottom of the ladder (Manipulation, Therapy, Informing, Consultation, Placation) indicate a low quality of participation, as people do not have the decision-making power. On the rungs of "Manipulation" and "Therapy", people's participation is used to obtain public support for the project, instead of genuinely involving them, to either 'educate' or 'cure' people. Although public participation on the rungs of "Informing", "Consultation", and "Placation" enable people to be informed and heard, they still do not have the power to make decisions. On the three top rungs (Partnership, Delegated Power, and Citizen Control), people have the decision-making power, or are able to take part in the management of the project. 
Similar to Arnstein's ladder of participation, Thomas-Slayter and Sodikoff have divided the types of participation into 3 broad categories (Thomas-Slayter \& Sodikoff, 2001). The three categories are passive participation, reactive participation, and active or full participation (Figure 3 overleaf). Passive participation can be easily manipulated and potentially create dependency because it involves a one-way communication from the more powerful to the less powerful, or even powerless people or organisations. Reactive participation is the type of participation that is initiated and controlled by 'outsiders' or external agencies, instead of the local community. Active or full participation is the type of participation that is initiated and managed by the local community, which works in partnership with external agencies.

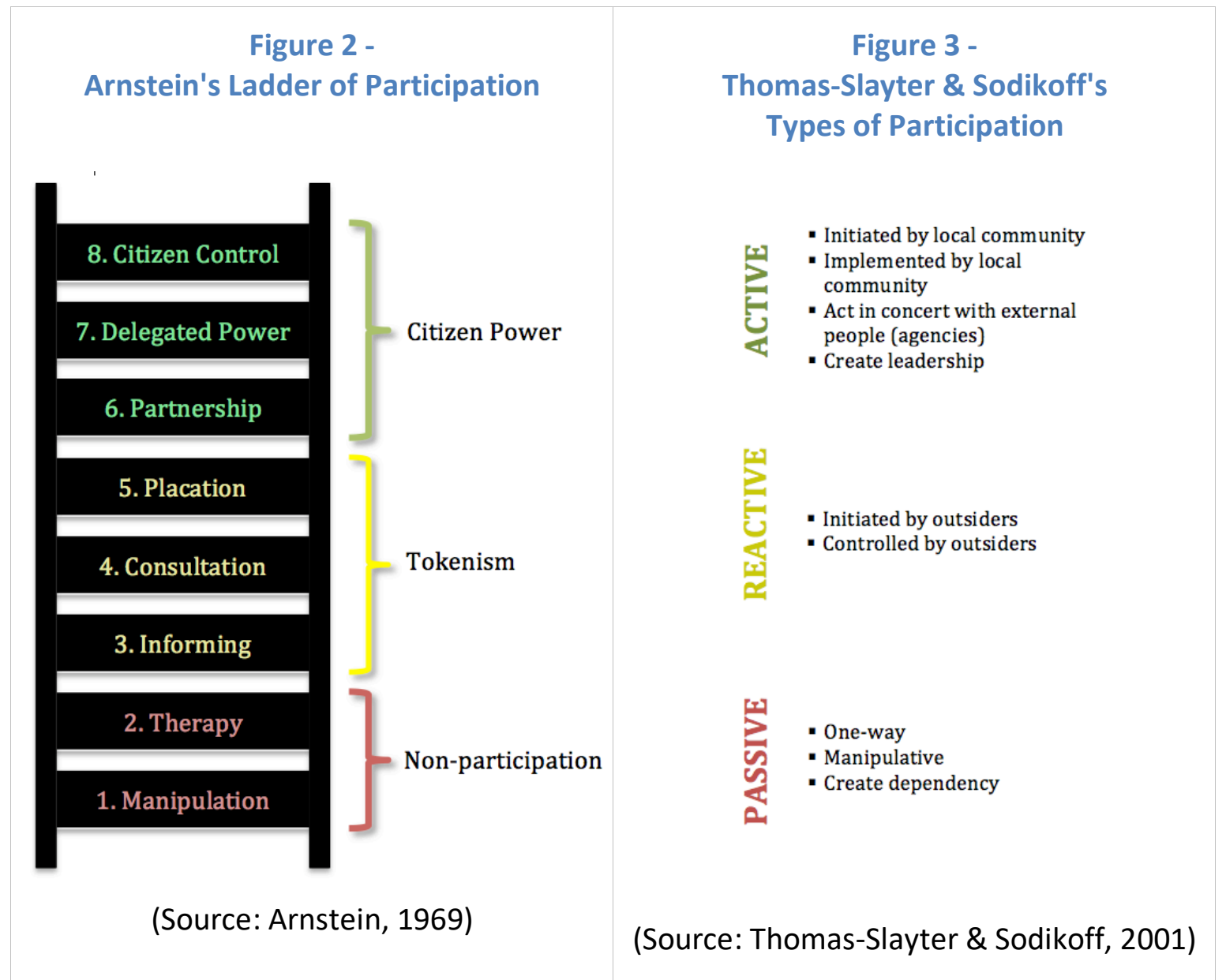

Similarly, Pretty suggests that the multiple interpretations and the use of the term 'participation' in development can be summarised into seven types (Pretty, 1995). Each 
of these types illustrates the characteristics of how people participate in development projects/programmes. The seven types include manipulative participation, passive participation, participation by consultation, participation for material incentives, functional participation, interactive participation, and self-mobilisation (Figure 4 overleaf). To be meaningful, Pretty (1995) makes a suggestion for development organisations and practitioners to shift their practices from the manipulative, passive, consultative, and incentive-driven participation toward the higher end of the spectrum, which shows greater signs of interaction and joint decision-making.

Figure 4 - Pretty's Typology of Participation

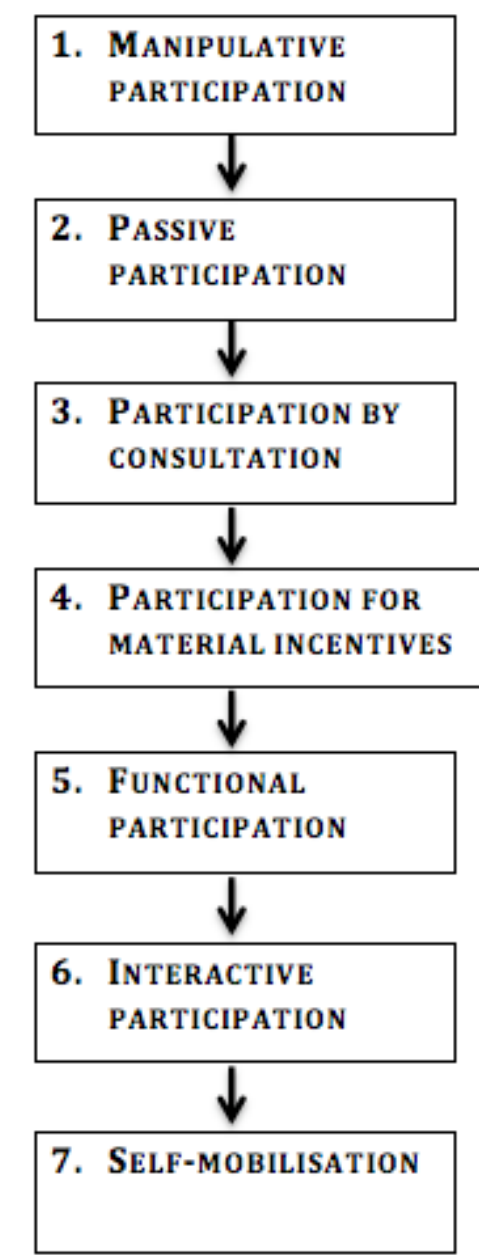

(Source: Pretty, 1995, p. 1252)

Additionally, there are other approaches to understanding people's participation in development. For example, a more detailed and comprehensive framework to analyse 
the practices of participatory development in rural areas is provided by Cohen and Uphoff (Figure 5 overleaf). Cohen and Uphoff (1980) call for the need to examine both the types of participation that are taking place, as well as the context of participation itself. The reason for incorporating the context of participation is because social, historical, and environmental aspects of a place can strongly impact on the practices of participatory development in rural areas. In contrast, White (1996) moves beyond analysing the practices of participatory development, and proposes a richer analysis by highlighting the interests of the people involved in participatory development, both from the top-down and bottom-up perspectives. White (1996) distinguishes the forms of participation into four main types by incorporating people's interests in participatory development and the overall function of each type of participation (Figure 6.

Figure 5 - Cohen \& Uphoff's Framework of Understanding Participation in Rural Development

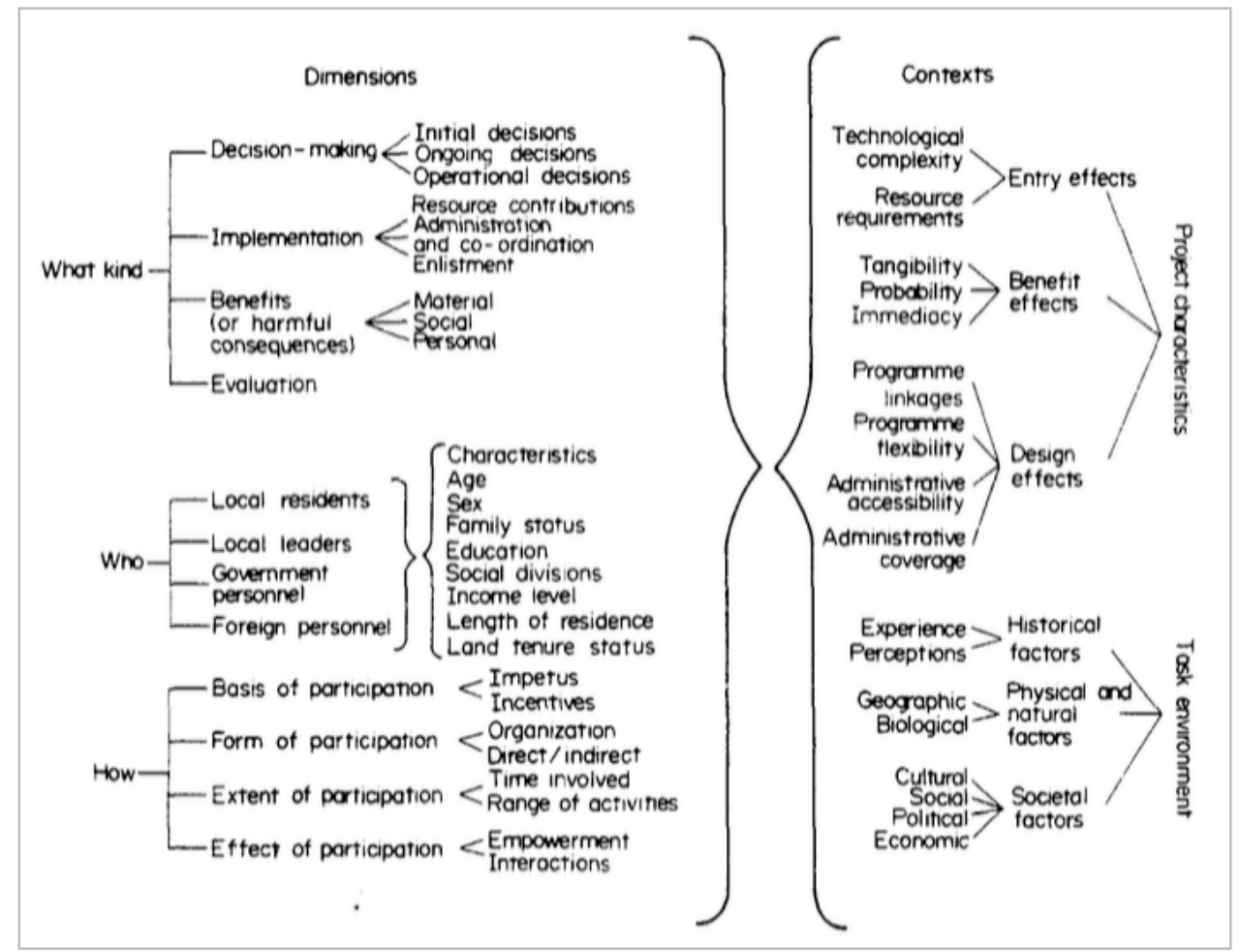

(Source: Cohen \& Uphoff, 1980, p. 219) 
Figure 6 -

White's Forms, Interests, and Functions of Participatory Development

\begin{tabular}{llll} 
Form & Top-Down & Bottom-Up & Function \\
\hline Nominal & Legitimation & Inclusion & Display \\
Instrumental & Efficiency & Cost & Means \\
Representative & Sustainability & Leverage & Voice \\
Transformative & Empowerment & Empowerment & Means/End \\
\hline
\end{tabular}

(Source: White, 1996, p. 7)

All of the above typologies show the differences in the quality of people's participation in development. Participatory development that involves one-way communication, manipulative, consultative, and incentive-driven practices are considered to be lower quality forms of participation, because they are less likely to have long-lasting and significant outcomes for the intended beneficiaries. On the other hand, people's participation that involves greater interaction and joint decision-making with the intended beneficiaries are considered to be higher quality, as these practices often lead to a more meaningful outcome, whereby the intended beneficiaries are eventually transformed into the agents of change in their community.

\subsubsection{Obstacles and Challenges in Participatory Development}

The variety in the quality of participatory development also signals the obstacles and challenges found in participatory development. Oakley et al. (1991, pp. 10-14) summarise three main obstacles to participatory development: structural, administrative, and socio-cultural obstacles. First, the structural obstacles relate to the political environment of a country. As Oakley (1991, p. 11) point out

In countries where the prevailing ideology does not encourage openness or citizens' comments but prefers to maintain the direction and decision-making concerning state affairs in strictly controlled hands, the prevailing political environment will not be conducive to genuine participation. 
The lack of a culture of openness within a country, as well as the legal systems that place constraints on the involvement of rural people in development, can be a major obstacle to participatory development.

Secondly, the administrative obstacles refer to centralised governance of development activities. Centralised governance will require a centralised administrative structure and can become a fundamental obstacle to participatory development (Oakley, 1991, p. 12). At the initial stage of a development programme, local people's involvement is often disregarded. The planning of development programmes are often centralised in places far from where they are going to be implemented. For development organisations, external demand for immediate and tangible impact may entail a strong vertical control of programme implementation (Mosse, 2003, p. 192). Time and cost are also major challenges as participatory development can be time consuming and expensive to achieve a meaningful impact (Chambers \& Guijt, 1995, p. 11; Mosse, 2003, p. 192; Oakley, 1991, p. 170). It requires a longer time of engagement with the local community, and thus, can be expensive. Development organisations often do not have the flexibility and funding to do this. However, time constraints are also a barrier for the local people as they may have higher priorities and consequently, choose not to participate in various stages of development.

Thirdly, socio-cultural aspects can pose significant challenges to participatory development. There is a wide range of socio-cultural obstacles that can hinder participatory development. These may include a society with male-dominated culture, socio-political exclusion within a community (due to power imbalances in relation to gender, ethnicity, age, etc.), the lack of confidence, knowledge, and skills of the local people (a feeling of inferiority), and the entrenched attitudes and bias of the field workers of development organisations against women's capabilities and roles (Cornwall, 2003; Mompati \& Prinsen, 2000; Oakley, 1991). 


\subsubsection{Why is it important to implement meaningful participatory development?}

Despite the obstacles and challenges, the potential to bring about substantial benefits for the participating communities and organisations shows why it is important for governments, as well as development organisations and practitioners to undertake meaningful participatory development in all stages of development projects. The benefits of having local people involved and participating in all stages of development include: a better understanding of, and more accurate information about the problem, needs, and priorities of the community; greater efficiency; greater possibility of gaining valuable insights from the local or indigenous knowledge and expertise; increased cooperation and ownership of the development project; increased capacity and selfreliance of the local people; greater transparency and accountability of the project (Chambers \& Guijt, 1995; Cohen \& Uphoff, 1980; Oakley, 1991; Pretty, 1995). However, these benefits can only be gained when there is a commitment from governments, development organisations or practitioners, and the local people in the targeted communities, to share 'spaces' in development. In particular, there needs to be a commitment to share 'power' between various development actors.

\subsection{Critical Views of Participatory Development}

Despite its potential benefits, participatory development has been critiqued, both at the theoretical and practical levels. At the theoretical level, three main criticisms are directed toward participatory development. The first critique is related to the concept of participation, which has a lack of clarity as it can be multi-interpreted as a means and/or an end (Nelson \& Wright, 1995; Parfitt, 2004). The integral ambiguity of the concept of participation has been criticised as it can influence the quality of its practices. However, the ambiguity of the concept has prompted further discussions and self-critical awareness among development practitioners, in relation to the extent to which participation is appropriate, who actually gains and loses from various types of participatory development, and the political dimensions of participation (Chambers, 1997; Pretty, 1995; White, 1996). The self-critical discussions are intended to maintain the quality, standards, and ethics of the practices of participatory development. 
The second critique refers to the notions of 'community' or 'local people' in participatory development. These notions of 'community' or 'local people' that underpin a lot of the practices of participatory development, particularly from the experiences of using the PRA and RRA methods, are considered too simplistic. This is because issues of important differences within a community, such as gender, age, and ethnicity, tend to be discounted (Mohan \& Stokke, 2000; Mosse, 2001). Mohan and Stokke (2000) argue that Chambers' participatory approaches tend to essentialise 'the local' and promote a consensual view by downplaying important power differences at the local level. The repercussion of such a tendency, as Mohan and Stokke (2000, p. 253) point out, is that "the actions based on consensus may actually empower the powerful vested interests that manipulated the research in the first place". In other words, instead of benefiting those who are powerless and marginalised, these participatory approaches are used intentionally or unintentionally in favour of the local elites.

Similarly, Guijt and Shah (1998b) question the implicit assumption of 'community' in participatory development as homogenous, static, and harmonious units. By uncritically treating 'community' as homogenous, participatory development is in danger of concealing power dynamics at the local level, perpetuating biases and marginalisation of certain groups in the communities, and for de-politicising development (Cornwall, 2003; Mosse, 1995; Shah \& Guijt, 1998b; Williams, 2004).

The third critique is related to the concept of power within participatory development. Participatory development has been criticised for being reductionist in its concept of power (Cooke \& Kothari, 2001; Kapoor, 2002; Mohan \& Stokke, 2000). Kothari (2001) argues that the binaries of social relations that Chambers presented in Rural Development: Putting the Last First and Whose Reality Counts? Putting the First Last, such as 'uppers' and 'lowers', 'the first' and 'the last', 'professional knowledge' and 'local knowledge', have reproduced a limited notion of social power and control. Drawing on Foucauldian insights into power, Kothari (2001) states that power can be found and analysed through the creation of social norms and cultural practices, which 
is the product of accumulated knowledge that serves as a powerful normative construct in society. ${ }^{1}$ In this way, Kothari $(2001$, p. 141) contends that

... the creation of dichotomies of power within participatory discourse (the haves and the have-nots) allows the revealing of power not as a social and political discourse or as embodied practice, but only as manifest in material realities.

On a similar note, by drawing on the Foucauldian insight of the interwoven process of power and knowledge, Kapoor (2002) criticises Chambers' participatory approaches for the lack of theorisation of power. By calling for a reversal of power in participatory development in order to reduce social inequality, Kapoor (2002) criticises Chambers' narrow view of power, as power is purely seen in a negative way, coercive, and repressive. By doing so, Kapoor (2002, p. 112) argues that Chambers' conception of power "... misses the important Foucauldian argument that power can be positive and that power/knowledge implicate one another".

The lack of clarity in the conceptions of 'participation', 'community', and 'power' have implications for the practices of participatory development and led to criticisms of Chambers' participatory approaches. One of the criticisms is that these participatory approaches undervalue the importance of the local contexts and of various differences within a community, particularly on issues of gender and ethnicity (Cornwall, 2003; Mompati \& Prinsen, 2000; Mosse, 1995; Shah \& Guijt, 1998a). Due to the tendency to treat communities as homogenous and harmonious, practical problems related to gender differences are not dealt with sufficiently. Instead, it has led many development practitioners to fall into the trap of 'community averages' or an assumption that a community has harmonious and consistent perspectives (Guijt, 1994; Guijt \& Shah, 1993, as cited in Guijt \& Shah, 1998a, p. 8). As Shah and Guijt (1998a) state, "Any gender differences that might appear in fieldwork usually disappear into the melting

\footnotetext{
1 'Foucauldian insights into power' refers to the way Foucault viewed power and how it is exercised in society, in which power is generated through cultural practices and social norms, then produces a powerful knowledge, and becomes an interconnected process (Kapoor, 2002; Kothari, 2001).
} 
pot of an 'average community plan'”(p.8). Consequently, certain segments of communities may miss out on the opportunity to be heard and take part in the process. For women, this is often apparent in many participatory development projects, as Cornwall (2003, p. 1325) rightly criticises:

Yet claims to 'full participation' and 'the participation of all stakeholders' familiar from innumerable project documents and descriptions of participatory processes - all too often boil down to situations in which only the voices and versions of the vocal few are raised and heard. Women, many critics argue, are those most likely to lose out, finding themselves and their interests marginalised or overlooked in apparently 'participatory processes'.

Similarly, drawing on the experiences from a project that uses Chambers' PRA method in Botswana, Mompati and Prinsen (2000) show the limitations of participatory processes in a traditional and ethnically heterogeneous community. Although members of various ethnic groups were present at the kgotla (the traditional meeting place in all Tswana communities), the participation of people from the subordinate ethnic groups was restricted. Mompati and Prinsen (2000, p. 230) find that "The male members of subordinate ethnic groups hardly spoke, and then usually only when directly addressed. Women and youngsters of ethnic minorities almost never spoke. They were seen but not heard". This experience, clearly, gives support to the critics who claim that participatory development tends to ignore important differences in a community. Therefore, there is a need for better understanding of the local context in participatory development, and how differences in a community, such as ethnicity, can play an important role in determining the involvement of people from various backgrounds.

Due to the lack of attention paid to local context and issues of differences, participatory development has also been criticised for reproducing and reinforcing the existing dominant power structures at the local level (Cornwall, 2003; Hildyard, Hegde, Wolvekamp, \& Reddy, 2001; Mompati \& Prinsen, 2000). Forms of exclusion, due to various differences in a community, can be exacerbated as only a few outspoken and 
powerful people in the community can fully participate in the process. This is clearly evident in the Mompati and Prinsen's experiences in practising participatory development in Botswana, where participation in the decision-making processes at kgotla were dominated by a few people of the dominant ethnic groups, and that people from ethnic minorities were merely present without having the power to raise their voice, or to exert influence (Mompati \& Prinsen, 2000).

Moreover, participation as a form of people's representation does not always translate into sharing of power. For example, Mohanty (2002, as cited in Cornwal, 2003, p. 1329) suggests that although women have their representatives in the committee of the Joint Forest Management in Uttaranchal villages in India, they still lack voice and influence. ${ }^{2}$ The lack of voice and power to influence in this project has led to a situation whereby many of these women were not only failing to benefit from the project, but also having greater workloads, and were not able to keep the usufruct rights that they previously had (Agarwal, 1997; Cornwall, 2003; Mohanty, 2002; Sarin, 1998). Even in a participatory development project that promised inclusivity for the poor, marginalised, and powerless people, the male-dominant power structure was perpetuated and gendered inequality persisted.

Similarly, another criticism directed at the practices of participatory approaches concerns power relations between development organisations or practitioners and their intended beneficiaries. Many critics argue that participatory development is actually no different than the traditional top-down development approaches, as experiences of participatory development show that paternalistic approaches continue to exist in practice, which has led to the reproduction of the status quo in terms of power inequality between donors, development organisations or practitioners, and their intended beneficiaries (Hildyard et al., 2001; Hussein, 1995; Mosse, 2001, 2003). At the planning stage, participatory approaches were often used as "a means for top-

\footnotetext{
2 The Joint Forest Management is a participatory development project in forest management in India, which aims to empower the women, men, and marginalised communities whose livelihoods depend on forest resources through gaining equal access to and control over the use and management of these resources (Sarin, 1998). The project was praised for its participatory approaches (Cornwall, 2003).
} 
down planning to be imposed from the bottom-up" (Hildyard et al., 2001, p. 60). In other words, the participation of local people is merely used as a tool to reach a consensus and gain their support to participate in the project that is pre-determined by the agencies outside of the community. Drawing on his experience from the Kribhco Indo-British Farming Project in India, Mosse (2001) points out that what is presented as 'local knowledge', which includes the local community's needs, interests, priorities, and plan, can also be strongly influenced by the outsiders' agenda.

A similar example is provided by Hussein (1995) who describes how an outside nongovernmental organisation in Africa pursued a paternalistic approach, made a decision from its central office based on its own assumption of what the local community needed, and provided a development project that was different to what was expressed as the needs of the local community by the local people themselves during the consultative process at the initial stage of the development project. In this way, development organisations or professionals, as well as donor agencies still have a significant power in the design of the development projects that they want to deliver. However, their substantial power can be concealed and made less visible under the rhetoric of joint planning sessions and participatory development.

Paternalistic attitudes and behaviours on the part of donor agencies and development organisations or practitioners can also be observed throughout the project delivery. These can be reflected through a strong vertical control of project implementation, due to external pressures by donor agencies to deliver the project effectively and efficiently (Mosse, 2003). Mosse (2003, p. 193) points out that

The need for close control over works schedules, fixed budget calendars, purchasing and expenditure norms, reporting formats, emphasized upward accountability, the proper use of funds, and the planning and delivery of highquality programmes against quantitative targets.

With such hierarchical structures, it is difficult for development organisations and professionals to transfer or share their power and authority to the local communities, 
so that they can make their own decisions of what they need, and undertake as well as take control of the development projects that are intended for helping them.

Lastly, participatory development has been criticised due to its symbolic use in practice. The mainstreaming of participatory approaches in the development field has put higher pressures on both project management and development practitioners. These greater pressures have led to the routinisation of participation (Cleaver, 1999; Mosse, 2003). Cleaver (2001, p. 53) asserts that

'Participation' in development activities has been translated into a managerial exercise based on 'toolboxes' of procedures and techniques. It has been turned away from its radical roots: we now talk of problem-solving through participation rather than problematization, critical engagement, and class.

Instead of using participation as a way of empowering people, participation is treated as a technical method of project work by certain development practitioners (Cleaver, 1999). Thus, the value of participation is reduced as it is only used as 'a means' to manage development projects, rather than as 'an end' to which the ultimate aim is a social transformation of the poor and marginalised people through the redistribution of power and control.

Nevertheless, the critiques also have their limitations. Since Chambers (1983) discussed the RRA method, participatory approaches in development have been continuously adapted and improved. There is now a great diversity in participatory approaches, such as Participatory Action Research (PAR), Social Audit, Participatory Budgeting, and Participatory Monitoring and Evaluation. The critiques of participatory approaches were mostly directed at PRA, and to a certain extent at RRA. Other methods of participation may still have the potential to be transformative. Kindon, Pain, and Kesby (2007) argue that PAR can be used as a means of re-politicising participatory development as it has the potential to transform the unequal power relationships in research and knowledge production. Williams (2004, p. 565) suggests, "participatory development has no pre-determined outcome, and the space for unintended 
consequences - both positive and negative - is always present with it." There is growing evidence from recent cases of participatory development, such as participatory budgeting in Brazil and social audit in India, that demonstrate the transformative potential of participatory approaches (Hickey \& Mohan, 2005). An Institute of Development Studies study, based on the analysis of over 800 outcomes of participation, shows that 75 per cent of the participation outcomes were positive, because it contributes to development results and other positive outcomes, such as improving the culture of accountability, and more pluralistic and inclusive societies (Gaventa \& Barrett, 2010). The other 25 per cent were more negative, as participation is, sometimes, used and co-opted by the more powerful group, or may lead to feelings of disempowerment, and reinforce existing social hierarchies (Gaventa \& Barrett, 2010). However, aside from pointing out the limitations of participatory approaches, it seems that no plausible alternatives are provided by critics of participatory development.

Suggestions have been made to improve the practices of participatory development in relation to the lack of theorisation of power and the de-politicisation of development. Parfitt (2004) opines that the main debate over the transformative potential of participatory development was largely caused by the integral ambiguity in the concept of participation, as it can be both interpreted as a means or an end. Thus, to be meaningful, he suggests that participation should be considered both as a means and an end, and proposes ways to strengthen the empowerment aspect in participatory development, such as through the use of PAR and institutional adaptions. White (1996) emphasises the importance of recognising that participation is political, and suggests that analysing the interests of various stakeholders involved in participatory development can help address the de-politicisation of participatory development.

\subsection{Power in Participatory Development}

The review of participatory development above also demonstrates that power relations are a key part of the discourse on participatory development. To achieve meaningful outcomes, participatory development encourages a reversal in development policy and 
practice, from the 'normal' top-down approaches to an alternative that supports 'bottom-up' approaches (Chambers, 1983, 1997). The reversal entails a transformative process of power relations between various stakeholders involved. These stakeholders, each with their own interest, engage in political circumstances that involve redistribution and renegotiation of power (White, 1996). Moreover, a great deal of the critiques of, and problems in, participatory development are related to issues of power, as has been discussed in great length earlier. It is clear that power, power relations, and power dynamics are part and parcel of participatory development.

As mentioned earlier, power can be exercised through conflictual or consensual mechanisms. The consensual power theorists argue that power does not always involve conflict. Parsons (1963) argues that power is created by society and not necessarily a zero-sum game, as it can be generated through consent. In contrast, the conflictual power theorists argue that power is gained mostly through domination that involves a zero-sum game, either through coercion or manipulation. Dahl (1961) introduces the first dimension of power, in which power refers to the act of taking control through making a decision (decision-making power). Building on the work of Dahl, Bachrach and Baratz (1962) also consider how decisions are made and can be influenced, and combine the decision-making power with the second dimension of power, that is the power to set an agenda. The agenda-setting power is exercised through excluding particular items from the agenda. Lukes (2005) introduces the third dimension of power, which refers to false consciousness as a result of social and cultural practices. In doing so, Lukes highlights the negative relationship between knowledge and power, in which power distorts the truth. The work of the three conflictual power theorists have largely contributed to the most commonly recognised form of power, namely power over.

However, the consensual and conflictual mechanisms are not mutually exclusive and can take place at the same time in the same setting (Brennan \& Israel, 2013, p. 80). Similar to Lukes, Foucault (1980) agreed that power is a social construction. However, Foucault differs from Lukes since he views the relationship between power and 
knowledge as 'positive'. Foucault critiques Lukes' view of the negative relationship as ignoring the 'agency' of individuals to make independent choices that engender power.

The complexities of power have prompted academics and practitioners of participatory development to gain a better understanding of power in development practice. Stephen Lukes' concept of power, which is known as the 'three dimensions of power', has been fundamental to better understand how power works in society (Lukes, 2005). The three dimensions of power framework provides a broader and radical view of conceptualising power, how they operate and manifest in development practice. The first dimension of power, the decision-making power, involves the power to control or influence other people that can be easily observed. The second dimension of power, or the agenda-setting power, includes the power to control or influence other people in a less transparent and open manner. The third dimension of power, or the ideological power, is the least observable power, which is exercised through shaping the beliefs and values of society.

To gain a better understanding of power dynamics in society, VeneKlasen and Miller (2002) introduce a new framework of power analysis. Similar to Lukes' three dimensions of power, VeneKlasen and Miller (2002) identify the three faces of negative power: visible, hidden, and invisible power. The framework also provides a guide for analysing the type of power that is usually associated with coercion or repression, that is power over. However, as power is often viewed negatively and as a zero-sum relationship, VeneKlasen and Miller (2002) suggest that there is a need to recognise and encourage the adoption of alternative models of power, which offer a positive form of power. In doing so, VeneKlasen and Miller (2002) introduce the three expressions of positive power, which include power to, power with, and power within. VeneKlasen and Miller's conceptual framework of power will be discussed in more detail in Chapter 4.

Additionally, drawing on Lukes' concept of power, Gaventa (2006) argues that the three dimensions of power should be understood in relation to how spaces for participation are created, and how levels of power can occur. Gaventa (2006) points 
out that power can be created through different spaces for participation, which can take place in either closed, invited, or claimed spaces. Power can also operate at the local, national, or global levels. His framework of analysing power is mostly known as the Power Cube. Since then, the number of analytical tools and frameworks to better understand the nature of power and power relations in development, also known as power analysis, has increased.

At the same time, there have been a growing number of approaches to confront issues of power in participatory development. Approaches that seek more meaningful participation, such as PAR or Participatory Budgeting, have now been widely exercised (Hickey \& Mohan, 2005; Kindon et al., 2007). Reflexivity is another important approach that has been increasingly used by academics and professionals in the development field to critically reflect and interrogate the meaning of their own power in relation to their identity (Cornwall \& Pratt, 2003; Eyben et al., 2006; Kindon et al., 2007; Rowlands, 2003). These approaches highlight the importance of a deeper analysis of power in any development cooperation, as it can help development practitioners to form strategies and take constructive action to overcome the issues of power in development practice, particularly in participatory development (McGee \& Pettit, 2019).

In conclusion, the ultimate goal of participatory development is to change the existing power relations for the benefit of the powerless. However, a number of issues in the practices of participatory development have resulted from the lack of understanding of power dynamics in society, and failures to significantly address the issues related to power differentials. Thus, to alter the balance of power requires a good understanding of power in general, and a deeper analysis of the power relationships involved in the various stages of specific development programmes, as well as the interests of various development actors.

\subsection{The Gaps in the Literature of Participatory Development}

Participation can be interpreted differently. The different interpretations entail different power relationships between various development actors and can also lead to 
problems related to power in the practices of participatory development. Both critiques and challenges, as well as suggestions for future improvement to overcome issues of power in participatory development, have been extensively documented in the literature. However, most of them are based on critical reflections and analyses by those whom Chambers calls as 'the First' or the powerful, due to their knowledge and professional background. However, studies that explore the perceptions, feelings, and experience of the local people involved in the process of participatory development, particularly the intended beneficiaries of development interventions, are still minimal. Furthermore, analyses of participatory development that look at the practices of local NGOs from the South seem to be rare.

This gap in our knowledge means that there is a need to explore the perceptions, experiences, and feelings of local people about their participation in development programmes to understand the issues better, and to unpack the underlying issues of power. 


\section{CHAPTER 3 \\ BACKGROUND OF THE LIFE SKILLS TRAINING PROGRAMME}

\subsection{Introduction}

This purpose of this chapter is to provide readers with relevant information regarding aspects of development within Indonesian society, particularly the people in the region, where this study was focused. This chapter is divided into five sections. First, it explains the background of the increase in people's participation in development processes in Indonesia. Second, it explains the condition and socio-cultural aspects of life in East Nusa Tenggara. Third, it introduces Yayasan Tangan Pengharapan, the Indonesian NGO whose programme is analysed in this study. Fourth, it outlines the programme that is examined in this study. Fifth, it provides more information about the regency, the administrative district that the study exclusively focuses on. Then, it concludes with a summary of the significance of the information provided in the context in relation to the study.

\subsection{Development in Indonesia}

Public participation in development processes in Indonesia is augmented by the government's decentralisation policy, which was launched after the fall of President Suharto in 1998. Under the authoritarian regime of Suharto, development in Indonesia was highly controlled by the central government, which concentrated on modernisation and capital-intensive programmes (Aspinall \& Fealy, 2003; Sutiyo \& Maharjan, 2017). Moreover, development was concentrated in Java (Jawa) and the Western islands of Indonesia, in terms of infrastructure and human development (Map 1 overleaf).

After Suharto's regime, however, the relations between the central and regional governments were restructured significantly through decentralisation. Politically, the central government's extensive power was devolved to regional governments (Aspinall \& Fealy, 2003). In parallel, the government's approach to development was changed from a top-down system to a bottom-up system (Sutiyo \& Maharjan, 2017). Many rural 
development programmes were implemented under the Community Driven Development (CDD) strategy, which addresses issues of participation, decentralisation, and bottom-up development in local communities (Sutiyo \& Maharjan, 2017).

\section{Map 1 - Percentage of Low-income People in Indonesian Provinces}

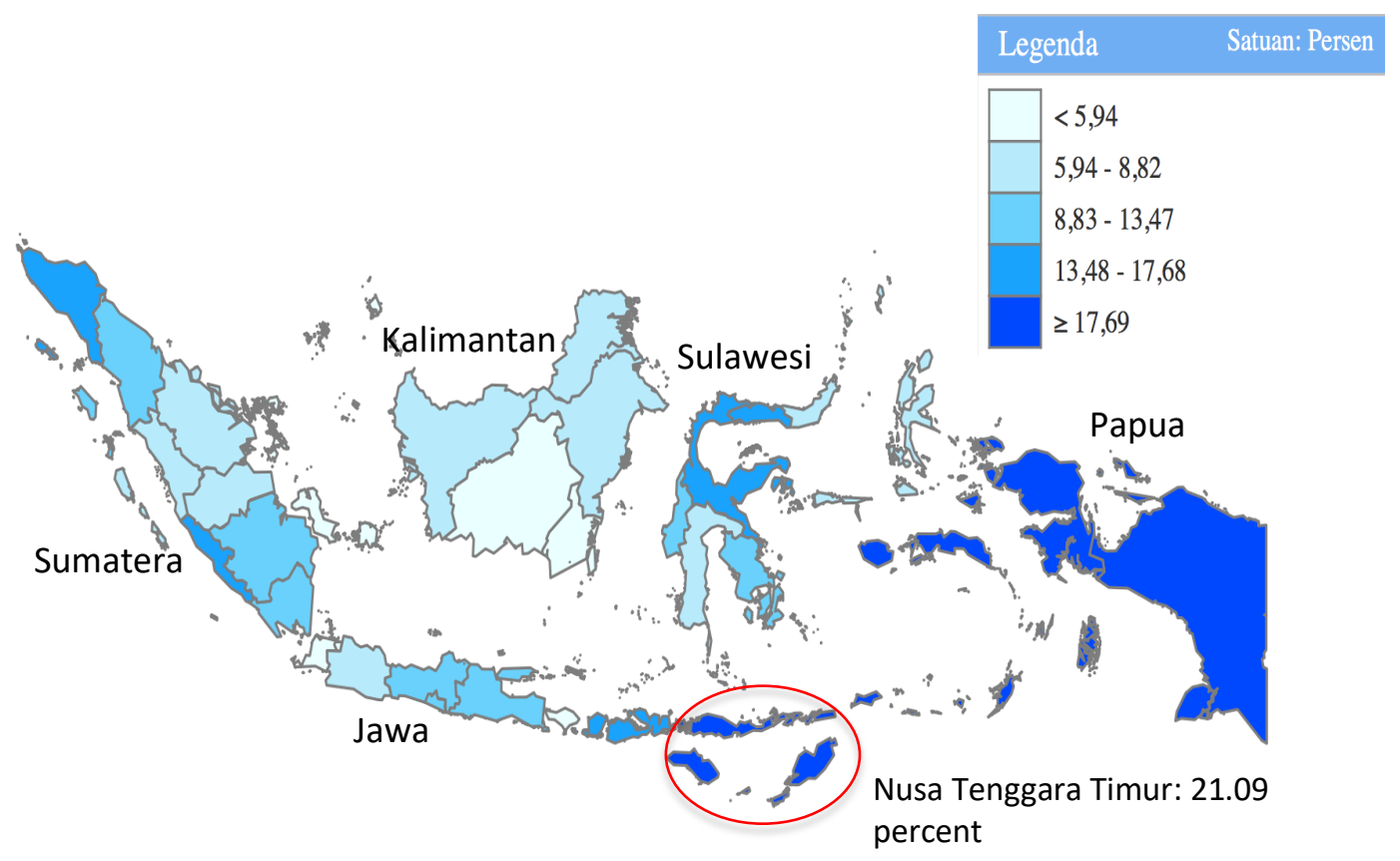

(Source: BPS, 2019b)

Considering the diversity in geography and culture in Indonesia, decentralisation and the use of a bottom-up system in development have been beneficial for encouraging people's participation. Geographically, Indonesia comprises over sixteen thousand islands, and its landscape ranges from mountains, rice fields, beaches, tropical rainforests, and dry savannahs (BPS, 2019c; Ellicott \& Gall, 2003). The archipelagic nature of the country and separation by sea increases the challenges in development in areas other than Java and the western islands. Moreover, Indonesia has the fourth largest population in the world, of 260 million people (Indonesia Investments, 2017a).

The country is also well known for its multiculturalism and religious pluralism. It has over 300 ethnic groups and more than 600 local languages (Indonesia.go.id, 2019; Kementrian Pendidikan dan Kebudayaan, 2018). However, in addition to their local languages, Indonesians generally speak Bahasa Indonesia, the national language. The 
state recognises six religions, but the majority of Indonesians (around eighty-seven per cent of the population) are Muslim (BPS, 2011). ${ }^{3}$ These diversities clearly bring huge challenges in development for the government. However, decentralisation and the use of a bottom-up system in development have increased levels of public participation in regional development and related decision making. During the first year of the implementation of decentralisation, the number of citizens' forums in both cities and districts throughout Indonesia significantly increased (Satriyo, 2003). Unfortunately, despite the increase in local people's participation, Indonesian women still face great challenges in participating in development, particularly in decision-making processes in the public sphere, due to more structural problems, such as entrenched patriarchal norms (Bland, 2019; Satriyo, 2003).

\subsection{East Nusa Tenggara (Nusa Tenggara Timur) ${ }^{4}$}

One of the consequences of the tendency to prioritise development in Java and western Indonesia during the 32-year of Suharto's administration is that development of the eastern parts of Indonesia has lagged that of other provinces. One of the Eastern regions that has lagged in its development, both in terms of human development and infrastructure, is Nusa Tenggara Timur (NTT). NTT also has a high percentage of lowincome people (Map 1 on page 30) (BPS, 2019b; Indonesia Investments, 2017b). Since 2010, the NTT province has continued to rank in the bottom five provinces of Indonesia with low Human Development Index scores (HDI) compared to other provinces in Indonesia (Table 1 overleaf) (BPS, 2019a)..$^{5}$ Moreover, infrastructure in NTT, particularly roads, bridges, clean water, irrigation, and electricity, has fallen behind Western parts of Indonesia (Novianty, 2016).

\footnotetext{
${ }^{3}$ The state recognised religions, one of which every person must affiliate to on their identity card, are Islam, Hinduism, Buddhism, Christianity, Catholicism, and Confucianism.

${ }^{4}$ East Nusa Tenggara and Nusa Tenggara Timur (NTT) are used interchangebly in this thesis.

${ }^{5}$ Badan Pusat Statistik (BPS) or Indonesian Central Bureau of Statistics adopts the UNDP's Human Development Index to measure health, level of educational attainment, and standard of living of the Indonesian people.
} 
Table 1 - Bottom Five Provinces in Indonesia with Low HDI

\begin{tabular}{|c|c|c|c|c|c|c|c|}
\hline $\begin{array}{c}\text { Rank } \\
\text { (province) }\end{array}$ & 2010 & 2011 & 2012 & 2013 & 2014 & 2017 & 2018 \\
\hline 29 & $\begin{array}{l}\text { Nusa } \\
\text { Tenggara } \\
\text { Barat }\end{array}$ & $\begin{array}{l}\text { Nusa } \\
\text { Tenggara } \\
\text { Barat }\end{array}$ & $\begin{array}{l}\text { Nusa } \\
\text { Tenggara } \\
\text { Barat }\end{array}$ & & & & \\
\hline 30 & $\begin{array}{l}\text { Sulawesi } \\
\text { Barat }\end{array}$ & $\begin{array}{l}\text { Sulawesi } \\
\text { Barat }\end{array}$ & $\begin{array}{l}\text { Sulawesi } \\
\text { Barat }\end{array}$ & $\begin{array}{l}\text { Nusa } \\
\text { Tenggara } \\
\text { Barat }\end{array}$ & $\begin{array}{l}\text { Nusa } \\
\text { Tenggara } \\
\text { Barat }\end{array}$ & $\begin{array}{l}\text { Kalimantan } \\
\text { Barat }\end{array}$ & $\begin{array}{l}\text { Kalimantan } \\
\text { Barat }\end{array}$ \\
\hline 31 & $\begin{array}{l}\text { Papua } \\
\text { Barat }\end{array}$ & NTT & NTT & NTT & NTT & $\begin{array}{l}\text { Sulawesi } \\
\text { Barat }\end{array}$ & $\begin{array}{l}\text { Sulawesi } \\
\text { Barat }\end{array}$ \\
\hline 32 & NTT & $\begin{array}{l}\text { Papua } \\
\text { Barat }\end{array}$ & $\begin{array}{l}\text { Papua } \\
\text { Barat }\end{array}$ & $\begin{array}{l}\text { Sulawesi } \\
\text { Barat }\end{array}$ & $\begin{array}{l}\text { Sulawesi } \\
\text { Barat }\end{array}$ & NTT & NTT \\
\hline 33 & Papua & Papua & Papua & $\begin{array}{l}\text { Papua } \\
\text { Barat }\end{array}$ & $\begin{array}{l}\text { Papua } \\
\text { Barat }\end{array}$ & $\begin{array}{l}\text { Papua } \\
\text { Barat }\end{array}$ & $\begin{array}{l}\text { Papua } \\
\text { Barat }\end{array}$ \\
\hline 34 & $N A^{*}$ & NA* & $N A^{*}$ & Papua & Papua & Papua & Papua \\
\hline
\end{tabular}

* The total number of Indonesian provinces was changed from 33 to 34 provinces in October 2012.

(Source: BPS, 2019b)

The geography of the NTT province has contributed to the lack of development. NTT is located amongst the Flores, Savu, and Timor Sea (Map 2). The province is mountainous and spreads across more than 1,000 islands, which increases the challenges of building infrastructure (Pemerintah Provinsi Nusa Tenggara Timur, 2019b). The five main islands of NTT are Flores, Sumba, Alor, Rote, and West Timor, where the provincial capital, Kupang, is located. Like other parts of Indonesia, NTT has two seasons: a dry and a rainy season. The dry season, however, can last between eight to nine months. Consequently, a lot of people in this region often experience drought and food shortages during the dry season. The geographical conditions, combined with insufficient infrastructure, and low levels of educational attainment, have all contributed to high levels of poverty in NTT.

\section{Map 2 - Nusa Tenggara Timur}

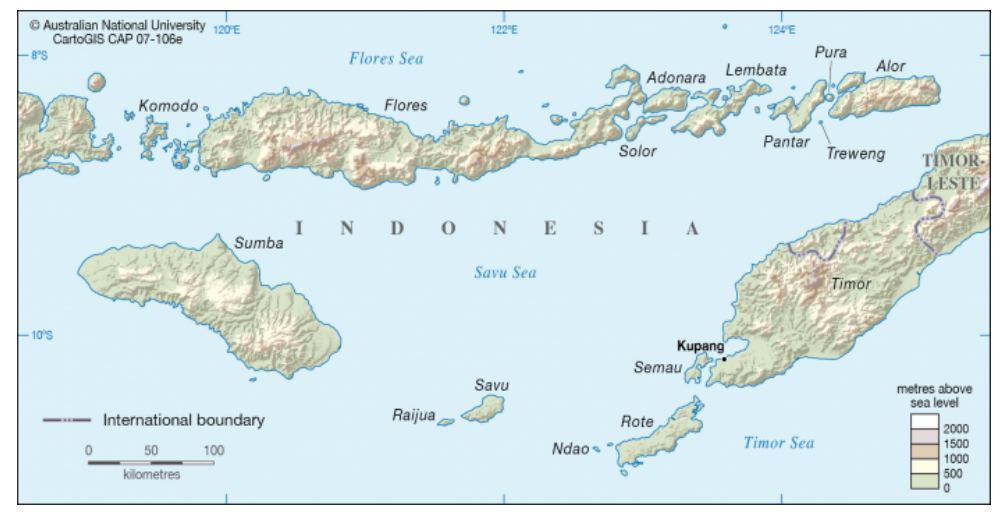

(Source: CartoGIS Services ANU, 2019) 
In terms of livelihood, generally people in NTT work in the agricultural sector

(Pemerintah Provinsi Nusa Tenggara Timur, 2019a). Most of those farmers live in rural areas. However, there is a trend of people moving away from working in the agricultural sector (Table 2).

Table 2 - People and Employment in NTT Province

\begin{tabular}{|c|c|c|c|c|}
\hline \multirow{2}{*}{ Field of Work } & \multicolumn{4}{|c|}{$\begin{array}{l}\text { Percentage of People Aged } 15 \text { and Over } \\
\text { Employed in NTT }\end{array}$} \\
\hline & 2005 & 2010 & 2015 & 2018 \\
\hline $\begin{array}{l}\text { Agriculture, Forestry, Plantation, } \\
\text { Fisheries }\end{array}$ & 78.34 & 64.70 & 61.65 & 54.73 \\
\hline $\begin{array}{l}\text { Community Service, Social Work, and } \\
\text { Personal Services }\end{array}$ & 6.19 & 11.18 & 13.25 & 14.03 \\
\hline $\begin{array}{l}\text { Wholesale and Retail Trade, } \\
\text { Restaurant }\end{array}$ & 4.42 & 7.31 & 8.52 & 10.47 \\
\hline Manufacture \& Construction & 7.41 & 10.01 & 9.53 & 13.39 \\
\hline Other & 3.64 & 6.8 & 7.05 & 7.38 \\
\hline Total & 100 & 100 & 100 & 100 \\
\hline
\end{tabular}

(Source: BPS Provinsi NTT, 2018)

Concerning religion, there is a clear difference regarding the majority and minority religion between the people of NTT and those who live in western parts of Indonesia. In NTT, the majority of people are Catholic (close to fifty-two per cent), followed by other Christian (close to thirty-nine per cent), whilst Islam and the other three recognised religions (nine per cent in total) are the minority (BPS Provinsi NTT, 2018, p. 211). ${ }^{6}$ However, the proportions may change on different islands in this region. For example, the majority of people on Timor Island are Christian, instead of Catholic.

In terms of culture, NTT is culturally diverse. It has numerous ethnic groups, who live in different islands of NTT (Indonesia.go.id, 2019). Each of these ethnic groups has its own local language, tradition, and cultural practices. The people of NTT province also hold strong patriarchal cultural norms. Combined with high levels of poverty, these often

\footnotetext{
${ }^{6}$ Badan Pusat Statistik (BPS) or Indonesian Central Bureau of Statistics use the term 'Christian' and 'Catholic' separately. 'Christian' therefore covers non-Catholic Christian religions.
} 
lead to violence towards girls and women, as well as gender stereotyping that often views women as subordinate (CNN Indonesia, 2018). ${ }^{7}$

\subsection{Yayasan Tangan Pengharapan}

In response to the high levels of poverty in NTT, Yayasan Tangan Pengharapan (YTP), an Indonesian Non-Governmental Organisation (NGO), took the initiative to provide development assistance for local communities in the region. YTP's mission is to help people find their potential, and to lift people out of poverty by providing practical solutions (Chart 1 on page 36 for the Organisational Structure of YTP). It was founded in 2006 by Mrs Henny Kristianus (hereafter Ibu Henny). ${ }^{8}$ The establishment of YTP began with her initiative to help street children in Bandung, West Java, Indonesia, through the provision of free lunches and English lessons. As a Christian priest, Ibu Henny felt that she received a calling to do something bigger to help others.

The same initiative to help poor children was conducted in NTT province, because the high levels of poverty have often negatively impacted on the children of poor families. Instead of going to school, these children have to work and help their parents earn money to meet their family's basic needs (food).

With this background, YTP intends to help by providing practical solutions. One of these is through its feeding and learning activity. YTP provides free lunches for poor children if their parents agree to allow them to go to school. The provision of free lunches was initially offered to attract these children to go to school and study. Over time, YTP has developed itself into a charity that focuses its work on improving the educational levels of low-income people in remote areas of Indonesia. Generally, YTP reaches out to local communities by approaching their traditional or religious leader first, as well as through cultural approaches (for example, by symbolically giving betel nuts to the representatives of local communities in NTT as a sign of respect towards the local

\footnotetext{
${ }^{7}$ NTT has the highest level of violence towards women compared to other Indonesian provinces (CNN Indonesia, 2018).

8 Ibu means mother in Indonesia. However, the word 'ibu' can also be used to greet older and/or married women and is a way of conveying respect for the person.
} 
culture). With the help of its donors, YTP has established schools, training centres, dormitories, delivered free teaching and learning activities for the children of poor families in various places in Indonesia, and delivered training programmes for those who are serving prison sentences.

However, Ibu Henny felt that supporting these children alone was inadequate. There was a need to implement additional programmes, which are intended to help their parents or the adults to help them out of poverty. With this in mind, YTP developed a number of community empowerment programmes. 
Chart 1 - The Organisational Structure of Yayasan Tangan Pengharapan

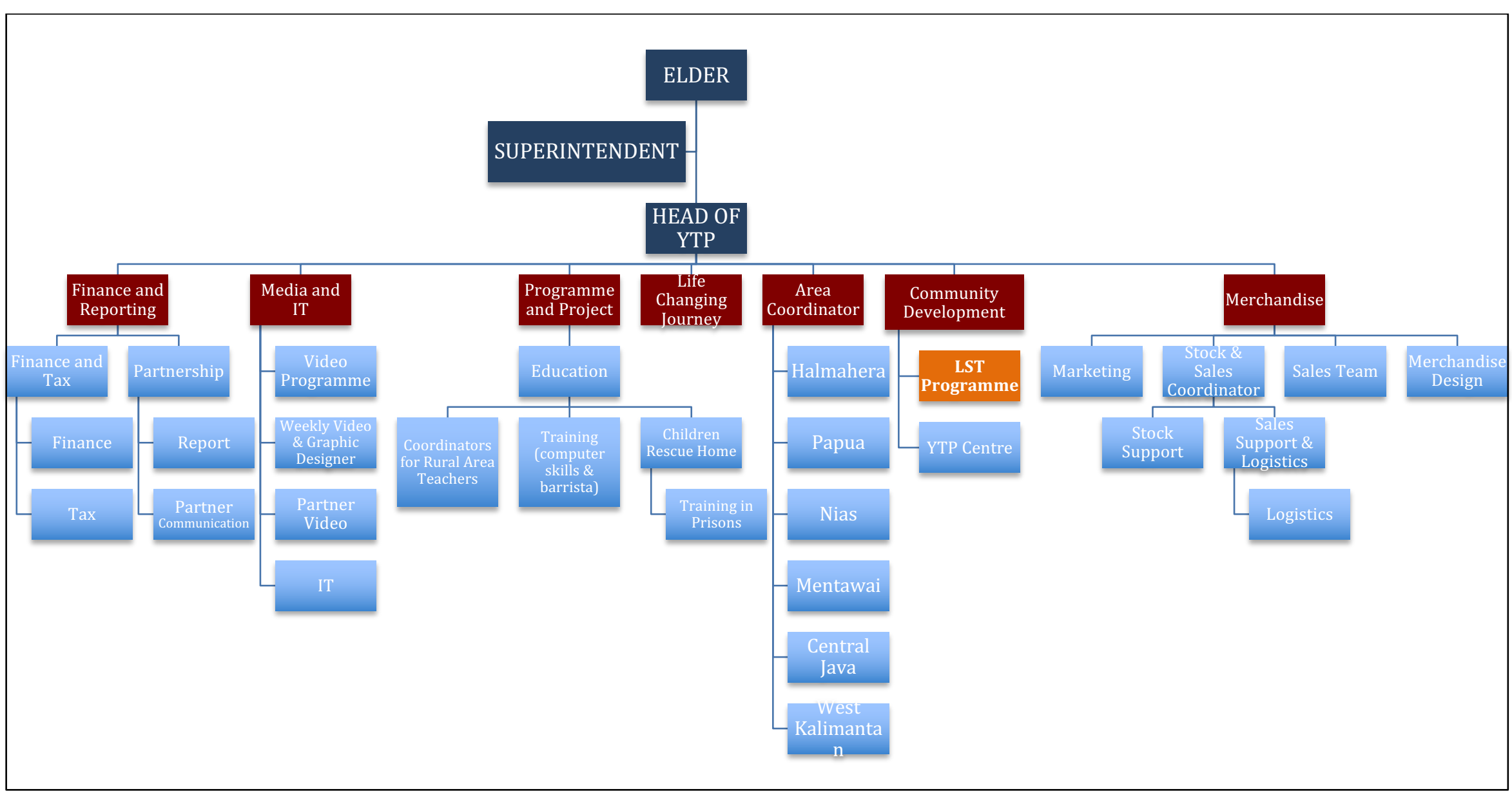

(Source: Yayasan Tangan Pengharapan, 2018, p. 2) 


\subsection{The Life Skills Training Programme}

One of these community empowerment programmes is the Program Sekolah Lapangan or the Life Skills Training (LST) programme. ${ }^{9}$ The programme targets the low-income people who live in rural and remote areas of Timor Island. It aims to empower them to be local agricultural leaders through the provision of training activities in agriculture, horticulture, water harvesting, poultry, and aqua farming. According to one of YTP's field staff, these topics were selected based on the condition of the local people in rural areas, who mostly have land and livestock. Since 2016, multiple series of training activities have been conducted in YTP's learning and training centre (LTC) in Kupang (Figure 7).

\section{Figure 7 - A Practical Session of the Life Skills Training Programme}

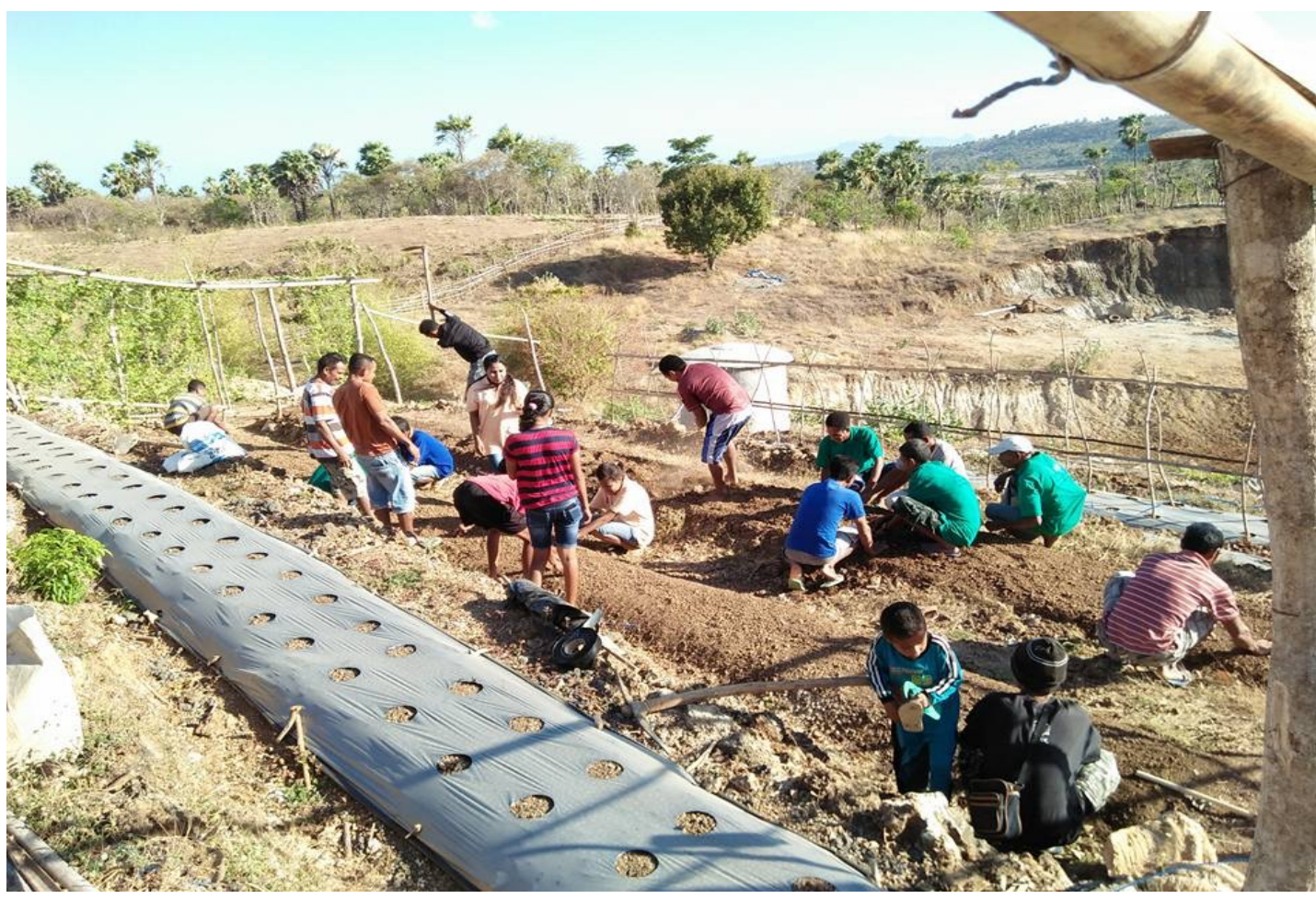

Location: Kupang

Source: Richi Mboro

Date: 21 Aug 2017

\footnotetext{
${ }^{9}$ The English translation for the programme that YTP has been using is the Life Training Centre. However, in order to differentiate the activity of the programme and the physical building where the training programme is delivered, I have adjusted the English translation of the programme into the Life Skills Training programme to make it clear.
} 
The implementation of the LST programme can be categorised into four main activities. These include the socialisation of the programme, the training programme, mentoring and assistance for local farmers in villages, and marketing assistance. The aim of the socialisation is not only to inform the local communities about the training programme, but also to get local people interested in taking part in the programme. The selected local people can then attend the training activities in the LTC in Kupang. After delivering each round of the training programme, YTP's field staff provide a mentoring and assistance service for the trained farmers (Figure 8). In addition, the field staff assist the trained farmers to sell their crops.

So far, YTP has concentrated on delivering the one-week training programme for farmers in two regencies, Kabupaten Timor Tengah Selatan (TTS regency) and Kabupaten Timor Tengah Utara (TTU regency).

Figure 8 - Mentoring and Assistance Visit

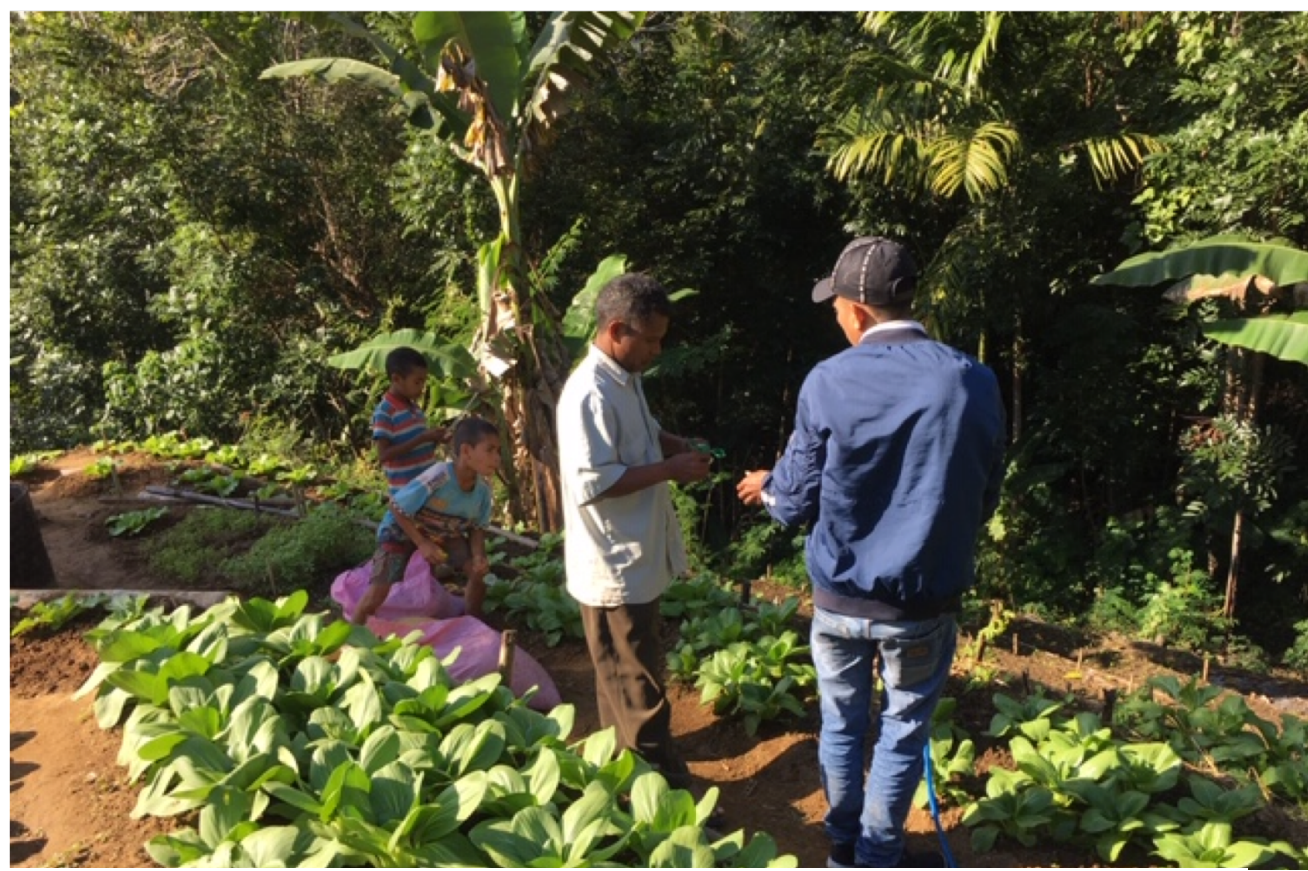

Location: TTS Regency

Source: Cynthia Ecclestone

Date: 25 Jun 2019 


\subsection{Kabupaten Timor Tengah Selatan (TTS Regency)}

The field research for this study was conducted solely in the TTS regency (Map 3). It takes a four-hour drive from Kupang to reach the main town of this regency. TTS regency is located at a higher altitude (generally between 250 to 1000 metres above sea level) (BPS Kabupaten TTS, 2018). The local people in this regency mainly work as farmers (food crops, horticulture, livestock, and forest resources) (Chart 2 overleaf). Most of them are Christian (Chart 3 on page 40), of Timorese ethnicity, and speak Dawan, in their daily conversation. The local communities highly respect their local culture and tradition, as well as religious values. In addition, similar to people in other areas of NTT, the local communities are strongly patriarchal.

\section{Map 3 - Timor Tengah Selatan Regency and Levels of Poverty in Timor Island}

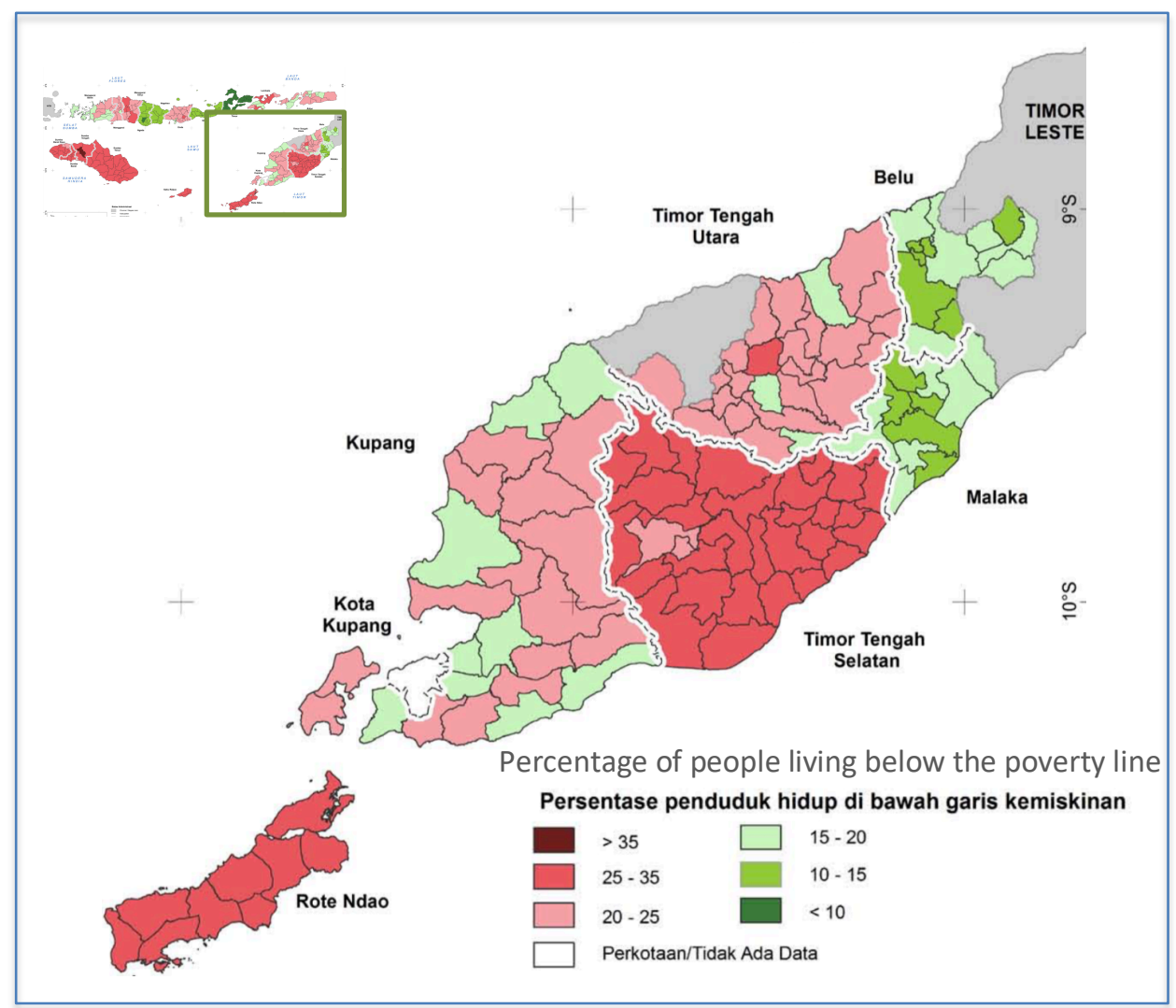

(Source: DKP Provinsi NTT \& UN-WFP, 2015) 
Chart 2 - Main Categories of Livelihoods in Timor Tengah Selatan in 2018

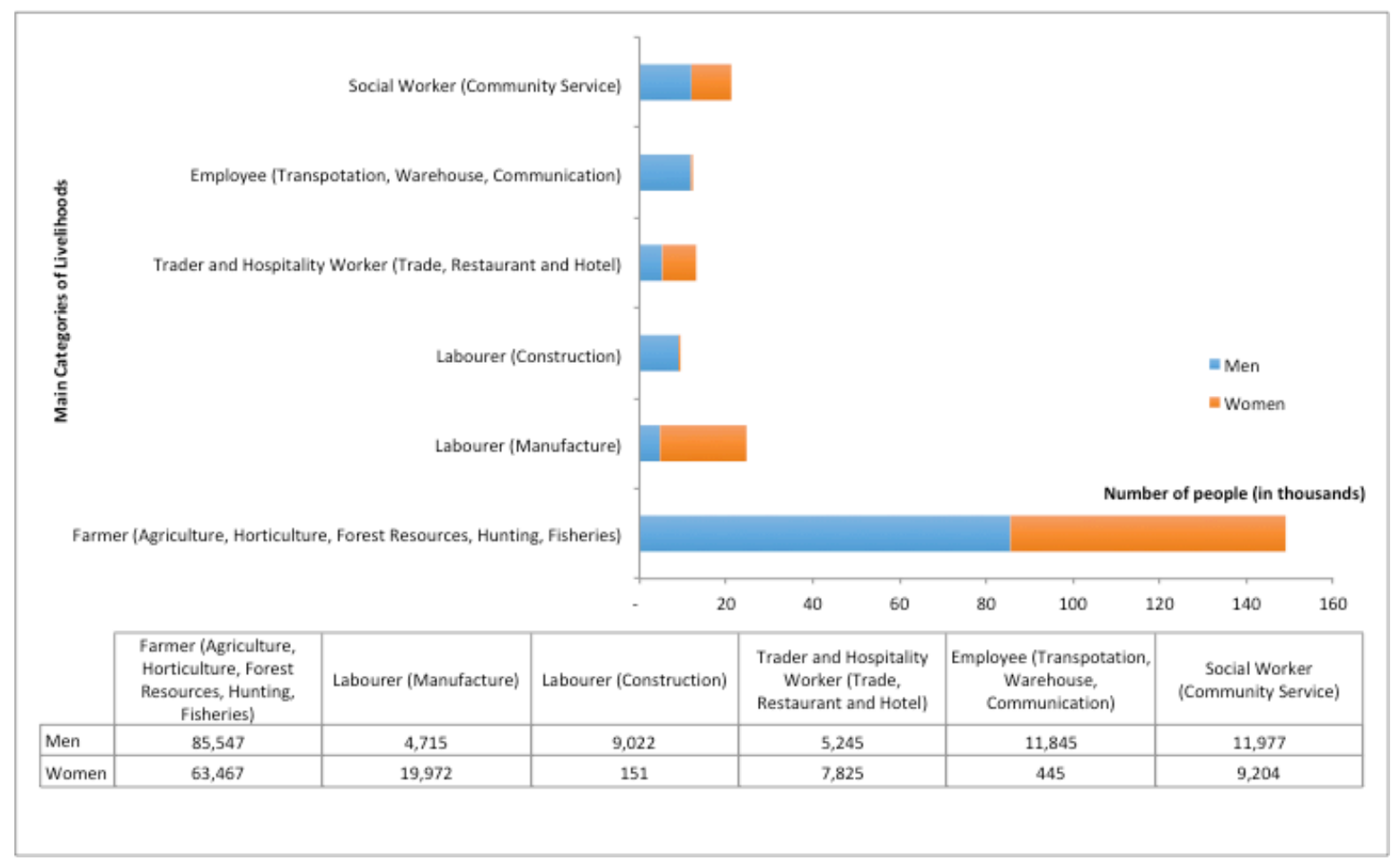

(Source: BPS Kabupaten TTS, 2019)

Chart 3 - Population by Region and Religion in Timor Island in $\mathbf{2 0 1 0}$

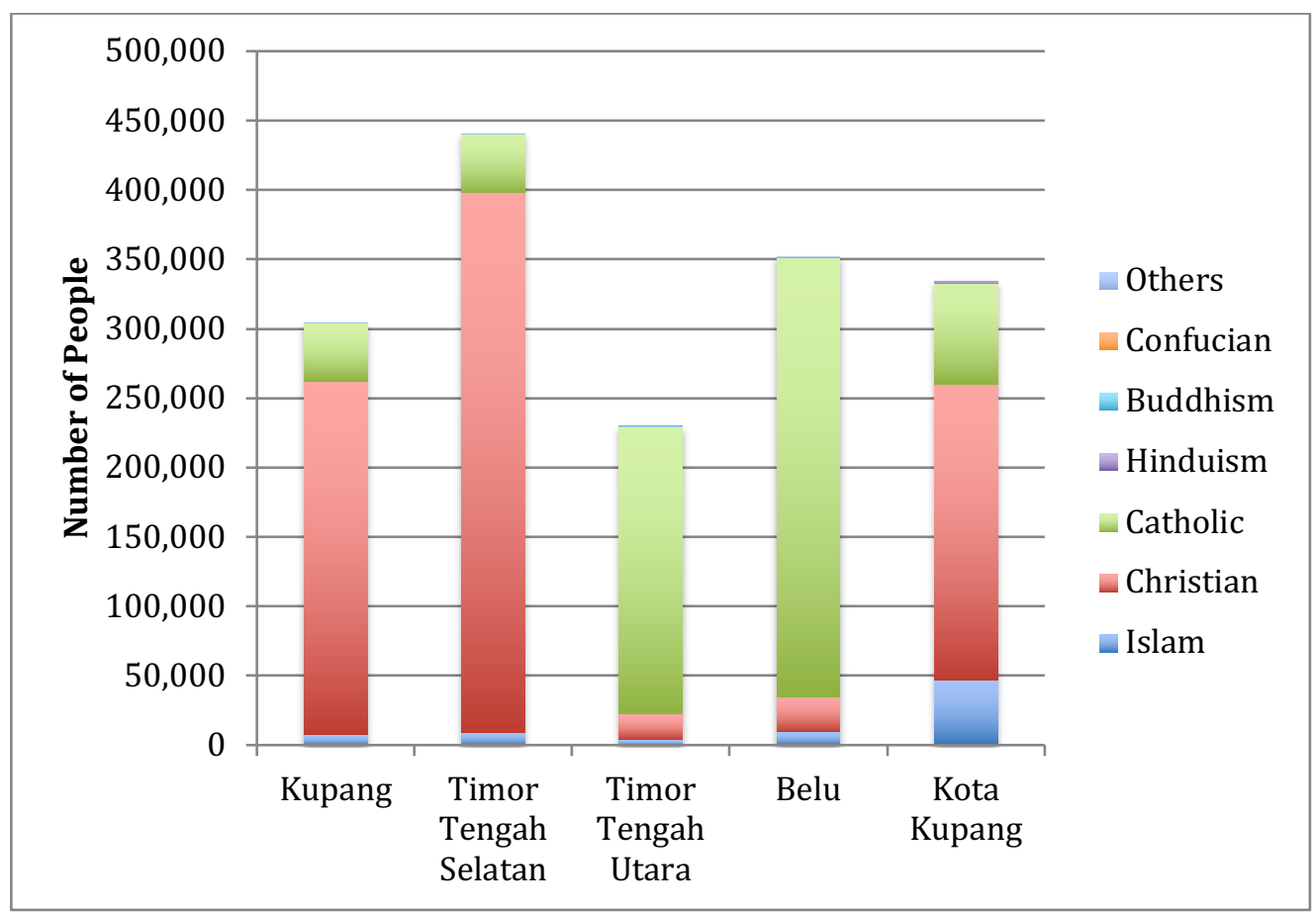

(Source: BPS, 2010) 
In terms of infrastructure, there are differences in the availability and quality of infrastructure between villages in this regency. For example, in Oe'ekam village, where I stayed at during my field research, the quality of the road is better than the ones in other surrounding villages (Figure 9). Electricity and phone connections are also available in this village. However, in other surrounding villages, the quality of the road is very poor and there was limited access to electricity and communication (Figure 9 and Figure 10 overleaf). Additionally, the availability of water resources is also varied. Some villages have more water springs and reservoirs than others.

Figure 9 -

Bridge in Poor Condition in Oelet Village

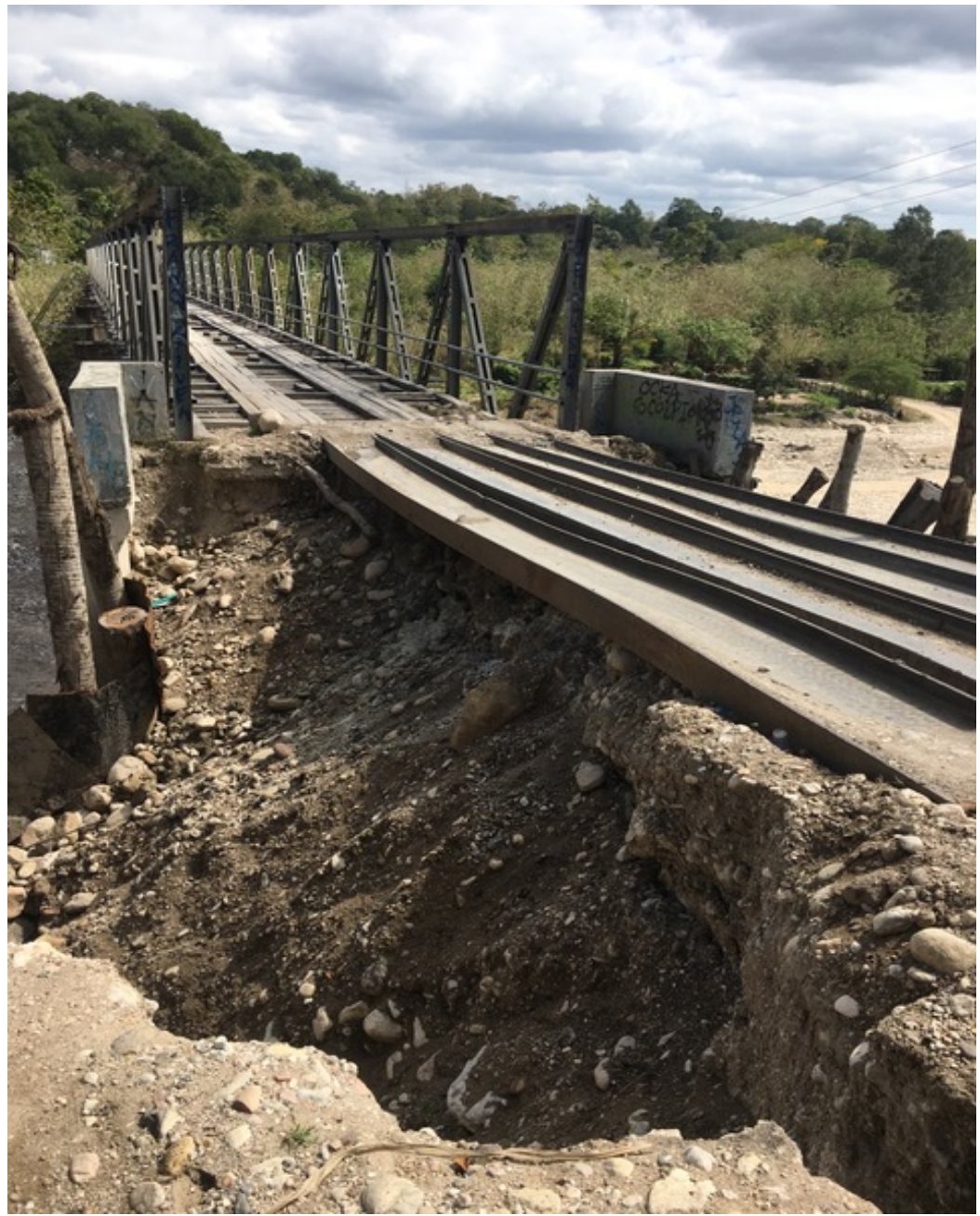


Figure 10 -

A Contrast in Road Quality between Oe'ekam Village and Other Villages

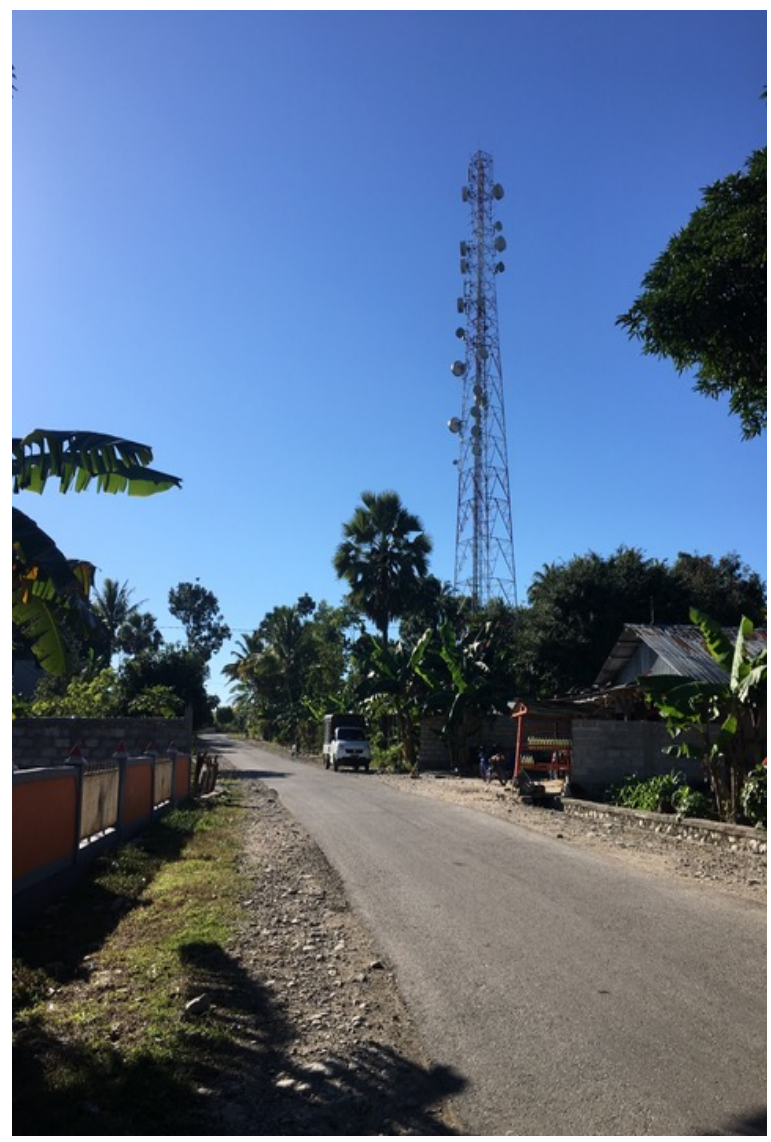

Location: TTS Regency

Date: 3 Jul 2019

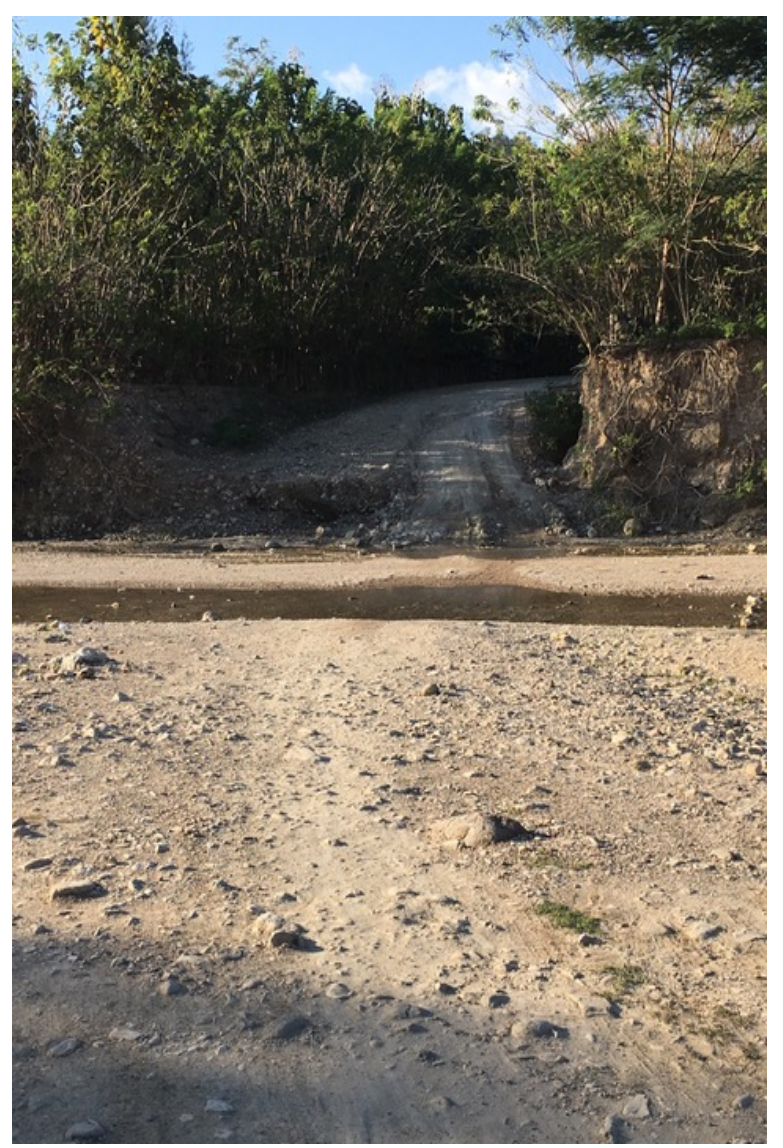

Source: Cynthia Ecclestone

\subsection{Summary}

This context chapter has provided information significant to the study. The general information about development in Indonesia provides a better understanding of the contributing aspects for the under-development in the Eastern parts of Indonesia, particularly in Nusa Tenggara Timur (NTT), the region where the study was conducted. It also provides a background for the increased levels of people's participation in development processes post Suharto's regime. Moreover, since the study looks at a specific development programme that is intended for low-income people, general information about NTT and the various factors that may contribute to the high levels of poverty in the region is included. Additionally, the information about the socio-cultural aspects of the people in NTT was included. It can serve as a starting point for understanding the various differences within the communities in NTT, and how these differences may affect their participation in the Life Skills Training (LST) programme. 
The brief information about Yayasan Tangan Pengharapan and the LST programme provides a better understanding about the organisation that delivers the development programme that is analysed in this study, and of the goal of the programme and the activities involved in the programme. Finally, due to various differences in NTT, more specific information about the Timor Tengah Selatan regency was provided to give a deeper understanding of the condition of local communities in the regency where the study was conducted. 


\section{CHAPTER 4 \\ METHODOLOGY}

\subsection{Introduction}

The purpose of this chapter is to provide readers with information regarding some key elements of the research. It starts with a brief explanation of the research objectives, which frame the questions to be explored in this study. Then, it explains the conceptual framework that guides and informs the research, before briefly explaining the epistemology, methodology, and research methods used in this study. It then points out some ethical concerns in my study, before turning to a reflection on the positionality of the researcher.

\subsection{Research Objectives}

This study aims to contribute to filling the gaps in the literature of participatory development, in which the experiences, perceptions, and feelings of the people involved in development programmes, particularly the intended beneficiaries, have been less explored. In doing so, this study explores the experiences, perceptions, and feelings of the people, particularly those of the intended beneficiaries, involved in a development programme that was delivered by a local NGO from the South. Moreover, this study seeks to analyse issues related to the power relationships between various stakeholders involved in the programme.

As such, the study focuses on looking at the practices of the 'Life Skills Training' programme in Kupang and the Timor Tengah Selatan regency (TTS regency), East Nusa Tenggara, Indonesia, which has been delivered for a few years by an Indonesian NGO, Yayasan Tangan Pengharapan (YTP). This programme has been selected for this study because it specifically targets the poor in the region and aims to empower the local community. The programme provides various life skills training activities (in the area of agriculture, horticulture, water harvesting, poultry, and aqua farming) in an effort to meet the needs, expand the capacity, and improve the livelihood of the local community. 
In addition, the study seeks to draw insights for improving the practices of the programme, which I can then give back to the local community, but also to serve as a way of empowering local people through the sharing of their perspectives, feelings, and experiences. Finally, in contributing to an improved understanding of power relations in participatory development, the study aims to share insights into the ways in which power can be transformed in favour of less powerful people.

\subsection{Research Questions}

The research problem and identified gaps in the literature (Chapter 2.5.) provide me with a direction in forming my research questions. The main question of my research is 'how are issues of power manifested in the 'Life Skills Training' programme?'

The main question will be supported by the following two sub-questions:

1. What experiences, perceptions, and feelings of the participatory process are held by the various stakeholders involved, particularly the targeted beneficiaries, in the Life Skills Training programme?

2. How does the application of a participatory process in the Life Skills Training programme relate to the needs, capacity, and livelihood of the local community?

\subsection{Conceptual Framework}

The research utilises three frameworks (Figure 11 overleaf for the Conceptual Framework). First, I use the qualitative methodology to gather information about the perceptions, feelings, and experiences of various stakeholders regarding the participatory approaches of the LST programme. I also observed the interactions between local stakeholders and the intended beneficiaries to triangulate the data collected from the interviews. Second, I use two frameworks of power analysis (the 'faces of power' and the 'expressions of power') to help understand the power dynamics in the LST programme (VeneKlasen \& Miller, 2002). The two frameworks of power analysis are chosen not only to provide a balance of perspectives on power, but 
also to help with the identification of conditions that may sustain inequalities, or signal the potential for greater empowerment (see Chapter 2 for an explanation about the literature on power in participatory development).

\section{Figure 11 - Conceptual Framework}

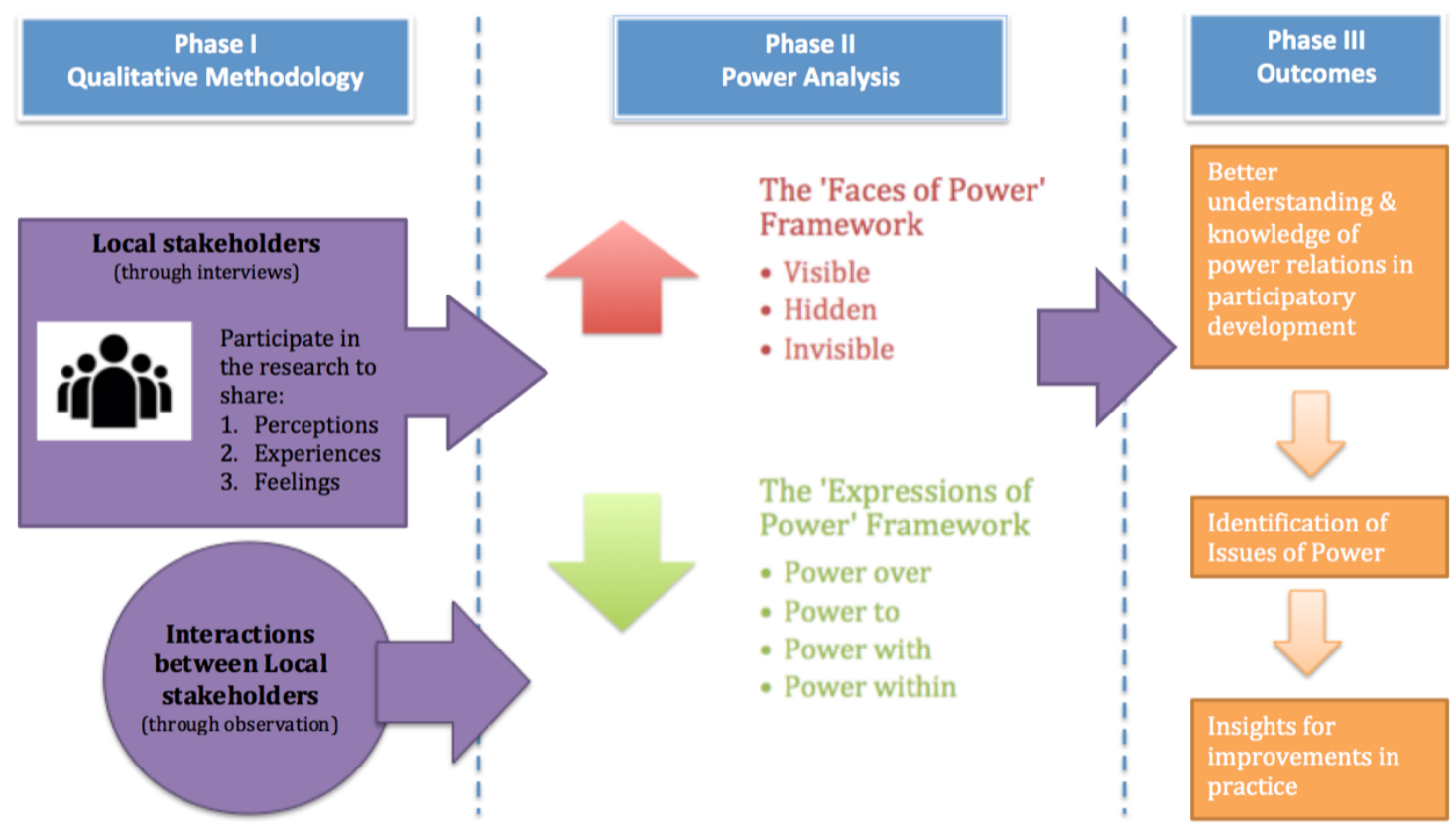

The 'faces of power' framework, which includes visible, hidden, and invisible power, provides insights into the ways in which negative forms of power were exercised in the programme (VeneKlasen \& Miller, 2002). Visible power includes aspects of political power that we can see, such as rules, laws, policies, and regulations. Visible power has the potential to make a situation more fair. However, it also has the potential to discriminate against certain interests and people. This happens when biased rules, laws, and policies are perceived as neutral, but only serve the interest of certain people at the expense of others (Miller, VeneKlasen, Reilly, \& Clark, 2006).

Hidden power is exercised when powerful people and institutions maintain their influence by setting and manipulating agendas and marginalising the concerns and voices of less powerful groups, such as the exclusion of some voices in some 
consultation processes. Hidden power operates behind the scenes (closed doors) and in a less transparent manner to exclude issues of certain groups of people.

Invisible power operates in ways in which people will adopt belief systems that are created by those with power, such as negative stereotypes that limit the roles of certain groups. Bradley (2019, p. 105) summarises invisible power as "the power of beliefs, ideology, social norms and culture to shape people's worldview, sense of self, values and acceptance of what is normal, right and even real." As power does not always operate in visible and tangible ways, the 'faces of power' framework is, thus, useful to reveal hidden and invisible power that can have a substantial impact on the design, implementation, monitoring and evaluation of a programme.

The 'expression of power' framework is useful in the analysis of power dynamics because it offers an alternative view of power that looks at it as a positive rather than a negative force (VeneKlasen \& Miller, 2002). Aside from the traditional view of power over that quite often has negative connotations, the 'expression of power' framework also includes power to, power with, and power within. Power to is the ability to act and make a difference. Power to relates to the notion of agency of individuals or groups of people, and can also be understood as capabilities to take action (McGee \& Pettit, 2019). Power with refers to the ability to act together (collective action). As Miller, VeneKlasen, Reily, and Clark (2006, p. 6) point out, it involves "finding common ground among different interests in order to build collective strength." Moreover, it opens up the possibilities to create a bigger impact by multiplying individual skills, knowledge, and resources. Power within can be described as the sense of confidence, dignity, and self-worth within individuals. It is the capacity to value oneself, think independently, envision, and have hope (Bradley, 2019; Miller et al., 2006). Together, the three frameworks (participatory methodology, the faces of power, and the expression of power) provide a guide for the researcher in conducting the study.

\subsection{Epistemology}

Constructivism (or social constructivism), which focuses on how individuals seek understanding of the world and develop multiple meanings of their experiences, forms 
the basis for this study (Creswell, 2014, pp. 8-9). As this study engages with nonempirical data, which include people's experiences, perceptions, and feelings about their participation in a development programme, constructivism is suitable to understand the multiple meanings of participation in development for various individuals or groups of people. Additionally, constructivism is chosen because the study aims to understand the complexity and issues of power that arise from the interactions between various stakeholders involved in the LST programme, as well as the dynamics of power from the perspectives of those who experienced them.

\subsection{Methodology}

The study uses a qualitative methodology through content analysis. A qualitative methodology places its importance on individual meaning and on engaging with the complexity of a situation (Creswell, 2014). In this way, qualitative methodology is useful in attempts to explore and gain a better understanding of the diversity of perceptions, meanings, and realities of various stakeholders involved in the LST programme. Additionally, qualitative methodology helps provide insights into how power operates during the interactions between the stakeholders.

\subsection{Research Methods}

The research for this study was conducted through a series of semi-structured interviews and observations in Jakarta (the location of the YTP's head office), Kupang (the regional capital of East Nusa Tenggara), and the TTS regency between June and July 2019 (4 weeks in total). Semi-structured interviews were the primary method of data collection in this study, as this method enabled the researcher to have direct access to the research participants' opinions. Moreover, semi-structured interviews provided the opportunities for the researcher to gather in-depth information on the participants' perspectives, experiences, and feelings about their participation in the LST programme, as well as how issues of power were at play. Semi-structured interviews were conducted with 14 research participants, who were selected purposively to provide insights from different perspectives (Table 3 overleaf). Interviews were recorded and then transcribed. 
Table 3 - List of Research Participants

\begin{tabular}{|ccccc|cc|}
$\begin{array}{c}\text { Research } \\
\text { Participants' } \\
\text { Code }\end{array}$ & $\begin{array}{c}\text { Marital } \\
\text { Status }\end{array}$ & Gender & Religion & Group Classifications & $\begin{array}{c}\text { Age } \\
\text { Group } \\
\text { (years) }\end{array}$ & $\begin{array}{c}\text { Number } \\
\text { of } \\
\text { Children }\end{array}$ \\
\hline G1/1 & Single & Female & Christian & YTP's Head Office staff & $25-30$ & 0 \\
\hline G1/2 & Married & Male & Christian & YTP's Head Office staff & $36-40$ & 0 \\
\hline G2/1 & Single & Male & Christian & YTP's local trainers or field staff & $31-35$ & 0 \\
\hline G2/2 & Single & Male & Christian & YTP's local trainers or field staff & $25-30$ & 0 \\
\hline G2/3 & Married & Female & Christian & YTP's local trainers or field staff & $36-40$ & $1-3$ \\
\hline G3/1 & Married & Female & Christian & $\begin{array}{c}\text { Training Participant/Spouse of } \\
\text { Training Participant }\end{array}$ & $36-40$ & $>=4$ \\
\hline G3/3 & Married & Male & Christian & Training Participant & $>=46$ & $>=4$ \\
\hline G3/4 & Married & Male & Christian & Training Participant & $41-45$ & $1-3$ \\
\hline G3/5 & Married & Female & Christian & Training Participant & $36-40$ & $1-3$ \\
\hline G3/6 & Married & Male & Christian & Training Participant & $41-45$ & $1-3$ \\
\hline G3/7 & Married & Male & Christian & Training Participant & $31-35$ & $1-3$ \\
\hline G3/8 & Married & Female & Christian & Training Participant & $>=46$ & $>=4$ \\
\hline G3/9 & Married & Male & Christian & Training Participant & $>=46$ & $1-3$ \\
\hline G3/10 & Married & Male & Christian & Training Participant & $41-45$ & $>=4$ \\
\hline
\end{tabular}

A major difficulty that I encountered in choosing my research participants is having participants from a variety of backgrounds. I acknowledge that all of my research participants are Christian, and that most of them are men. With regard to religion, there are two main contributing factors for this. First, this is due to the fact that the vast majority of people in Timor are Christian. Second, there was a low number of nonChristian/Catholic people that participated in the programme. As for gender differences, the over-representation of men in this study is due to the fact that most of the field staff were men, and that only a small number of local women participated in the programme. Consequently, when analysing issues related to gender and religious differences, I had to rely on the data that I collected through a secondary method.

The secondary method of data collection in this study is observation. The observation was conducted mainly through making field notes and by taking photographs. This method was useful for analysing issues related to power and how power operates in the process of interactions between various groups. 
Moreover, data from other materials relevant to the LST programme, such as the programme proposal and YTP's annual report and regular publications, as well as the government's statistical data regarding agriculture and population of the people in the East Nusa Tenggara province, were used to help with the analysis of the data.

The qualitative data transcribed from interviews were analysed using NVIVO software and coded into a number of themes, which were both developed before the data collection as well as during the coding process. The findings were analysed by focusing on people's participation in the LST programme, and how power was exercised, both positively and negatively, in the programme.

\subsection{Ethics}

It is important to conduct ethical research to ensure that the study will not have negative implications for its research participants (Banks \& Scheyvens, 2014). As this study explores issues related to power relations between the local people and YTP staff, a key ethical issue related to the research participants is confidentiality. Maintaining the confidentiality of my research participants is important to minimise the risk of harm, and to help them feel secure in knowing that their identity is protected so they can provide honest responses, particularly in relation to issues of power that they experienced. To maintain the confidentiality of my research participants, pseudonyms are used in this study. Moreover, informed consent was obtained, either in written or verbal form, during the process of data collection. Additionally, in order to minimise harm or discomfort during the interviews, the research participants were assured that their participation was voluntary, that they could choose not to talk about things that made them uncomfortable, or stop the interview at any time.

Nevertheless, when conducting interviews with the local people, privacy and confidentiality were often disregarded by the participants themselves because quite often their family members (spouse or children), relatives, and neighbours would come and join in our conversation. At that point, privacy and confidentiality seemed to be 
two Western concepts that were not applicable in this setting, as insisting or strictly applying these concepts in this situation and in this community would be considered culturally insensitive and inappropriate. However, despite this occurring during interviews, individual identities have remained protected in the analysis and presentation of the data in this thesis.

This study was subject to a human ethics review process. The human ethics application for this study was approved by the Human Ethics Committee of Victoria University of Wellington on 11 June 2019 (Application ID: 0000027409 - see Appendix A). A sample of the information sheets and consent forms that were used for interviews and observation are included in this thesis (Appendix B, Appendix C, Appendix D, and Appendix E).

\subsection{Reflexivity and Positionality}

Engaging in reflexivity and positionality is equally important in undertaking ethical research (Cupples \& Kindon, 2014; Sultana, 2007). At each stage of the research process, I reflected on the power relations between myself, as a researcher, and my research participants. At the design stage, I have the power in designing the research, and in deciding what kind of topic that I want to explore and investigate. Although this study intends to empower my research participants by creating a space for them to share and express their voices and perspectives, they have no input into the design of this study. In this way, this study lacks a fully participatory process. Moreover, although my research participants were able to express their voices during data collection, these opportunities were limited to the space of a given interview. Additionally, the decision about which information needs to be included in my thesis rests in my hand.

However, I realise that having this power was also useful for my research process as it gave me some leverage to negotiate things with the field staff to ensure that I had control and autonomy over my research. In selecting my research participants from the village, I was able to negotiate with the field staff and to convince them that I required the flexibility to choose my research participants (rather than have the YTP staff choose 
them for me) in order to conduct my research ethically, as required by the university. I was also able to politely ask the field staff, who took me to my research participants (since access to the training participants can only be obtained from them), to leave me and my research participants during my interviews.

During my interviews and observations, I also felt that my identity, socio-economic background, and privilege of being a post-graduate student in a Western university and of living overseas often put me in the position of power. Simultaneously, it can create a 'distance' between my research participant and myself, which is not helpful for my research as they may be less forthcoming in the interviews.

However, as a researcher seeking information from the research participants, I realise that I was also in a less powerful position. During my interviews with the staff of YTP, both in the head office and in the field, I felt a sense of being viewed as someone who is going to evaluate one of their programmes. Consequently, they may hold back from providing the information openly. Moreover, as most of the local people that I interviewed live in areas where the road conditions are poor and there was no reliable public transportation, I could only reach them through the assistance of the field staff. I had to depend on the field staff to take me to meet the local people.

When the field staff contacted my research participants to arrange the time for me to have the interviews, the field staff would give a brief background about myself. I found out later that most of the time, the field staff would inform them that I am a researcher, who is studying overseas and interested in having a chat with them because they had participated in the Life Skills Training programme. Although this was a true representation of myself during my data collection, this introduction seemed to create a big gap between me and my research participants in the village. As I did not have the opportunity to build good relations with them before the interviews, I noticed that when I arrived at their homes or land, they already felt nervous about the interviews. 
However, being aware of the power imbalances has helped me to take actions to address this situation. Although my research participants have no input in the design of this study, I made sure that they understood the intention of my study. During data collection, I made sure that their privacy would be protected and provided them with opportunities to ask me questions about my study and background. When I had greater access to communicate with my research participants, I made sure that they could view and edit the summary of their interviews before I used the data for analysis. Finally, I will develop a brief summary of the results of the research and recommendations for programme improvements in Indonesian language, and share it with YTP, as a way of reducing the power imbalances.

In conducting this study, my positionality, both as an 'insider' as well as an 'outsider', has also influenced my research process. My positionality as an 'insider' is particularly due to the fact that I am originally from Indonesia. Growing up in Indonesia has given me a major advantage as I had knowledge about the country, the people and its culture, prior to conducting my field research. Apart from being able to speak the national language (Bahasa Indonesia), I am also aware of what is socially appropriate or not. Additionally, another similarity I have with all of my research participants is that I am a Christian.

However, I am also an 'outsider' in many ways. Although I am from Indonesia, I grew up in a totally different environment than most of my research participants. Unlike most of my research participants, who live in rural and remote areas of East Nusa Tenggara, I grew up in an urban setting. More specifically, I grew up in Jakarta, a big city and the capital of Indonesia. I am also an 'outsider' due to my gender, as most of my research participants were men. Moreover, after I arrived in the village where I stayed, I found that although the local people understand the national language, they normally speak using their local language. This is quite different from both the national language and the language spoken in Kupang (the regional capital) that I am more familiar with. In addition, I have no doubt that my experience of living in New Zealand 
for more than a decade and of studying in a 'Western' university for my tertiary education have influenced and shaped my thinking and interpretations in this study.

Being an 'insider' during my interactions and data collection with YTP's staff members, both in the head office and in the field, certainly provided me with some benefits. Using the same language, I had the ability to converse with them and to understand them, which helped to minimise the risk of misinterpretations. It also helped to reduce the formality during my interviews with them, and to create a more friendly atmosphere for my research participants to share their opinions. More importantly, it helped me to gain their trust and build rapport, so that I could get their informal support to undertake my research independently. In short, it created a less intimidating situation for my research participants, and reduced the gap in power imbalances between the staff members in the head office and myself as a researcher.

Similarly, I also enjoyed similar benefits as an 'insider' during my interactions with the field staff and while collecting data in East Nusa Tenggara. Although the field staff and local trainers use the local dialect, I was able to communicate with them using the national language without any difficulties. The ability to communicate in the same language, as well as having similar physical appearance in terms of skin colour, significantly influenced the way they viewed me, and the way they interacted with me. I was not perceived as a distant 'outsider' during my stay in YTP's premises while I did my research in the village. Consequently, it made it easier for me to collect data from the field staff as they become more open during the interviews, especially in sharing their negative experiences and feelings.

Yet, I was also aware that other attributes that are attached to my personal identity, in relation to gender, ethnicity, and socio-economic backgrounds, made it impossible for them to view me totally as an 'insider'. On my way to meet the field staff for the first time in the village, I overheard a phone conversation between a staff member, who drove me from Kupang to the village, and a young male field staff member, who asked for more information about my gender, age range, marital status, and physical stamina. 
Apparently, the field staff member was slightly concerned about my ability to conduct my research in a rural and remote area. As most of the field staff members in the village were young and single men, I was instantly viewed as an 'outsider' in the context of doing research in rural and remote areas. I had to make extra effort to convince them that although I am a female and relatively older than them, I was capable of conducting my research in those areas.

While I feel that I was successful in building trust and good relations with the field staff and local trainers, I felt that building good relations with the local people that I interviewed was quite challenging, mainly because I cannot speak Dawan, their local language. Being able to speak Bahasa Indonesia, the national language, turned out to be less useful as they seemed to find it difficult to express themselves in Bahasa Indonesia, even though they understood me.

In addition to coming from a different socio-economic background, my feeling of being an 'outsider' was also contributed by my physical appearance. Compared to the local people in the village, I had a quite distinctive appearance, regardless of my effort to wear modest clothing. I also have a relatively lighter skin colour compared to most people in the village. Thus, I could be easily spotted as a 'foreigner' in the village, an 'outsider' in a country where I was born, grew up and lived for 30 years.

To minimise the distance between the local people and me, I always started my interviews with an explanation of the similarities that I share with them. I explained that although I now live and study overseas, I grew up in Indonesia. I also explained that my ancestors are from East Nusa Tenggara, even though they were from a different island. Additionally, I told them about my interest in growing vegetables and fruit in my garden at home, in order to establish some connections. I reinforced this by giving each of the local people that I interviewed a packet of tomato seeds that I brought from New Zealand. Moreover, I always tried to be open about myself when they asked questions about me, such as my religion, marital status, or how many children I have. I took every opportunity to spend a longer period of time to engage 
with them, by getting involved in their activities, such as helping them to make compost, replanting seedlings, and joining a prayer session with a family whose son was going to be sent to Kupang to continue his studies. However, as I had a limited period of time to engage with them, I felt frustrated at times at the barrier this created to them opening up to me. I was concerned that the lack of time to build relationships with them meant that I sometimes received brief answers to my questions, except from those who seemed to have more self confidence in interacting with people.

Being an 'outsider', however, was also helpful for my data collection. It gave me the advantage of getting some information that the local people may be hesitant to share with the field staff. Being seen as an 'outsider' and independent from YTP had helped me to get the information about their needs and preferences, or their negative experiences and feelings about their involvement in the programme.

Regardless of my limited engagement with the local people, I learned that navigating myself through the process of data collection, being both an 'insider' and 'outsider', is an intricate process. It involved a constant shift between the two positions throughout my fieldwork. Being able to speak the language or understanding basic norms and common courtesy of the society may help. However, it requires greater efforts, time, and patience to build relationships with the local people, and to immerse myself in their realities, mindset, and culture.

Similarly, in analysing the data and presenting the findings of the study, I found myself in situations where I struggled between the two positionalities. In order to capture the realities of the people that I interviewed, I had to temporarily put aside my 'outsider' values and knowledge. I felt that this was an important step to gain deeper insights into the mindset and culture of the people when I wrote my findings.

Concurrently, my personal experience as an 'outsider', of being a woman, who grew up and has lived in a different environment than most of my research participants, has shaped my personal values and interpretations of the people whose views I researched. In analysing the data and presenting the findings of the study, I quite 
often had to step in the shoes of an 'outsider' to allow me to analyse the data autonomously, free from the commitment to conform with the social norms and cultural practices of Indonesian society, particularly when analysing issues related to gender differences in this study.

The struggle between the two positionalities, particularly in presenting the findings of the study, have made me feel uncomfortable. On one hand, I felt that putting myself into the position of an 'outsider' is important to reveal the problems that are less obvious for, particularly, the people involved in the Life Skills Training programme and for Indonesian society in general. On the other hand, in writing the findings of this study, I often asked myself whether the presentation of the findings is a betrayal of the trust from the people, whom I tried to convince to consider me as "one of them" during my field research. However, this discomfort is useful because it makes me reflect on my role as a researcher and the power I have in terms of interpreting the data.

\subsection{Summary}

This research involved research in the field in East Nusa Tenggara Timur with an intensive period of interviews and observations. Although there were some issues to be faced (such as negotiations with YTP in choosing my research participants, and issues related to positionality and power relations between my research participants and myself), I was able to collect some rich data to analyse participatory practices and power dynamics of the Life Skills Training programme. 


\section{CHAPTER 5 \\ EXPERIENCES, PERCEPTIONS, AND FEELINGS ABOUT PARTICIPATORY PROCESSES OF THE LIFE SKILLS TRAINING PROGRAMME IN EAST NUSA TENGGARA}

\subsection{Introduction}

Although there is extensive literature on ways to improve practices of participatory development (see Chapter 2.3.), there is still minimal documentation on the experiences, perceptions, and feelings of various stakeholders involved, particularly those of the intended beneficiaries of a participatory development programme. This chapter provides the findings of a study that explores these issues. These findings are divided into three main sections. First, I explain people's experiences of participatory processes in the Life Skills Training Programme. Simultaneously, I point out key barriers and challenges that people experienced, as well as the supporting factors for people's participation in this programme. Then, I present people's perceptions of the local problems, needs, capacity, and livelihood relating to their involvement in the programme, before touching on people's feelings of their participation. I then discuss the major findings of the study in relation to the literature on participatory development. Finally, the chapter concludes with a summary of the study's major findings.

\subsection{Experiences of Participatory Processes in the Life Skills Training (LST) Programme}

\subsubsection{Practices of the Programme}

The LST programme emerged from an initiative of two of the YTP's teachers for rural and remote areas, who are originally from Nusa Tenggara Timur (NTT) and were assigned to positions in North Halmahera, Maluku, another island of the Eastern part of Indonesia. During their assignment, they made use of their free time with gardening. 
One of these teachers thought that he could do more for the community. He then cleared YTP's land, where he was staying and planted various vegetables. The land was a swamp and full of tall grass and coconut trees. The community in North Halmahera used to think that a swamp area could not be used for planting vegetables. With the help of another YTP teacher, they managed to successfully transform the land into a horticultural area, where they grew vegetables, tomatoes, and chillies. The local community became interested and went there when they harvested their crops. The crops were initially not for sale and only used for the YTP staff's own consumption. Over time, more people came to YTP to buy some of the food crops. After discovering that the result of their gardening activities had been widely used by the local community, Ibu Henny advised one of these teachers to reduce his teaching time and to focus on developing gardening and horticultural skills to be a community empowerment programme in North Halmahera.

Learning from the success of this activity, Ibu Henny, who also manages and supervises YTP's programmes and projects, suggested that a similar initiative could also be trialled in NTT, even though the natural condition in some parts of NTT is more challenging (due to the lack of water) and not as good as in North Halmahera. In November 2016, built a learning and training centre in Kupang. Soon after its completion, YTP started to deliver the Life Skills Training (hereafter LST) programme in NTT. The two teachers who initiated the programme in North Halmahera were given the responsibility to manage the programme in NTT.

However, the preparation to implement the LST programme in Kupang seemed to be conducted with minimal internal discussion. This later led to problems that were expressed by one of YTP's field staff. He received the information in June 2016 that the training centre in Kupang was going to be launched in November 2016. He also heard that YTP was looking for staff, who could help with the implementation of the programme because the regional head of the programme had resigned. To fill the gap, the field staff member who was reassigned from his role as a rural teacher in North Halmahera, had to travel back to Kupang at short notice to help prepare for the launch and roll out of the programme in Timor. 
"So, at the end, I said 'Ok, I'Il have a meeting with the community here because I already promised to help them.' However, only within two weeks, also because there was no internet connection there, we got the information from the Head Office about our tickets [...] At that time, I thought 'Ok, there's still plenty of time (to prepare my replacement in North Halmahera and for moving back to Kupang).' But, when I went to a place where I can get some internet connection, I found that my ticket to Kupang was already bought and issued, without any confirmation with me. The staff at the Head Office did that probably because they could not reach me. They sent me the ticket directly so I could prepare to leave straight away. When I looked at my ticket, I got the information on Thursday and the following Tuesday, I already had to leave." $(G 2 / 1)$

Moreover, the allocated time to prepare for the launching of the programme was very limited. Although the training centre was built and ready to use, the field staff still had to prepare the soil and plants for the practical sessions of the training programme. YTP had to assign a number of staff to help make sure that the programme could be launched and implemented on time and as planned.

"So, we (my research participant and a group of people) had a mandate from Ibu Henny to prepare the land so the training programme can be conducted in November. The timing was very limited. So, we tried our best. When we arrived in Kupang, the soil was not prepared." (G2/1)

In addition to the limited input from the field staff, there was also an absence of participation from the rural communities of Timor Island in planning and designing the programme. Previously, YTP had had a similar community empowerment programme. The local people were invited to attend community gatherings in their villages, so YTP could provide them with information and training activities related to agriculture. However, it did not generate the results that YTP had expected because no one in the village followed up YTP's initiative by deciding to work in agriculture after attending 
these community gatherings. Learning from this past failure, YTP had made some adjustments, which then led to the delivery of the LST programme.

"We cannot find the people who really wanted to work in agriculture, they did not do the agricultural work at all. From there, we learned that the system needed to be changed. We learned that if we deliver our training programme in a community gathering in the village, with a lot of people attending the gathering, they will not be able to focus, because they possibly think that they have to go somewhere else after the gathering, or do something else. They were present but they did not really pay attention to what we taught them. However, if we bring them to the training centre in Kupang, they can focus on learning what we teach them. They also cannot leave the training centre to do other things." (G2/1)

Although YTP had a good intention to help the local communities, community involvement was minimal since they were not invited to take part in defining their own problems, priorities, and needs. The staff members in the Head Office may have had the opinion that the field staff knew about the local problems because they are originally from the NTT province and they can represent the local communities. However, the decision to initiate and implement the programme was made by the head of YTP. Moreover, the experience of one of the field staff members, who had to travel back at short notice to help with the implementation of the LST programme in Kupang, further highlights the top-down approach and centralised governance of this programme. The voice of the head of YTP seemed to carry more weight in the early stage of the programme.

At the implementation stage, the local people had a greater level of participation. They could ask questions and provide inputs. Moreover, before each training programme ended, they had an opportunity to make decisions about what kind of seeds that they wanted to grow on their land. 
However, some aspects of the governance of the LST programme may prevent greater participation of the local communities. The first aspect is that the top-down approach was echoed at the local level. To invite local people to participate in the programme, the field staff sought permission from the relevant village governments. Then, the field staff asked for the support of the village heads to spread the news about the programme, or to make recommendations about which local people were suitable and interested in attending the training programme, before selecting the ones that met YTP's criteria to join the training sessions in Kupang. In this way, the village heads were the ones who mostly made the decision of their village representatives to attend the training programme in Kupang. Although this can be a good indication of respecting the local authority, this also means that there is no equal opportunities for others, who were also interested in participating. Moreover, the village heads may choose their representatives based on favouritism toward the people that have closer relationships to them. However, according to the field staff, the village head in some villages had a more inclusive style and asked people to nominate themselves if they were interested in participating.

The second aspect that hindered local people's participation is the different priorities between YTP and the local people. Although the trained participants can make their own decisions and prioritise their work to meet their household's needs, or to focus on non-horticultural type of plants, the field staff put a higher priority on supporting farmers who work on a bigger scale and focus on horticulture. In one of my interviews, I found that the trained participant who later on decided to focus on growing rice in a paddy, instead of horticulture, was not given sufficient advice when he had problems with his rice.

"Pak Ricky came once when it was almost the time for us to harvest our crop. At that time, I think Pak Ricky focused more on the vegetable crops ... Although he pointed out that our rice paddy did not look as well as it should be, he did not give me the advice on what to do with those rice so it can grow better." (G3/9) 
It is possible that the measures of success for the LST programme may be behind this. The answer from a member of the field staff reflects this mindset. When I asked for the reason why the participant who focused on growing rice paddy was viewed as less successful by YTP, even though he had utilised the skills and knowledge that he gained from the training programme, his answer was:

\footnotetext{
"Because he planted some vegetables at the beginning, had successful harvests a couple of times ... but then he stopped growing vegetables and focused on growing rice paddy instead. He does not fully apply the training materials that YTP gave him. He only chose a few useful ones for his rice paddy, such as making organic pesticide and compost." (G2/1)
}

Because the field staff focused on supporting farmers who work on a bigger scale and focus on horticulture, the small scale and non-horticulture farmers received less advice and assistance for their chosen type of farming. This kind of mindset on the part of the field staff may well be a barrier to certain types of farmers, who simply grow food for their own families, or who grow other crops such as rice, in getting the most out of YTP's mentoring and assistance. It may also discourage them from participating in the LST programme in the long term. More importantly, it reflects the paternalistic approach of this programme.

The monitoring and evaluation of the programme was mostly conducted by YTP, both by the staff in the field and in the Head Office. The programme participants did, however, have opportunities to contribute to the monitoring and evaluation. During the training sessions, YTP staff observed the reactions of the training participants and listened to their inputs. If needed, the training method could be modified. For example, when participants seemed bored while learning the theoretical part in the class room, the training method could be changed immediately.

After a series of training programmes were held, the field staff continued to monitor the progress of the programme through their mentoring and assistance service. They 
had regular meetings once every two weeks. In these meetings, they discussed and tried to come up with solutions for the problems that farmers encountered in the field. They also discussed the reasons for the slow progress that were demonstrated by certain farmers. These less successful stories would be reported at YTP's annual meetings. However, the field staff did not record these less successful stories in written reports.

The trained participants could also take part in monitoring their own work in the field. They were able to observe their work, analyse the problems they had, and make decisions on how to solve the problems that they faced, such as how to combat pests.

\footnotetext{
"It (problem with their plants) happens quite a lot to our chillies. Maybe the cause of the problem with our chilli plants is pests. I did not have the time to ask for advice from YTP's staff, but I tried to solve it by myself." (G3/5)
}

Findings from monitoring farmers' work in the field, particularly their success stories, were reported by the field staff to the Head Office every month. These success stories were collated, by a staff member in the Head Office, and published in YTP's monthly bulletins, which are sent out to its donors. If the Head Office staff have not received the report by a certain date each month, payment of the field staff member's salary would be postponed until they send the report. If there were significant problems that could not be resolved by the field staff, they could arrange for a meeting (by phone, Skype, WhatsApp, or rarely in person) with the Head Office staff in Jakarta. The head of YTP generally provides suggestions, and decides the best strategy for the organisation to overcome the problems.

The evaluation of the LST programme was carried out in various ways. The evaluation of the training sessions took place on a daily basis at night in a sharing forum. In this forum, the participants, field staff, and a number of trainers gathered to evaluate the activities that they had during the day. The participants can express their opinions about the training programme. 
"The daily evaluation and sharing forum, according to our training participants, is the one that makes our training different because the government's training programmes are, normally, conducted in a one-way teaching method. They explain about how to do things and demonstrate them to the local people and that's it ... they then let the participants do the work by themselves. So, no interactions between the trainers and participants. In our training programme, the participants can ask as much as they want and there were interactions too." $(\mathrm{G} 1 / 1)$

Sometimes, the participants' feedback was taken into account by the field staff for the improvement of the following training programmes. Other times, the field staff received feedback from the participants when they visited them in the village. For example, the field staff have reduced the amount of time needed for making a ferrocement water tank by half, after they heard from a few participants during their visit in the village that the workload was too heavy. Now, key components are pre-fabricated and given to the farmers during practical sessions.

Additionally, YTP holds regular meetings to evaluate its programmes, including the LST programme. These meetings are conducted two times a year (mid and end of year). However, only staff members of YTP can attend these meetings. In these meetings, the coordinator of the LST programme is required to give presentations about the programme and its achievement. The head of YTP would then provide her feedback.

However, the local people and trainers, who are not staff members of YTP, did not seem to have a dedicated forum, which they could use to discuss and share their ideas or feedback for improvements.

"So far ... there has not been any meeting between the trainers and YTP staff to specifically evaluate the training programme and what needs to be improved. The discussions took place in between the training sessions. About making the Virgin Coconut Oil, I remember that I have suggested it to them ... but we did not follow it up ... no further discussions about it. Maybe a specific meeting 
(workshop) to evaluate the programme can be conducted after each round of the training programme finishes." (G2/3)

The above explanation demonstrates that YTP's paternalistic approach to monitoring and evaluating its programme can create a significant barrier to greater participation by the local people at this stage. Although the local people who were involved in the programme, can take part in this process, the solutions for the problems that the local people faced in the field, quite often, came from YTP, not the participants. Moreover, YTP's staff were the ones who made important decisions about the programme based on their analysis of the progress of the programme. A member of the Head Office staff $(G 1 / 1)$ said that, in a recent coordination meeting between YTP field staff and the staff in Jakarta, it was decided that the location of the training programme needs to be changed. The training sessions in Kupang will be replaced with the ones closer to where potential participants live. Apart from a major difficulty in getting funding to implement the programme, this was decided due to the high cost of bringing the participants to the LTC in Kupang, compared to the expected outcomes so far. The YTP's cost and benefit analysis also considers that only a few participants are truly committed to following up on the knowledge gained from the training programme.

\subsubsection{Local Differences and Contexts}

The study found that there were three main barriers and challenges for greater participation, which were related to local differences in age, gender, and religion. First, these were partly due to the set criteria and rules that were set by YTP and its field staff. In selecting the training participants, YTP had a number of criteria (Appendix F). These criteria required training participants to be in the age range between 25 to 48 years old, for both male and female participants. There were no specific requirements in relation to literacy, marital status, religion, or ethnicity. The other requirements mostly involved people's attitudes and behaviours, such as having a strong willingness to learn, be a hard worker, and be keen to improve their living conditions and their community. 
Moreover, YTP had a set of rules for the participants who were selected to join the training programme (Appendix G). Some of these rules stated that YTP was not going to provide any financial reward for the participants in exchange for their attendance. Instead, YTP covered the cost of participants' transportation, accommodation, and meals during the training programme. Each participant was given a hoe and seeds, so they can start working on their land after attending the training programme. However, an interesting finding about these rules is the inclusion of a gender-specific rule. This rule is specifically addressed to female participants, and forbids them from bringing small children to the training centre.

Although the age limitation and the gender-specific rule were not set in stone in practice, they may discourage people from participating, especially those who are older or younger than the age limit, or women with small children.

Second, the physical workload in some of the practical sessions was considered too heavy for certain participants. One of my research participants (G3/4) expressed the view that the physical workload

Figure 12 -

in building a ferro-cement water tank was too heavy for Training Participants Making a Ferro-cement Water Tank him (Figure 12). The older and female participants may also find it much more challenging to participate in this kind of activity than the younger male participants.

Third, people's attitudes and

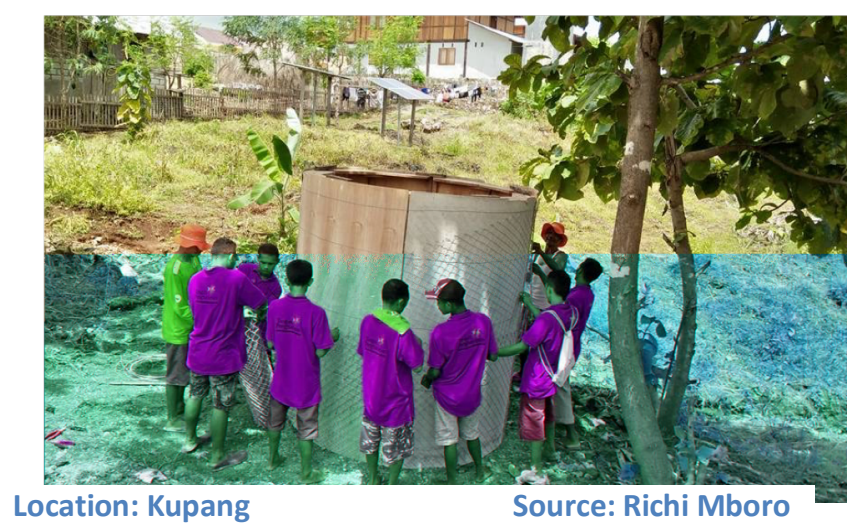
behaviours toward gender roles, the nature of the work, and aspects of religion, can prevent certain people from participating in the programme. Aside from the genderspecific rule for women to not bring their small children during the training programme, I also found that there was a tendency to choose male participants to attend the training programme. 
"Actually ... at the beginning, we want to invite farmers (who have already worked in agriculture, horticulture, and farming). We normally ask (the village heads' recommendation) for male participants ... and mostly the ones that are interested to join are men. However, we don't set it as a standard." (G2/1)

It seemed that the staff's preference to have male participants was based on their assumptions about the nature of the work, e.g. because agricultural work requires hard labour, thus the programme was more suitable for men. Consequently, these assumption impacted on the way they recruited the participants and created unequal opportunities for female participants. Despite the high proportion of women working as farmers in the TTS regency (up to forty-two per cent of the total number of people working in the agricultural sector), only a small number of women participated in the programme (BPS Kabupaten TTS, 2019). The small number of female participants who have attended the training programmes also indicates a lack of attention toward gender equality in this programme.

Furthermore, the nature of the agricultural work seems to be unattractive for younger members of the local communities. According to a field staff member (G2/2), there was a lack of interest among young people in participating the programme because most of them have an opinion that agriculture or farming is not prestigious work and that they will not earn their income quickly by doing this work. Others prefer to gain work experience in other parts of Indonesia.

Moreover, I also found that most of the training participants were Christians. It is most likely because Christianity is the dominant religion (see Chapter 3.6.) throughout the island of Timor (BPS, 2010) . A few participants may be Catholics. However, only one of them was a Muslim.

It seemed that religion plays an important part in this region. When I visited a village to conduct my interviews, the principal of a nearby elementary school came by and joined my conversation with a research participant. He asked me about my religion and the 
purpose of my visit. I was quite surprised when he asked me about my religion, because I did not expect to be asked such question. A couple of teachers, who later on joined us, told me about the story of a boy in the nearby village, who was filmed when he was in the process of converting to be a Muslim. This experience provided me with an indication of the significance of religion in the lives of the local communities.

Initially, YTP also had difficulties in reaching local communities due to its Christian values. The local people were slightly reluctant to receive assistance from YTP because of the background of the organisation and its founder, which are tied to charismatic denomination of Christianity. In anticipating this problem, YTP has now adopted a new strategy of clarifying its organisational background early on when they reach new communities, and approached the village head or traditional leader to provide information about the organisation and its approach.

Although it is an NGO with

Christian values, YTP does not

require its trainers to be only

from a Christian

background. ${ }^{10}$ One of the

field staff (G2/1) said that YTP

also has a Muslim lecturer, who delivered training sessions for the participants (Figure 13).
Figure 13 -

A Muslim Female Trainer Giving a Training Session

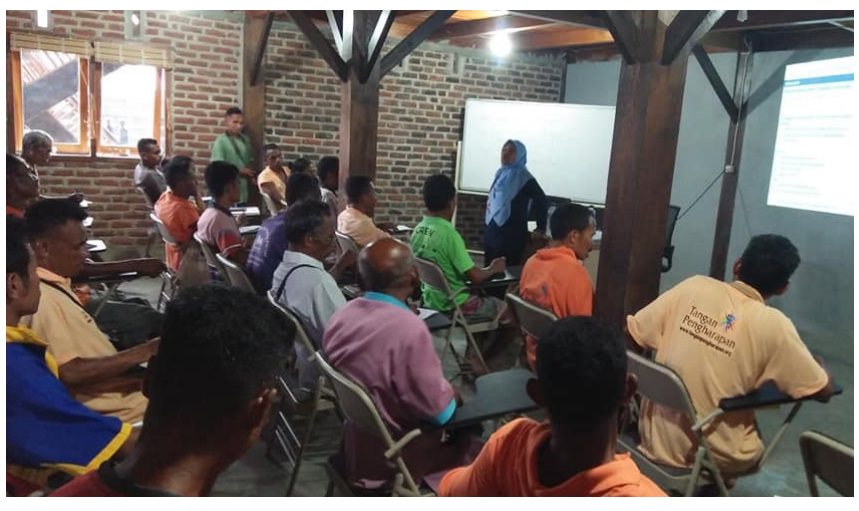

Location: Kupang Date: 30 Mar 2019
Source: Richi Mboro

During the training sessions, YTP has a daily short session for prayer and worship. According to a field staff member (G2/1), a Muslim participant who attended the training programme had no problem that there was a daily session for prayer and worship in the training programme.

\footnotetext{
${ }^{10}$ Some of the trainers are YTP's field staff. However, YTP also works with a number of lecturers from the Faculty of Agriculture of local universities. Additionally, YTP works with individuals, who have the expertise in agriculture, and business that work in agriculture.
} 
Nevertheless, one of the trainers had an interesting experience with a Muslim participant, who misunderstood and was scared of being converted to Christianity while attending the training programme.

"I have got an interesting experience. One of the participants was a Muslim. At that time, I was explaining how to make baits, so farmers don't need to use a lot of pesticides. To make that bait, I use a syringe. He got very scared and panic. He thought that I was going to inject him with some drugs. It turned out, before he came to join the training programme, his friend tried to scare him by saying that he will be indoctrinated and converted to be a Christian. After seeing me holding the syringe, I can really feel that his body language changed drastically. So, I tried to explain it to him that I use the syringe to inject some liquid. When his friend from the same village explained it to him, he then understood. Later on, he came to me and apologise because he thought that he was going to be injected." (G2/3)

The trainer's experience reflects that the attitudes and behaviours of the local people towards the religious background of YTP may discourage people from different religions, particularly Islam, from taking part in the LST programme.

It appeared that important differences within the community were discounted, as YTP seemed to view the local communities as one homogenous and harmonious entity. This was reflected by the comments of a Head Office staff member, when she was explaining about the purpose of the socialisation of the LST programme.

"So, the socialisation was done so the people in the village can have the same inclination. If a person that we support can succeed and if we inform the public of this success story, for example through an exhibition of their crops, others who live in the same village can see and become interested to learn too." $(\mathrm{G} 1 / 1)$ 
Concerning the local contexts, a widely found problem that was expressed by most of my research participants is water scarcity. This was mainly due to the region's climate and geography. For local people, their ability to water their plants was significantly reduced during the dry season. This was exacerbated by the fact that the condition of infrastructure in rural areas of West Timor (road, water, irrigation, electricity, and communications) is quite poor.

Figure 14 - Embung

\begin{abstract}
"We need an embung to get more water, because water is scarce (Figure 14). ${ }^{11}$ If the village head plans to make an embung, I can slowly dig the soil." (G3/7)
\end{abstract}

However, the proximity to the

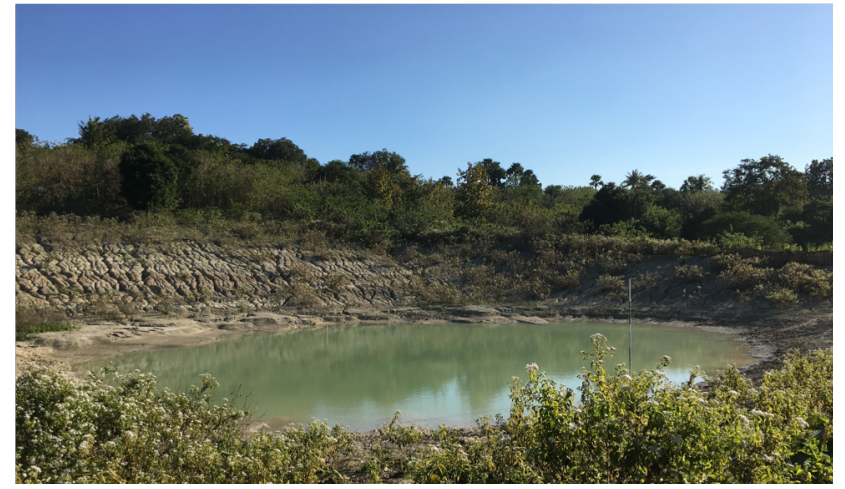

Location: TTS Regency Date: 28 Jun 2019

water supply was not the only obstacle. The plots of a number of my research participants were close to water springs, but they still had problems with watering their plants because they do not have the technology to help them reduce the time and energy used for doing this task (Figure 15 overleaf).

"For this agricultural work, it is quite hard, physically, for us to do it here because the location of our plot is a bit far from here and my plot is quite large too and it's only the two of us (my wife and I), who work here. Because we water our plants manually, using buckets of water. To get water, we had to dig a hole first (and make a small reservoir). This watering job has been done every morning and afternoon. We have to carry buckets of water. I don't have problems with getting water. However, watering the plants manually is the problem." (G3/7)

\footnotetext{
11 Embung is a catchment reservoir.
} 


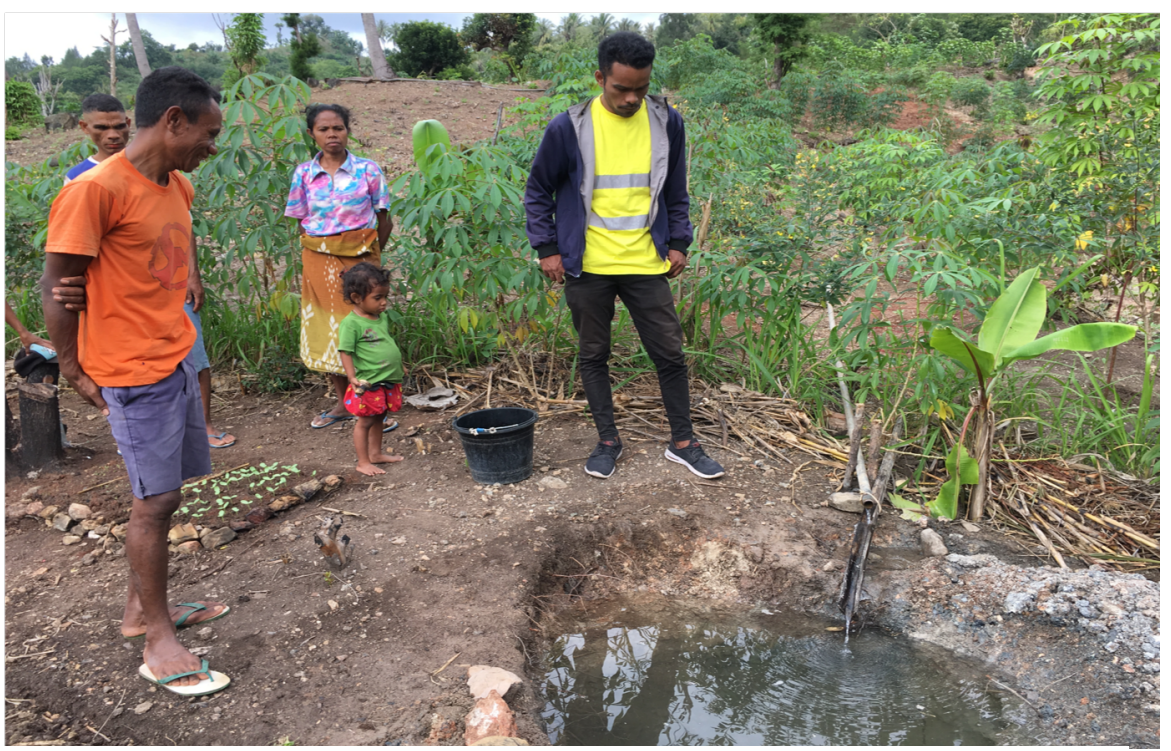

Location: TTS Regency

Source: Cynthia Ecclestone

Date: 1 Jul 2019

Although the physical contexts (and the lack of attention to important differences in the community) have increased the barriers and challenges for the local people to participate in the programme, it seemed that YTP attached little importance to these aspects.

\subsubsection{People's Attitudes and Behaviours}

The mindset of the local people can also create a barrier to participation. One example is the culture of receiving uang duduk. ${ }^{12}$ Some of the local people have the idea that receiving uang duduk is normal. They were reluctant to take part, after they found out that they would not be given any payment for their time. Another example is that a lot of the local people prefer to see the result of the work first, before they even try to do the work. With this mindset, it is quite difficult to convince them to join the training programme, let alone do the work.

\footnotetext{
12 Uang duduk is a financial incentive that is normally given for the local people in exchange for their attendance in training activities, meetings, workshops that are held by government agencies or NGOs.
} 
From my interviews and informal interactions with YTP staff members in Jakarta, Kupang, and TTS regency, it appeared that YTP staff commonly have a perception that the local people tend to have a passive attitude, and a lack of motivation to improve their situation. This perception is also reflected on YTP's recent video publication of its work in the regency (Yayasan Tangan Pengharapan, 2020, 6:42-10:36).

Another staff member in the Head Office (G1/1) also said that it was quite challenging to convince the training participants to join the programme, because the LST programme is not something that can produce tangible outcomes quickly. It requires their participation through hard work and perseverance.

However, people's attitudes and behaviours can also encourage greater participation. The positive attitudes and behaviours on the part of YTP staff and trainers, throughout the project cycle, were fundamental in ensuring and retaining the participation of the local people in the LST programme. All of the staff and trainers seemed to be highly motivated to help others. Moreover, the field staff and local trainer that I interviewed, all of whom are locals from NTT, were really passionate about helping the people in rural and remote areas of Timor Island. Additionally, they understood that their role is to help the local people to do things for themselves in order to have a better living condition. These positive attitudes were reflected in a comment by a trained participant, when I asked him whether his attendance in the training programme in Kupang had caused him any financial difficulties (since he could not work for a week while attending the training programme):

"It's not a problem, because it was for transferring the knowledge for us. The transportation, both ways from Oe'ekam village to Kupang, was covered by YTP. As for uang duduk, I remember what Pak Ricky said 'When you ask us to give you some fish for food, we cannot give the fish. But, we can give you the fishing rod, teach you how to catch the fish and some fishing techniques. [...] If we give you the fishing rod and teach you how to catch them, you can always eat fish later on, because you know how to catch them.' ... So, this advice sticks with me." (G3/6) 
Moreover, the field staff and local trainer respected the culture and existing knowledge of the local people. A trainer (G2/3) also said that she normally adjusts the content of her sessions to suit the different conditions and locations of the participants.

\begin{abstract}
"When the material I gave them was contradictive to what they've experienced, they even disagreed and said something about it. They said 'no, the result was not like that, it was more like this' [...] So, they have their local wisdom to solve their problem. [...] I was thinking, that can be right too. Theoretically, the quality of the crops will not be as good (as monocultures). However, for the sustainability of their economy, it will help them to survive if they use their method." (G2/3)
\end{abstract}

Additionally, the trainers were keen to encourage greater participation from the local people, particularly during the training programme.

\footnotetext{
"So, I always tried to create a friendly atmosphere during my session. When I asked them questions and they told us their stories, then the session became more alive and interesting." (G2/3)
}

However, the attitudes and behaviours of the local people can also affect positively on their participation. The local people who are open to new knowledge and agricultural practices, keen to learn, and understand the benefits of participating in the programme, were more likely to participate than those who expected financial rewards for attending the training programme. Additionally, the local people who are diligent, optimistic, and do not easily give up seemed to be more successful and thus, they have participated for a longer period of time.

"From 2017, we started our work, cleared the land, prepared the soil, making the raised bed ... sowing seeds and cultivated the land. Because we have been taught and trained, we sowed the seeds we got from the training programme and they turned out well. Actually, not $100 \%$ successful, because I had some 
challenges too. Along the way, we may succeed or fail ... but, for me, I won't regret it if I fail. I have to be able to get up again. [...] The workload (of the practical sessions) was not too heavy and we had our daily schedule. I think it was alright. So, I said, when we come back to our village and we manage our time just like what we had during the training programme, we can succeed." $(\mathrm{G} 3 / 6)$

\subsection{Perceptions of the Problems, Needs, Capacity, and Livelihood of the Local Community}

\subsubsection{Problems and Needs}

Those working in the head office of the YTP had different perceptions of programme participants' problems and needs than the participants themselves, and the local trainers. Based on their existing knowledge and information about the conditions of the local people in NTT, staff in the head office had identified what they saw as the main problem that the local people were facing. In YTP's view, the main problem of the local community is the high levels of poverty, which are mainly caused by a lack of opportunities, knowledge, and skills. The delivery of the LST programme, thus, reflects YTP's perception of the needs of the local community.

\footnotetext{
“These people just don't have the opportunities (to improve their lives). They lack of education [...] They already know how to plant, harvest, and water their plants but they don't know better ways of doing agriculture. Why don't we teach them (the better ways of working in agriculture)?" (G1/2)
}

The field staff and local trainers that I interviewed were in agreement with the YTP head office's perception of the problems and offered solution. However, they also had important insights about other problems that most local people face in the region. All three of them identified water scarcity as a major problem for the local people. The other significant problems include a lack of skills in time and money management, a lack of finance, a lack of initiatives to improve living conditions, and poor infrastructure. These problems indicate the needs of the local community. Therefore, during the 
implementation of the LST programme, practical solutions in relation to some of these problems were given. For example, training in making a ferro-cement water tank, water management and irrigation were included in the training programme; polybags were given as a way to conserve water in horticulture; and advice on combating pests was given during mentoring and assistance visits.

Similar to the perceptions of the field staff and local trainer, the majority of the local people that I interviewed said that their main problem is water. They either had difficulties in getting water in the dry season, or in watering their plants because the task requires a considerable amount of time and energy. A participant also mentioned a lack of training programme in their village. These problems shed light into what the local people see as their needs and priorities. During the interviews, they said that they need technology and infrastructure to help them in addressing this problem. Moreover, a participant said that animal farming would be the most suitable topic of the training programme, because it fits with the conditions in her village.

\footnotetext{
"I think the topic about farming is the most suitable one here ... because we need to adjust with the condition and potential in our village, right? So, if we say we want to be trained in some other topics, but the situation in our village does not support us to apply the knowledge and implement it, it's going to be useless. In this area, however, the difficulties are getting the water and probably the seeds." (G3/5)
}

It seems that the LST programme only answers some of the needs of the local community. When the local people went back to their village after attending the training programme, they still had significant challenges. The training to make a ferrocement water tank becomes less effective because they lack funds to build one in their village, or because the materials were not easily found. Although polybags are useful, they were more suitable for those who work in a small scale. Most importantly, as mentioned above, the topic of the training programme may not fit with the context of the village. 
A research participant who showed me a pile of triplex that has some patterns and measurements to make a ferro-cement water tank said "This one, I brought it from the LTC in Kupang. This is to make a water tank. When I got here, I got together with other members of my farming group. We talked about making a water tank here and I calculated the cost. We normally make things with cement and concrete, but for this (the triplex), we have difficulties. The material (triplex) is difficult to find here. We wanted to make one, but it's difficult ... because the triplex is expensive. So, it would be good if the trainers can teach us using the materials that can be easily found and which are inexpensive." (G3/9)

The differing perceptions of the local problems and needs were further illustrated when I did my analysis of the most common words mentioned during the interviews by various groups of people (Figure 16 overleaf). The figure shows the most commonly used words for each group of interviewees, and is a reasonable proxy for the concerns and priorities of each group. The word 'water' was the most common word mentioned by the local people. In comparison, 'water' was mentioned less frequently by the field staff and local trainers, while the staff members in the head office scarcely mentioned it. This suggests that there is a discrepancy between the perceptions of the three groups. 
Figure 16 - The Most Common Words Mentioned in Interviews

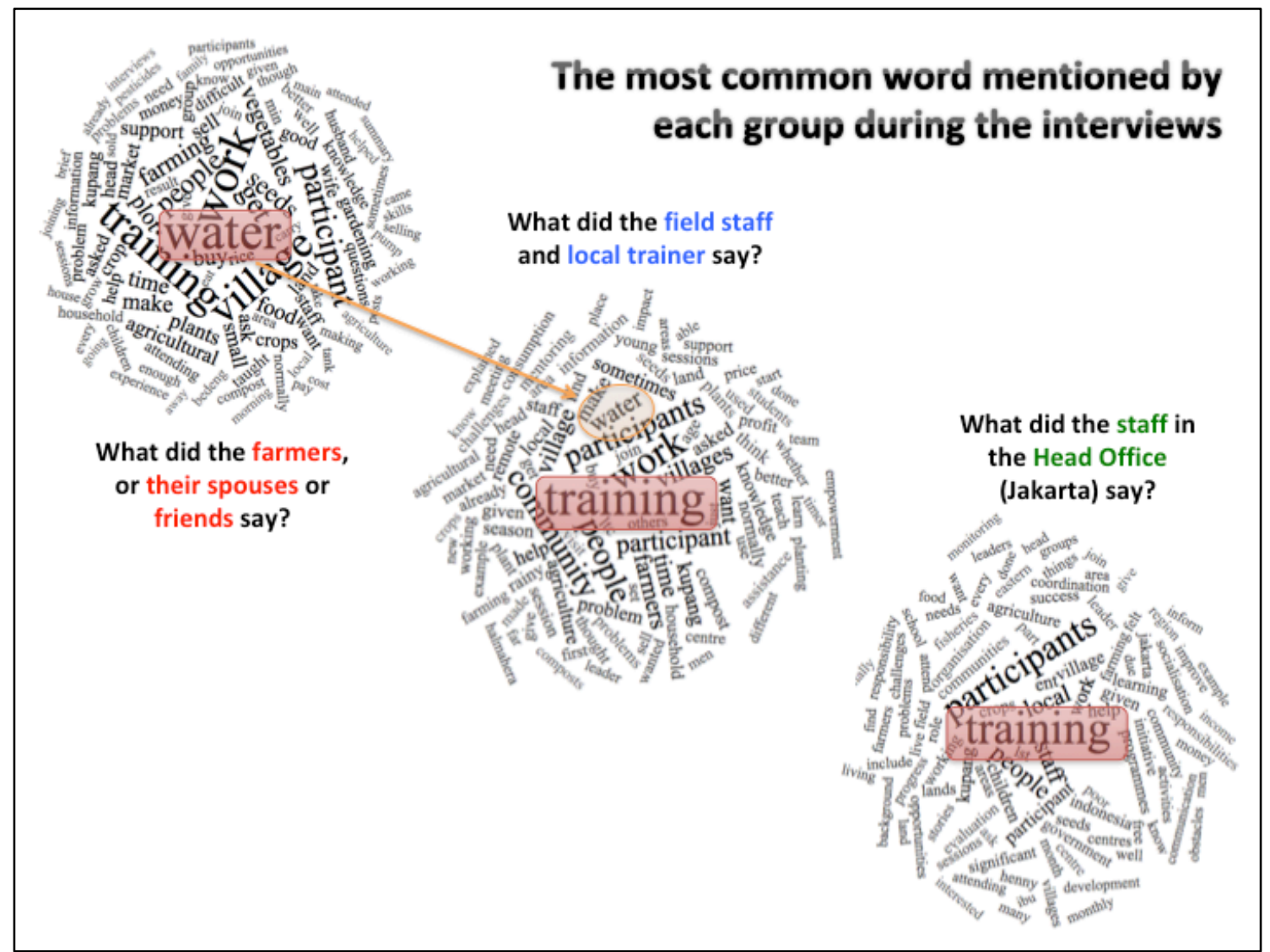

\subsubsection{Capacity and Livelihood}

My research found that the implementation of the LST programme has led to an increase in the capacity of the local community in agriculture. Although this was not demonstrated by all of the training participants that I interviewed, due to various contributing factors and other higher priorities, such as water scarcity and a sick spouse, most of them said that they gained new knowledge, skills, and techniques in agriculture.

\footnotetext{
"Before joining the programme, I already did some agricultural and farming work." However, he said that he learned new things from the training programme, such as making compost or combating pests. (G3/9)
} 
Moreover, some of them shared their knowledge and experience with others in their community, particularly with the people that they work with in their farming groups. This has led to a growing number of people in the village with increased capacity.

"I made the composts and pesticides together with others in my farming group. We rent a drum to make liquid compost and pesticides. After they are ready, I will call all members of my farming group, so we can share them." (G3/9)

Additionally, some participants, who worked only for their households' consumption, are now able to manage to grow and sell their food crops on a large scale.

"Now, we can eat our food crops and sell them too. There is a sufficient amount of food crops for our household's consumption as well as for selling them. On average, we can get Rp.50,000 per day, sometimes we can get up to Rp.100,000. That's not even on the market day. If we sell our crops on market day, we can get hundreds of thousands of rupiah. That's roughly the money that I get." (G3/6)

The livelihood of people in TTS regency, based on statistical data, is mostly from working in agriculture (see Chapter 3.6.) (BPS Kabupaten TTS, 2019). The top three agricultural products in the regency are sweet corn, cassava, and rice. Sweet corn and cassava are most likely the preferred options as these plants require a warm climate and less water (compared to other vegetable crops). Farmers who grow rice only work in the rice fields during the rainy season.

However, YTP field staff had their own reasons for encouraging the local community to focus on growing vegetables. The first reason is because horticultural vegetables require a shorter period of time, which means that farmers can get their income from the crops more frequently, instead of having to work only during the rainy season to grow rice. The second reason is that horticulture is less expensive because it requires less maintenance, compared to growing rice. 
Despite the variations in types of crops grown as the source of people's livelihoods in the TTS regency, and the different views of the participants and YTP field staff, most of my research participants recognised the improvement in their livelihood by participating in the LST programme. According to the wife of one of my research participants (G3/1), they were able to gain some profit, and used it to open a small kiosk next to their house that she managed (Figure 17). In general, most of the programme participants said that they were able to gain additional income.
Figure 17 -

The Wife of a Training Participant

Attending Their Kiosk

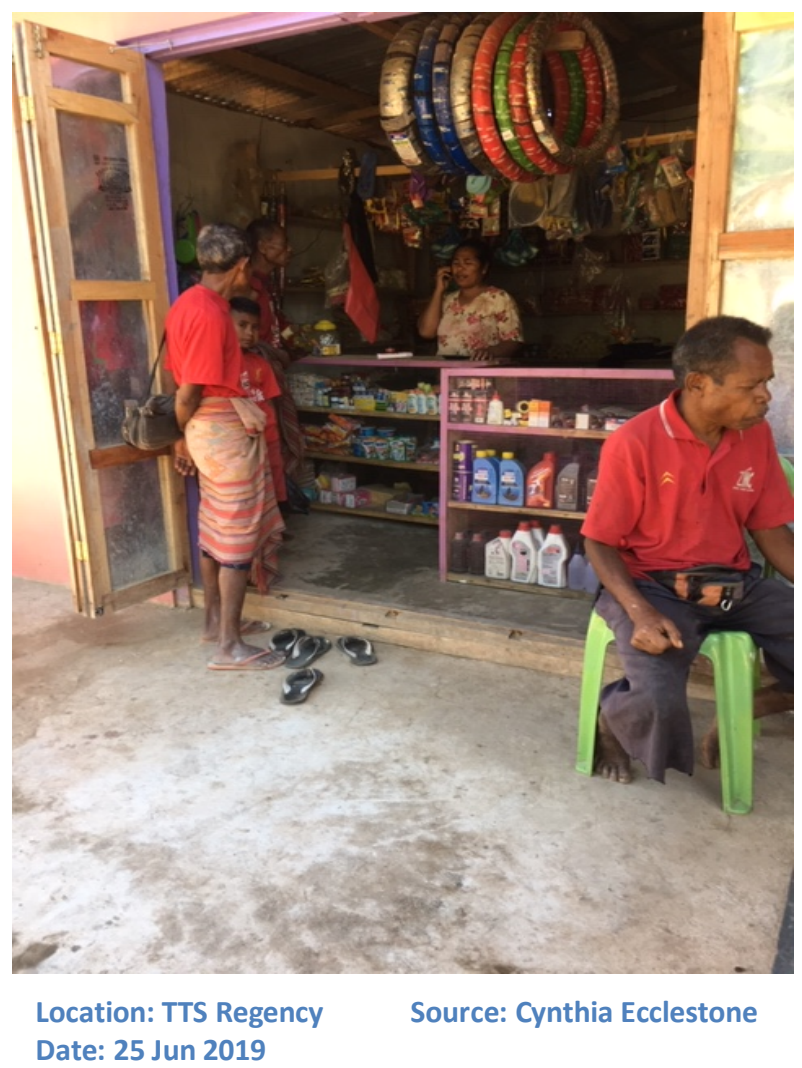

"I can still get a bit of money from selling the crop ... to buy, let say, other ingredients for cooking, like salt and seasoning." (G3/5)

"After attending the training programme in Kupang, I can contribute to paying the household's expenses since my wife's salary is used to pay the university's tuition for my oldest child." (G3/4)

"Before joining the training programme, my work only involved clearing the land and helped out to build something (handyman), but I felt that my income was not enough to support my family. After the training programme, I gained more money and my income is better now. I can now pay the school fees for my three children." (G3/10) 


\subsection{Feelings about Participating in the LST Programme}

Overall, YTP staff and the local trainer had positive feelings about their involvement because they can help those who are less fortunate. Although the involvement of staff members in the head office was limited during the implementation, they mostly had positive feelings about their contribution.

"I feel happy to find out that there is an improvement in the quality of life of the people that had attended the training programme." (G1/1)

"I am very glad because with this programme, I can meet people from various backgrounds and characters. [...] I am happy doing my job because by doing this, I can help others." (G2/1)

"For me, personally, I feel tired because the distance that I have to go through is quite far and the road is bad. So, I do feel tired. However, when I feel tired, I try to think of how my work and service can be useful for a lot of people. There must be a way for me. Also, God must have seen what we do, when we help others because that's what God wants us to do. When we do our work seriously, and we can see the good result, the feeling of being tired will disappear." (G2/2).

However, my interviews with another field staff member and a local trainer also revealed some negative feelings. At the early stage of the programme, a member of the field staff expressed his disappointment because of the minimal discussions and communication about his reallocation process before he was posted back in Timor Island to help the implementation of the LST programme. However, although he felt disappointed, sad, shocked, and stressed out about his reallocation process, he still accepted the decision at the end.

"Honestly, I was disappointed at first because it was too early to leave a project that I was about to start working on and developing, we cannot see the impact 
yet. [...] At the time, I was really sad and shocked I already felt comfortable because I have a great relationship with the communities. There were 3 villages, they have considered me as their family or son. I was stressed out, I wanted to contact them (head office) ... but ... (he became silent). [...] Whatever decisions that our leader made, she is still our leader ... and I have to follow her decision, even though there were a lot that I had to sacrifice. That is my principle when I joined YTP." (G2/1)

\begin{abstract}
A local trainer (G2/3) felt a slight discomfort because she was treated as special and different than the training participants during mealtimes. Additionally, a field staff member occasionally had some negative feelings due to disagreements and misunderstanding over certain aspects of the programme between the field staff and the staff in the Head Office. However, most of the time, these can be resolved with the help of YTP's leader.
\end{abstract}

"Sometimes we were given some targets. When we started the training programme, it has to be this way but we explained to them the reality in the field sometimes we make certain plans, but in reality those plans cannot be implemented for various reasons. Sometimes, when it happens, it creates some misunderstandings, we have different opinions. Normally, when it happens, Ibu Henny becomes the way out. We would inform her, explain the situation by phone to her and the staff at the Head Office, we explain our opinions and reasons." (G2/1)

When I asked what is an example of the targets, his answer was "The example of the target is 'try to have people to work this week. After the training, every trained participant has to start working.' Sometimes, other things happen, like the passing of their family members ... so they don't immediately start working. Normally, Ibu Henny would call us and we will explain the situation. At the end, the staff at the Head Office understand our view, although sometimes they would say 'community empowerment should have done this and this'. 
However, it is not a big problem ... just a misunderstanding. When we openly communicate, we can get the solution and mutual understanding." (G2/1)

On the other side, a trained participant expressed his unhappiness about the heavy workload in making a ferrocement water tank at the training centre in Kupang. He also felt that making the water tank at the training centre was a waste of time, because even though he thought that the knowledge was useful, it took a long time to build one and it only benefited YTP.

"I do have a less enjoyable experience when I attended the training sessions.

We were asked to work, making a ferro-cement water tank but we were mostly old and were ordered to do so. It would be great if we were only asked to do a more simple one, to make it easier for us, who are old. When we were asked to make the tank, it was too physically hard and it was almost a full day and the weather was quite hot too. So, it can reduce our interests in attending the training sessions. So, please adjust the practical session so it is also suitable for those of us, who are old, so it is not too physically tiring. [...] By making the water tank there (in Kupang), it only benefitted YTP and we were disadvantaged as it wasted our time." (G3/4)

Additionally, a local farmer said that he felt embarrassed by receiving packages of seeds from YTP for free all this time.

"When they (YTP) gave us the seeds, we can see the prices. It made me feel embarrassed." When asked why he felt ashamed, he said "because we never paid for the seeds so far." (G3/3)

Nevertheless, most of the training participants felt positive about their participation in the programme. Almost all the training participants enjoyed the training programme and felt that it was good and useful. 
"In my opinion ... in my household, if I did not join the training programme, my family would find it difficult to earn money. We had some knowledge on agriculture, but we did not know how to manage the work. Now, we feel a bit better, my agricultural work runs properly ... even though we only do small steps at the moment, it's enough to support our household's needs and to pay for our children's school fee. Little by little, we can already see the good result out of it." (G3/7)

\subsection{Discussion}

The perspectives of various stakeholders involved in the LST programme can be summarised into a number of major findings. First, top-down and paternalistic approaches exist throughout the project cycle, even though there are signs of greater participation during the programme implementation. Second, there is a lack of attention to local differences and contexts. Third, people's attitudes and behaviour can both support or inhibit people's participation. Fourth, there are differing perceptions of the local needs and problems between the local communities and YTP. Fifth, most research participants view that the participation of the local people in the LST programme has led to an increase in the capacity of the local community in agriculture, and to an improvement in the livelihood of the trained participants. However, these achievements were not demonstrated by all of the trained participants that I interviewed. Sixth, the people involved in the programme generally have positive feelings about their participation. However, all the negative feelings that were expressed during the interviews are related to power and disempowerment.

In what follows, I will evaluate these findings in relation to the literature of participatory development.

\subsubsection{Top-down and Paternalistic Approaches}

Top-down and paternalistic approaches consistently occurred throughout the project cycle. The local people were not involved, from the beginning of the programme. The 
identified and proposed solution to their problems were initiated and decided by an outsider. In this case, the decision to implement the programme was solely made by YTP. Interestingly, these findings bear more resemblance to the mainstream development theories and practices, which largely rely on top-down approaches, focus on the economic aspects of development, and ignore the needs of poor and marginal people in rural areas (Friedmann \& Weaver, 1979, p. 107). Although YTP has targeted the low-income people in rural and remote areas in Timor island, contrary to Chambers' call for greater participation of low-income people in rural areas, YTP has failed to recognise and value their views and needs (Chambers, 1983). However, it can be misleading to suggest that the LST programme is not participatory by observing its practices only at the initial stage of the programme.

During the programme implementation, top-down and paternalistic approaches continued to occur. The local people may have greater participation at this stage, from voicing their opinions during the training programme to making decisions about their preferred work (in scale or types of plants). However, important decisions are often made by those who are more powerful, such as the village heads and the field staff. The village heads quite often make important decisions in choosing the people in their community to participate in the training. Moreover, the field staff are the ones who make the final decisions in terms of the farmers who need to be prioritised, which have made good progress, and which deserve to get additional support.

Similarly, top-down and paternalistic approaches are seen at the monitoring and evaluation stage. Although the training participants can monitor and evaluate their own work, solutions to the problems in the field were often provided by the field staff. Moreover, they cannot participate in monitoring and evaluating the LST programme or the staff involved. Additionally, the programme's target and monthly reports, which field staff have to meet and deliver, reflect a strong vertical control of the programme and upward accountability. The strong vertical control and emphasis on upward accountability bear resemblance to common practices of donor agencies in participatory development as Mosse (2003, p. 193) points out in his critique of participatory development: 
The need for close control over works schedules, fixed budget calendars, purchasing and expenditure norms, reporting formats, emphasized upward accountability, the proper use of funds, and the planning and delivery of highquality programmes against quantitative target.

Additionally, the persistence of the top-down and paternalistic approaches throughout the whole cycle of the programme manifests in the centralised governance of the programme. As Oakley (1991, p. 12) points out, centralised governance requires hierarchical administrative structures and such structures are not helpful for genuine participatory development.

The persistence of the top-down and paternalistic approaches in the practices of the LST programme is contradictory to Chambers' participatory approach that is famously known as 'putting the first last' (Chambers, 1997). The 'putting the first last' approach seeks greater participation of the poor and vulnerable people, which requires the disempowerment of the more powerful people. As Chambers (1997, p. 234) puts it, "those who are uppers and powerful step down, disempower themselves, and empower others". However, the lack of participation and decision-making power of the local people demonstrate YTP's failure to enable the local people to take control of the programme that is intended to help them.

The levels of people's participation in the LST programme reflects the type and quality of participation. The participation of the local people in the programme reflects what Thomas-Slayter and Sodikoff (2001, p. 151) call 'reactive participation'. During implementation, the local people are able to participate in different ways. However, the initiative and control of the programme still lie with the party that is external to the local communities. In comparison, the local people's participation in the LST programme may fall between the category of 'passive participation' and 'participation by consultation' in Pretty's typology of participation (Pretty, 1995, p. 1252). It may fall into the 'passive participation' category because the local people are encouraged to 
participate only after the programme has been designed and decided. Although a consultative process takes place, especially during the training sessions, the local people still do not have the power to make important decisions about the LST programme. Despite the differing terminology used to interpret the types of local people's participation in the LST programme, they all indicate lower quality forms of participation, as they are less likely to have long-lasting and meaningful outcomes for the local people (Pretty, 1995; Rahnema, 2011).

\subsubsection{A Lack of Attention to Local Differences and Contexts}

The experiences of a number of people that participated in the LST programme suggest that local differences and contexts have been downplayed. The ignorance of the diversity within the local community appears to be, partly, due to the simplification of the concept of 'local community'. Consequently, the local community is treated by YTP as homogenous. Individuals within the community are considered as if they all desire and need the same thing for their development, which is a training programme, particularly in horticulture, chicken farming, and fisheries. The tendency to treat the local community as homogenous can be observed from the comments made by staff members in the head office.

\footnotetext{
"So, the socialisation (of the programme) was done so the people in the village can have the same inclination." (G1/1)

\begin{abstract}
“These people just don't have the opportunities (to improve their lives). They lack of education [...] They already know how to plant, harvest, and water their plants but they don't know better ways of doing agriculture. Why don't we teach them (the better ways of working in agriculture)?" (G1/2)
\end{abstract}

In this way, YTP has fallen into the trap of 'community averages' (Guijt, 1994; Guijt \& Shah, 1993, as cited in Guijt \& Shah, 1998a, p. 8). The simplification of the notion of 'local community' corresponds to the criticism by Mohan and Stokke (2000) who argue 
that participatory approaches tend to be reductionist in their conception of community.

The tendency to underplay important differences within the local community have led to a situation whereby certain segments of the community were less likely to participate in the programme. This was particularly evident in the under-representation of young and non-Christian participants.

Moreover, YTP's assumption that the local community in rural and remote areas of Timor is homogenous has led to the situation whereby gender differences are undervalued in this programme. As Shah and Guijt (1998a, p. 8) state "Any gender differences that might appear in fieldwork usually disappear into the melting pot of an 'average community plan'”.

The practical implication of overlooking (in practice, ignoring) differences in gender is that women, especially those who are married and have small children, are less likely to take part in this programme. In a patriarchal society, the ingrained attitudes and biases of the field staff against women's capabilities and roles in agriculture also seem to add to the list of major socio-cultural obstacles for women's participation in development (Cornwall, 2003; Oakley, 1991). Consequently, the disregarding of gender differences perpetuates biases toward and marginalisation of women. This finding supports the criticisms of participatory development for reproducing the existing dominant power structures at the local level (Cornwall, 2003; Hildyard et al., 2001; Mosse, 1995; Shah \& Guijt, 1998b).

Moreover, the physical contexts (which include the infrastructure, geographic and natural factors of the local community) are a major obstacle to people's participation in this programme, and they are not given significant consideration by YTP. Subsequently, those who live in areas where water is very difficult to get (as they do not live close to springs or embung), have to adjust and work on a small scale or grow other nonhorticultural plants that are more suitable to the climate and the availability of water in their area. However, this means that they are less likely to get the most out of the 
assistance that YTP provided. This finding supports the argument that Cohen and Uphoff (1980) put forward, that there is also a need to examine the context of participation, as it can considerably impact on the practices of participatory development in rural areas.

As issues related to local diversity and contexts are not dealt with adequately in this programme, some sections of the local community that include young men, who may desire different kinds of development assistance, and others who prefer different types of training, may not have their views heard, or are unable to take part in the development process that is intended to assist the local community in the first place.

\subsubsection{Attitudes and Behaviours that Support and Inhibit People's Participation}

The attitudes and behaviours of the local people and the staff or trainers of YTP can both reinforce or impede people's participation in the programme. Positive attitudes and behaviours can support and sustain people's participation. Burkey (1993, p. xii) contends that "self-reliant participatory development is the only foundation of true development". The attitudes and behaviours of the field staff and local trainers that foster self-reliance and encourage greater participation of the local people are found to be useful and necessary to create a supportive environment for the local people to participate. However, these positive attitudes require actions from both sides, as Burkey $(1993$, p. 50) points out that "self-reliance comes from within". Therefore, positive attitudes and behaviours on the part of the local people, such as openness to change, keenness to learn, and determination to succeed, are all key for their participation in the programme. Intrinsic motivation will always outperform extrinsic motivation.

On the other hand, people's attitudes and behaviours can also pose significant barriers to participation. As pointed out earlier, the entrenched attitudes and biases on the part of YTP against women's capabilities and roles have significantly limited women's participation. This finding further supports Chambers' perspective on the common biases that hinder outsiders' contact with rural poverty and development, which 
include male bias (Chambers, 1983, pp. 13-23). However, the local people's attitudes and behaviours toward financial incentives, living conditions, the nature of agricultural work, can also constrain their participation. What I find more interesting, although not surprising, is that their attitude toward YTP's background in relation to religion, particularly those who are non-Christian/Catholic, seems to play a major part in their decision to participate in the programme. These findings add to the existing evidence showing that the socio-cultural aspects of a community can present substantial challenges to participatory development (Oakley, 1991). Moreover, these findings further confirm the importance of examining the contexts of participation, as Cohen and Uphoff (1980) suggest.

\subsubsection{Different Perceptions of the Local Problems and Needs}

As identified earlier, there are differing perceptions of the local problems and needs between the local communities and YTP, particularly those who work in the head office. While staff members in the head office identify poverty as the main problem of the local community, due to the lack of education, knowledge and skills; most of the local people identify water as their main problem. The discrepancy between the perceptions of the three groups (Figure 16) also suggests that the local people know what they need in relation to addressing their problem, or are perfectly capable of expressing their preference for the types of assistance that are more suitable for them individually, or for the people in their village. This finding is in accordance with the statement made by Fuglesang (1982, as cited in Burkey, 1993, p. 52) that "No one should decide in advance what the village community needs to know. Ask people, very often they know what they need to know". However, given that YTP mainly uses the top-down approach from the beginning of the programme, this finding is not surprising.

The discrepancy in the perceptions of the local problems and needs indicates that genuine levels of participation is missing from the LST programme. The discrepancy also suggests that the participation of the local people in this programme serves 
instrumental purposes, as their participation is used as a means to achieve the objective of a programme that has been defined for them (White, 1996).

The absence of people's participation in the early stages of the programme can impact on the success of the programme itself. This is evident from a member of the field staff pointing out that the programme, initially, failed to attract the local people to participate in the programme. However, a study by Development Alternatives, Inc. that evaluates the success of over 50 rural development projects, found that local participation in decision-making during implementation was much more important for the success of development projects or programmes than their participation in the initial design (Cohen \& Uphoff, 1977 as cited in Burkey, 1993, p. 56). The study measured success by increases in farmer income and agricultural knowledge, ability to solve their own problems, and the likelihood of project benefits becoming selfsustaining.

However, there are various plausible explanations for the different perceptions of the local problems and needs. It is possible that the staff members of YTP, who have higher educational backgrounds, believe that they are more knowledgeable than the local people and thus, can provide solutions to what they perceive as the local problems. However, conditions and problems in various places can be quite complex, diverse, dynamic, and unpredictable (Chambers, 2007). Due to the complexity and diversity of problems and conditions, a problem that is faced by a local community can be contributed by several factors (Burkey, 1993). Yet, there is a tendency on the part of development practitioners and academics to focus on one or a few explanations and actions, and ignore others (Burkey, 1993; Chambers, 1983). The tendency towards partiality, on the part of YTP, may result in the failures to see the linkages of rural poverty in Timor Island. Additionally, the knowledge of the staff members of YTP about the conditions and problems in rural Timor has mostly "come laterally or from above, instead of from below" (Chambers, 1997, p. 31). Consequently, there is a misfit of the perceptions of the local problems and needs, which can lead to a situation in which the provided solutions are not actually helpful for the local people. In addition, the local 
people may place a higher priority on other issues that affect the quality of their life, such as water, than their economic development.

Another plausible explanation for the discrepancy in the perceptions of the local problems and needs is related to YTP's limited resources. As expressed by staff members in the head office (G1/1 and G1/2), the limited funding is a major difficulty for the organisation to implement its programmes, including the LST programme. Consequently, YTP may not have the time and flexibility to support and conduct the activities that are intended to encourage greater participation of the local community. Clearly, time and financial constraints can be major challenges in participatory development (Oakley, 1991). As a result of the financial and time constraints, YTP staff may have to rely on their knowledge about the local community. However, there is not much indication of YTP being aware of the limitations of its approach.

\subsubsection{Increase in the Capacity and Improvement of the Livelihood of the Local Community}

The perceptions of increased capacity in agriculture and improved livelihood suggest that aspects of empowerment occur to some extent. These aspects of empowerment particularly relate to the personal development of the targeted beneficiaries, which include self-confidence and the feeling of having control over aspects of their lives (Marsden, 1994, pp. 90-91; Rowlands, 1995). An increase in the confidence of the local people is reflected in the sense of being able to help their family and community (Marsden, 1994, pp. 90-91). A number of participants felt that they are better able to meet the needs of their family, such as through being able to pay for their children's school fees and to provide vegetables for household's consumption. Some participants felt that they are able to help their community, by sharing their knowledge, skills, and experience with other farmers in their village. Moreover, from the profit gained, one of these farmers is able to generate a new source of income by opening a small kiosk that is run by his wife. 
However, not all trained participants are able to gain the intended benefits from their participation. Although all of my research participants admitted that their capacity in agriculture has increased, a few of them are unable to achieve meaningful improvements in their livelihood due to various contributing factors, such water scarcity or a sick spouse. Again, these findings support the need for taking into account the various contexts of participation in understanding participation in rural development (Cohen \& Uphoff, 1977).

\subsubsection{Positive and Negative Feelings of People's Participation in the LST Programme} Most of my research participants have positive feelings about their contribution to the programme. On the part of YTP staff and trainers, the feelings of being able to help low-income people are also a reflection of them being empowered as they can exercise their agency to make a difference (Gaventa \& Barrett, 2010). Moreover, through the transfer of knowledge and skills to local people, they become agents of change who initiated a process of change that seeks to reduce inequality (Burkey, 1993). Their participation also strengthened their sense of dignity and self-worth. In this way, this finding provides an insight into the relationship between empowerment and participatory development, as the empowerment outcomes are not only felt by those who are powerless, but also by the more powerful ones as they take part in the development process.

On the part of the local people, their positive feelings were influenced by the positive outcomes from participating in the programme. For most of them, their participation in the LST programme has contributed to positive results and beneficial outcomes in their lives. With increased knowledge and skills in agriculture, their capacity also increases. Subsequently, they have more confidence to do agricultural work, either on a small or big scale, and have greater control over things that they previously were not able to manage, such as meeting the needs of their family in food consumption and or paying for their household's expenses. This finding is interesting because the local people that I interviewed appeared to have positive feelings, despite the fact that they were not 'invited' to participate at the planning and designing stages (Gaventa, 2006). This 
finding is also in line with the study by Development Alternatives, Inc., which found the participation of the local people in the initial design is less critical for the success of development projects than their participation in decision-making during the implementation (Cohen \& Uphoff, 1977 as cited in Burkey, 1993, p. 56).

In contrast, all the negative feelings that were expressed during the interviews are linked to power and disempowerment. The trainer who had a negative feeling because of the special treatment that she received during mealtime is a result of her awareness of power differences between her and the training participants. As she was aware of the power imbalances that positioned her as superior than the training participants, due to her educational and professional backgrounds, she understands that the privilege she received in the training programme can reinforce social hierarchy, especially between her and the training participants (Gaventa \& Barrett, 2010).

Additionally, the negative feelings regarding the disagreements about the targets and achievements of the programme between a member of the field staff and staff at the head office can also be linked to power differences between them. The field staff have the responsibility to undertake the programme, whilst the staff in the head office have the responsibility to monitor and evaluate the progress that the field staff make in implementing the programme. Moreover, the negative feelings that were expressed by a field staff member reveal a sense of disempowerment, due to a reduced sense of agency (Gaventa \& Barrett, 2010).

Similarly, a trained participant had a negative feeling that can be linked to power differences between young and old people. Although his main complaint is about the heavy workload in making a ferro-cement water tank during the training programme, he made a remark about age differences between him and the field staff or trainer, who are relatively much younger than him.

"I do have a less enjoyable experience when I attended the training sessions. We were asked to work, making a ferro-cement water tank, but we were mostly old and were ordered to do so." (G3/4) 
Within Indonesian society, older people are culturally viewed as superior to younger people. As such, older people are often very hesitant to follow the advice and instructions provided by those who are much younger than them. However, in the training programme, he did not have the power to refuse the instructions given by the younger field staff or trainers, which has led him to feel disrespected and powerless. The feeling of powerlessness indicates a sense of disempowerment (Gaventa \& Barrett, 2010; VeneKlasen \& Miller, 2002).

VeneKlasen and Miller (2002, p. 44) point out that one of the common responses to situations that make people feel powerless is shame. The feeling of embarrassment was also expressed by one of my research participants.

"When they gave us the seeds, we can see the prices. It made me feel ashamed." (G3/3)

It is possible that the field staff feel that they need to support him by giving packages of seeds for free. While this may be true, it did not appear that the staff had considered whether it would lead to the feelings of humiliation, rather than empowerment on the part of participants (Gaventa \& Barrett, 2010).

\subsection{Summary}

This chapter provides an exploration of the experiences, perceptions, and feelings of various stakeholders involved, particularly the intended beneficiaries, in participatory approaches in the LST programme. The results of the study can be summarised into six major findings. First, top-down and paternalistic approaches exist throughout the project cycle, even though there are signs of greater participation during the programme implementation. Second, there is a lack of attention to local differences and contexts. Third, people's attitudes and behaviour can both support or inhibit people's participation. Fourth, there are differing perceptions of the local needs and problems between the local communities and YTP. Fifth, most research participants view that the participation of the local people in the LST programme has led to an 
increase in the capacity of the local community in agriculture, and to an improvement in the livelihood of the trained participants. However, these achievements were not demonstrated by all of the trained participants that I interviewed. Sixth, the people involved in the programme generally have positive feelings about their participation. However, all the negative feelings that were expressed during the interviews are related to power and disempowerment. 


\section{CHAPTER 6 THE DYNAMICS AND COMPLEXITY OF POWER}

\subsection{Introduction}

Throughout the programme cycle of the LST programme, the two main forms of power (negative and positive forms) have been exercised by the various groups and individuals involved. In what follows, I use the 'faces of power' framework to explain the ways in which negative forms of power were exercised in the programme. Then I use the 'expressions of power' framework to outline how power over was used, and to highlight how positive forms of power were exercised in this programme. Subsequently, I explain the power dynamics to underscore the multidimensional and changeable nature of power. Additionally, I evaluate the major findings of the power analysis of the programme and relate them to the literature on participatory development and power. Finally, I conclude with a summary of the major findings about the exercise of power in this programme.

\subsection{The Faces of Power}

\subsubsection{Visible Power}

Visible power was exercised in the LST programme particularly through the use of the organisational structure, authority, and formal rules. At the early stage of the programme, both the hierarchical structure of the organisation and the authority of the head of the YTP have significantly influenced the decision-making process in deciding the problems, priorities, and needs of the local communities in NTT. The head of the YTP, who also manages and supervises the organisation's programmes, had a key role in making the decision for the organisation to implement the LST programme in NTT (Chart 1 on page 36 for The Organisational Structure of the YTP). Although YTP came with good intentions to help the local communities, the programme was already designed for them, without their first being consulted. The voices and concerns of the local communities, who were the main beneficiaries of the programme, seemed to be ignored. Moreover, the head of the YTP also played a major role in the operational 
decision of the programme at the beginning of the implementation. Operational decisions, such as when the programme was going to be implemented, what should be done, and who were needed to ensure that the programme could be launched on time and as planned, were mostly made by the head of the YTP. Such operational decisions also led to the situation whereby the concerns of YTP's field staff, who were assigned to other programmes in a different part of Indonesia, were not taken into account.

During implementation, the formal rules turned out to be a visible power that has the potential to discriminate against certain groups of people in the local communities. As discussed earlier, an age limit (between $25-48$ years) was set by YTP as one of the requirements for local people to join the training programme. If this requirement was followed strictly by the field staff, it would have excluded local people who are older (than 48 years) or younger (than 25 years). Additionally, the gender specific rule that did not let female participants bring their small children to the training centre is an example of visible power that clearly discriminates against women who have small children.

At the monitoring and evaluation stage, hierarchical structures and authority were also used by different groups and individuals to exercise their power. The field staff used their authority to make decisions about the progress of the farmers that they assisted, and which farmers deserved to get additional support from YTP. Feedback from the local communities about the programme, however, was not properly recorded to assist with evaluation. With this authority, the field staff were able to make decisions to prioritise their assistance for the trained farmers, who focussed on horticulture and work on a larger scale. However, by doing this, they deprive the other groups of farmers, who only opt for a smaller scale of agricultural work, or non-horticultural types of plants, from getting the most out of their participation in the programme. Similarly, based on the hierarchical structure, the head of the YTP and staff members at the head office used their authority to assess and evaluate the programme's achievement. A staff member at the head office can decide to withhold the salary of the field staff if they do not send their monthly report on time, or if the report is not up to the standards set by the staff at the head office. An interview with a member of the 
field staff (G2/1) revealed that, sometimes, there were disagreements between the field staff and the staff at the head office regarding the programme's target and achievement. However, these internal disagreements were often resolved after the head of the YTP intervened and provided solutions.

The above explanation clearly shows that the use of visible power, by the more powerful groups in the LST programme, have resulted in a situation in which the local people, as the powerless group in the programme, cannot take control of their development process and that their voice does not have significant weight in the programme.

\subsubsection{Hidden Power}

A form of hidden power that excluded women from participating in the programme was also at play in the LST programme. Despite the fact that the written criteria to join the training programme allowed women to participate, the unwritten practices in recruiting potential participants revealed that male participants were specifically requested by the field staff.

In an interview, a male field staff member said that:

"Actually, at the beginning, we want to invite farmers. We normally ask for male participants and mostly the ones that are interested to join are men. However, we don't set it as a standard." (G2/1)

The preference for male participants was expressed to the village heads during the programme socialisation, when the field staff asked for the support from the village heads to help them with recruiting training participants from their villages. This finding suggests that women have been largely excluded from participating in this programme. Although data regarding the number of female participants has never been included in YTP's reports and monthly publications, the proposition is supported by the fact that interviews with a number of my research participants confirmed only a limited number 
of women have participated in the programme. Women's interests were mainly excluded from the agenda of empowerment that was promised by YTP in the first place. The hidden power of male preference in this programme is also linked to the type of power that is difficult to observe, namely invisible power.

\subsubsection{Invisible Power}

The tendency to recruit male participants to the LST Figure 18 - The Wife of a Training Participant Helping to Put Compost on the Field

programme is largely caused by the invisible power of patriarchy. As pointed out earlier, the preference for men to participate in the programme has led to the perpetuation of inequality between men and women in participating in the

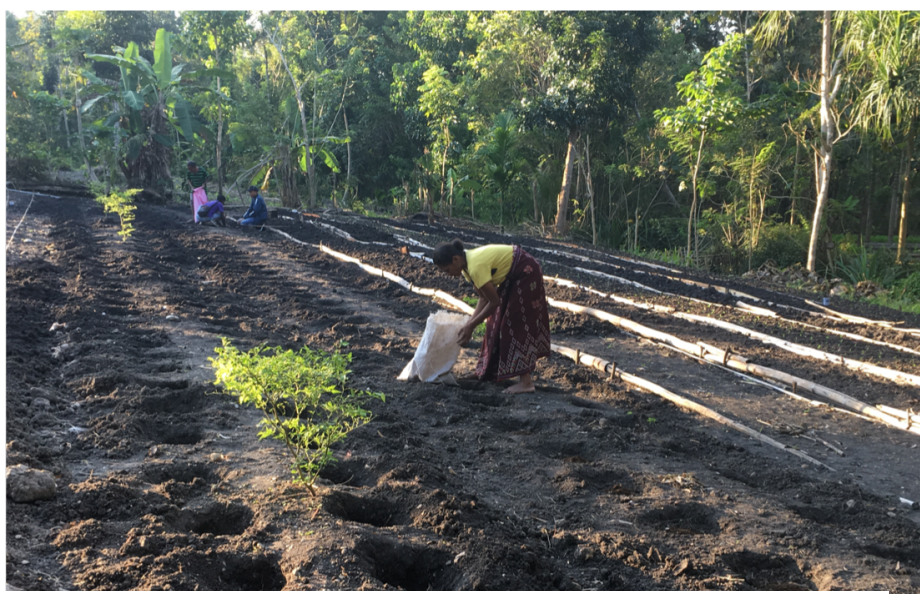

programme. Even though

Location: TTS Regency Date: 24 Jun 2019

women were largely excluded from the programme, this was in spite of the reality of the wives of the male participants helping and working with their husband on their land (Figure 18 and Figure 19 overleaf). The wives also cooked lunch for their husbands in the huts on their plots. Sometimes, the women also had to care for their small children at the same time (Figure 20 overleaf). 
Figure 19 - Women Helping Their Husbands on Their Land

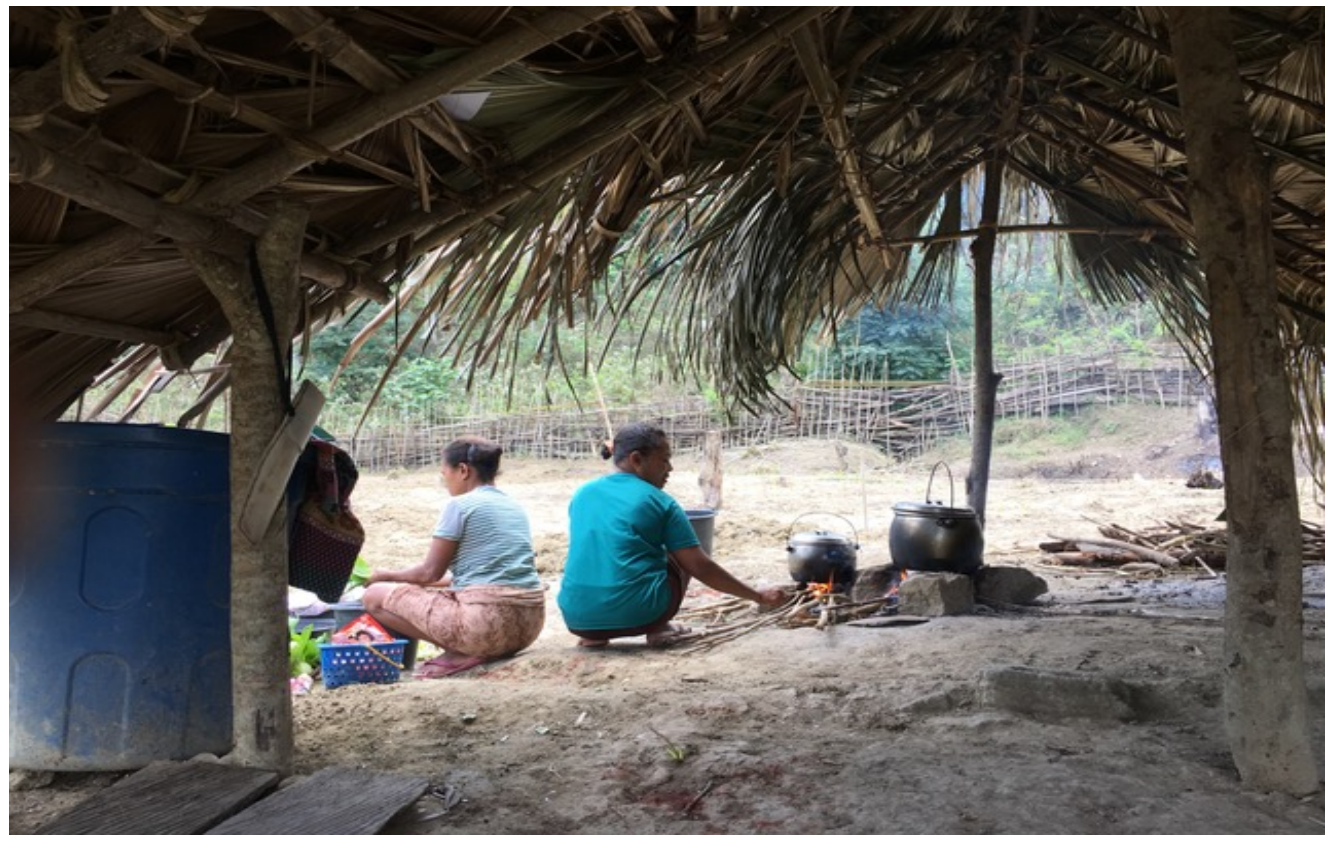

Location: TTS Regency

Source: Cynthia Ecclestone

Date: 29 Jun 2019

"I only work with my wife ... From the morning until late afternoon. When it's time to have lunch, we stop and have lunch. After lunch, we continue working in our plot. My wife cooks in our plot. She brings the cooking pot, plates, and cutlery to the hut in our plot." (G3/7)

Figure 20 - The Wife of a Training Participant Caring for Her Small Child

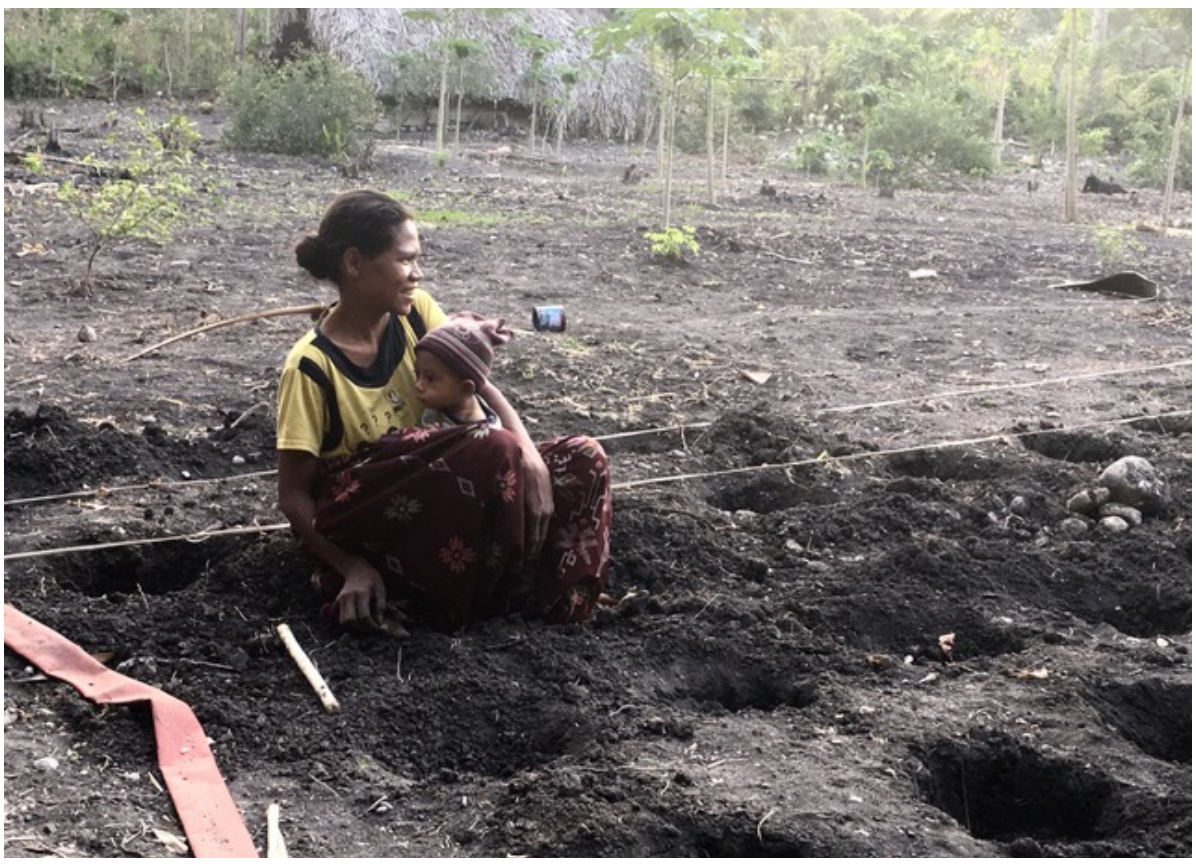


The perpetuation of gender inequality is most likely due to the fact that the Indonesian society, including the people of NTT, is a patriarchal society. Like other patriarchal societies, Indonesians have been taught about their gender specific roles. Consequently, they tend to accept their respective roles as natural. Agricultural work is largely perceived as the men's job, because it requires hard labour outside home, while women's role is to take care of the family and support their husbands. Moreover, men are normally perceived as the breadwinner. The internalisation of gender roles and the relationship between men and women can be clearly observed from most of my research participants, both male and female.

A male staff member in the head office said that:

"Most of the training participants are men, as far as I know ... because men are basically the head of family." (G1/2)

When a female trainer who was also younger than most of their training participants was asked whether she felt uncomfortable in this situation, she said that:

"At first, there were [some uncomfortable feelings]. However, I said to them at the beginning that I was there not to teach them, but to tell them about my experience, to share, and I position myself not to be higher or above them, because of their mind-set. I said for planting, they must be better than me. I may have planted once or twice. I 'plant' more on a piece of paper, so the result cannot be eaten. I also motivate them and tell them that they are here because they are important. I tried to make my position lower than them. Then, I said ... I may have read and learn about agriculture more than you, but if you open the internet and read, it's possible that you know better than me. I can also learn from you because you have the experience. So, let's share our knowledge and experience. I made jokes so they were not nervous." (G2/3)

The female trainer's answer suggests that she may have internalised the unequal relationships between men and women. Moreover, the traditional value of respect for 
elders, which is commonly found in many Asian cultures, has influenced how she thinks about her position in relation to the training participants, who are mostly older than her. Her answer demonstrates that, sometimes, the invisible power of patriarchy intersects with other forces of power, such as culture and tradition. It is also possible that culture and tradition can limit the roles of young people, as expressed by a member of the field staff below:

"If I go back to Rote island and do this programme there, one of the big challenges that I will have is the local culture and tradition. They like to stick with local traditions. If we teach them something that is different to the local traditions, even though it's useful for them, they will not follow our advice. Also, if we teach the people who are older than us, about the same age as our parents, they will always think that we are the children, so we are the ones who need to follow their advice." (G2/1)

The limitation of the roles of young people, as a negative impact of the strongly held traditional value of respect for elders (filial piety), was also reflected from a remark made by a trained participant (G3/5), who were unhappy to follow the instructions given by the relatively much younger field staff during a training session.

However, another member of the field staff that I interviewed, a single man in his early 30 's, said that he never had any difficulties with the age difference between him and the training participants, who are much older than him.

"I've never felt such difficulties, because I thought what we suggest or advise is the knowledge that we have learned and practiced before. So, I've never felt like 'Oh, I am still quite young and I need to talk to them who are older than me.' I only think that this advice would be good and valuable for them, I never thought about the age difference between the participants and me. The most important thing is that the advice I give out is useful for them." (G2/2) 
The above explanation demonstrates that social norms and cultural practices have affected the implementation of the LST programme. Both patriarchy and filial piety have shaped the minds and consciousness of various people to accept the existing unequal relations, in terms of gender and age differences, as normal. Whilst patriarchy affected the implementation of the programme to a great extent and led to the perpetuation of gender inequality, filial piety affected the implementation of the programme indistinctly. Filial piety may limit the roles and contribution of young people in the programme, others may have to adjust their position, while the rest may not necessarily feel its negative impact.

\subsection{Expressions of Power}

Similar to the faces of power, the type of power that is often associated with a negative form of power, power over, was also exercised in the LST programme.

\subsubsection{Power Over}

The exercise of power over was demonstrated by YTP and its staff in all stages of the programme and in various degrees. In particular, YTP and its staff had control over the resources needed to implement the LST programme, and the decision-making processes, compared to the local community. Having control over the resources automatically put YTP in the position of power. With such power, YTP made the decision to implement the programme that was formulated based on their knowledge and understanding of the local problems, needs, and priorities. Aside from making important operational decisions, YTP was also able to exercise their power over to organise, direct, and teach the local people during the programme's implementation. In the monitoring and evaluation stage, YTP exercised its power over to make important decisions about the programme, which could have significant impacts on the local people, without consulting first with the local people.

In contrast, a number of positive expressions of power that are useful for analysing aspects of empowerment of the LST programme can also be identified. 


\subsubsection{Power To}

Each of the three groups of my research participants had the power to make a difference through their participation in the LST programme. The head of YTP has the power to decide and financially assist the programme that can help the local communities in the rural and remote island of Timor to escape from poverty. Moreover, staff members at the head office believed that they contributed to the improvement in the lives of the local communities through carrying out their responsibilities in this programme.

The belief of being able to help the local communities was felt even more strongly by the field staff and local trainers, based on my observation of them during and after the interviews. Through the funding provided by YTP for the programme, the field staff and trainers have the ability to share their knowledge and skills with the local people through the training programme. Subsequently, the transfer of knowledge and skills increases the knowledge, skills, and capacity of the local communities in agriculture, farming, and fisheries. Moreover, through mentoring and assisting participants after they attended the training programme, the field staff have the power to ensure that the trained participants not only know what to do, but also have the ability to do their work. Although the field staff felt that the programme's achievements have not yet been maximised, they trust that they can make positive impacts for the people that they trained and for their local communities.

By participating in the programme, most of the trained participants believed that their knowledge, skills, and capacity, particularly in agriculture, have improved. With increased knowledge, skills, and capacity, a few of them were able to make new decisions based on their interests or situations, whether they want to work in small or big scale, or used the skills and chose to grow non-horticultural plants. Most of them could meet their household's needs in vegetable consumption. With an increase in their income, they also had the power to attend to their family's needs, such as paying for their children's school fees. Moreover, the trained farmers who work on a larger scale could now help fill the gap in the supply of vegetables in their communities and surrounding villages. 
"The people from the sub-district even come and buy our vegetables and we also sell our food crops in the local market. When we harvest our crops, we cannot leave our plot from early morning until late afternoon because a lot of locals go there to buy the crops. So we have to be there early and stay there in the afternoon too. Sometimes, when I am busy here (to take care of their small shop, next to their house), my husband goes to the plot alone. Sometimes, people from other villages also come and buy vegetables here (in our plot) because we are fortunate that we have plenty of water (as their plot is close to a spring." (G3/1)

\subsubsection{Power With}

Another positive form of power that can be identified is the power generated through a collective action. By working together with the field staff, local experts and lecturers, YTP has the ability to implement a programme that contributes to the improvement of the lives and economy of some local communities in Timor.

On the part of the local people, by working collaboratively with other people in their communities, or with their family members, they can achieve better results more efficiently (Figure 21). Figure 21 - Local Farmers Working Together in The wife (G3/1), whose husband is a farmer working on a larger scale, said that they now work with four other people in their village, including their village head and land owner. With the profits that they earned from horticulture, they are able to buy a

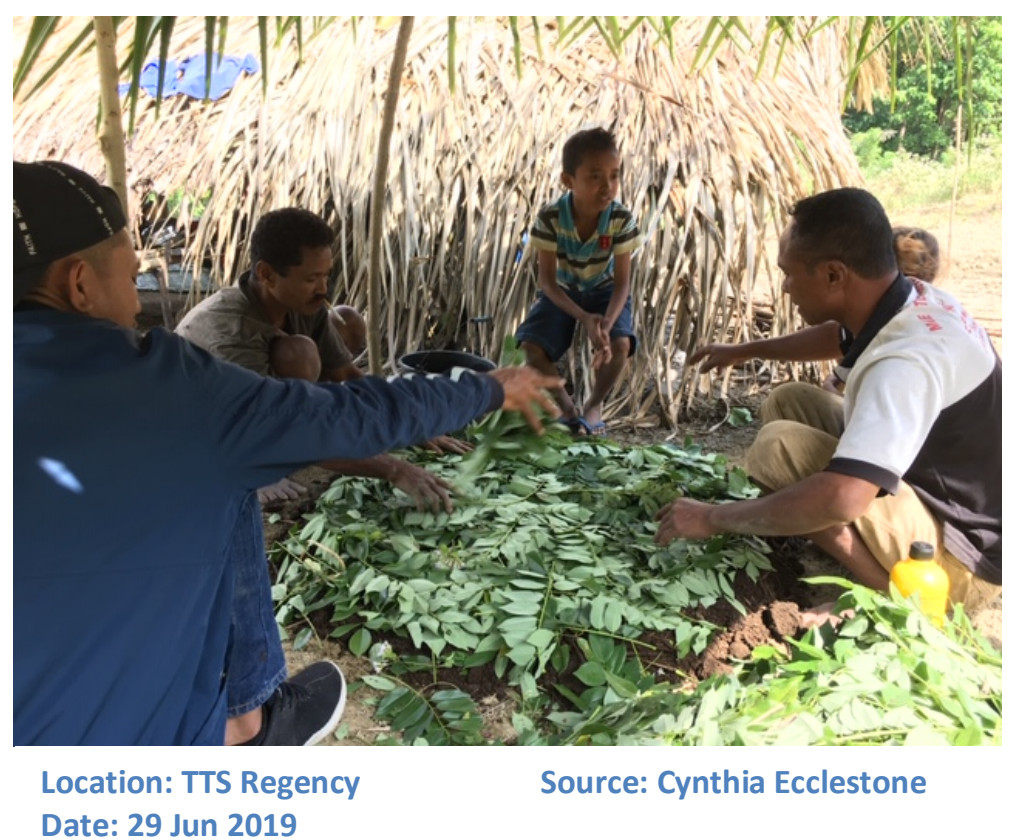


motorcycle and open a small kiosk. Another farmer that I interviewed (G3/6) said that he has worked with 10 other people in his village, aside from working with his wife and children, in managing 30 acres of land. At their recent harvest, they made a large profit from their crops and were planning to increase the size of their land to 1 hectare. Due to their successful crops, their village head also planned to give them more financial support to help them in cultivating their land (Kota, 2019).

\subsubsection{Power Within}

Another positive form of power within individuals can also be identified. All of the YTP staff and trainers that I interviewed expressed that they felt a sense of self-worth from being part of the LST programme as it has positive impacts for those who are in need. In an interview with a staff member (G1/2), I was informed that most of the field staff were keen to work longer than were expected from them, because they felt that they can be a blessing for other people. The field staff often felt proud of their work when they heard about the successes that the trained farmers can achieve, or when there were other positive outcomes for the wider communities.

On the other side, most of the trained participants felt more confident in practicing what they were taught after attending the training programme. When they encountered problems with their plants, some of them had the confidence to solve the problems by themselves. Others, especially the farmers who work on a larger scale, were confident that they can improve their income and be more successful, by applying the knowledge and skills that they gained from participating in the programme.

\subsection{Power Dynamics}

The framework of the 'faces of power' and the 'expressions of power' provide a better understanding of the power dynamics in the LST programme. The 'faces of power' framework particularly highlights that power is multidimensional and changes in different settings or circumstances. The multidimensional aspect and dynamics of power were illustrated by the experience of the young female trainer who participated in the LST programme. Outside of the training setting, her position in a strong 
patriarchal society, such as in NTT, is viewed as lower than men, particularly those who are older than her. In other words, she is less powerful in social hierarchies in a 'normal' setting, viewed through a socio-cultural lens. However, in the training setting, she becomes more powerful than the men and older people that she teaches, due to her knowledge and information about agriculture. Her backgrounds, which include educational, professional, and quite possibly economic backgrounds, have put her into a position of power. However, she tends to adjust her superior position in these areas in her training sessions, both to reduce the power imbalances and to fit within the 'normalised' culture of patriarchy.

Similarly, the 'expressions of power' framework demonstrates the dynamics of power in various contexts. Over the course of the LST programme, we see changes in the types of power, from negative to positive. As pointed out earlier, at the start YTP and its staff have more power over resources and decision making than the local people in the context of planning and designing the LST programme. However, in the following stages of the programme, positive expressions of power can also be identified. In the context of training, the transfer of knowledge has enabled the local people to have the power to improve the lives of their family and community. Moreover, the local people have the power to make decisions about their work. In the post-training context, the local people continue to have the power to take control of their work and make decisions about their agricultural work, based on their preference. In some cases, the ability to make important decisions about their work leads them to a decision to work with others in their community. By exercising the power with others in their community, these trained farmers are able to get better results more efficiently. With increased knowledge and skills, a number of trained participants also demonstrate the power within themselves, as reflected through greater self-confidence in themselves or in doing their work.

\subsection{Discussion}

Based on the two frameworks for analysing power in the LST programme, the results of the analysis can be summarised into three major findings. First, issues related to 
power, which are common in the practices of participatory development, can be identified in the LST programme. Second, the empowerment of local people occurs to some extent. However, their participation in the LST programme has not fully transformed them to be 'active participants'. Third, although power was exercised both through conflictual and consensual means, opportunities for changing the unequal power relations to benefit the powerless still exist when those who are relatively more powerful have a genuine interest in empowering the powerless and less powerful ones, and to have the willingness to 'hand over the stick'.

\subsubsection{Issues of Power in the LST Programme}

The issues related to visible, hidden, and invisible power in the LST programme are similar to some issues that are commonly found in the practices of participatory development. As explained, important decisions about the programme were made and dominated by YTP and its staff. In contrast, the local people had no control over the decision-making processes of the programme at any stage. In this way, the usage of visible power has resulted in the reproduction of power inequality between YTP and the local people. The same problem of power imbalances between donors, development organisations or practitioners, and their intended beneficiaries also happens in some practices of participatory development (Hildyard et al., 2001; Hussein, 1995; Kapoor, 2005; Mosse, 2001, 2003).

Meanwhile, the exercise of hidden power through prioritising male participants further confirms that important differences that can produce and bolster power inequalities within the local community, particularly differences in gender, were ignored in the LST programme. Consequently, it has contributed to the perpetuation of the existing maledominant culture within the local community. The downplay of local diversity, particularly on issues of gender, which resulted from the tendency to treat a local community as homogenous, also appears to be a common problem in participatory development that has received substantial criticism (Cornwall, 2003; Mosse, 1995; Shah \& Guijt, 1998a). This problem is in line with the criticism directed at participatory development, as some of participatory practices have led to the perpetuation of the 
existing dominant power structures at the local level (Cornwall, 2003; Hildyard et al., 2001). The hidden power of male preference in the LST programme parallels Lukes' second dimension of power, since the act of prioritising male participants was done by the field staff in a less transparent and open manner (Lukes, 2005).

Additionally, the 'faces of power' framework helps reveal the invisible power that is at play and has affected the LST programme. The social and cultural norms and practices within Indonesian society, regarding gender and age in social relations, have influenced the minds and consciousness of various people involved in the LST programme to accept the existing conditions and unequal relations as normal. As VeneKlasen and Miller (VeneKlasen \& Miller, 2002, p. 49) point out that

Significant problems and issues are not only kept from the decision-making table, but also from the minds and consciousness of the different players involved, even those directly affected by the problem. By influencing how individuals think about their place in the world, this level of power shapes people's beliefs, sense of self, and acceptance of their own superiority or inferiority.

The invisible power that operates in the context of the LST programme is in keeping with Lukes' third dimension of power, which refers to false consciousness as a result of social and cultural practices (Lukes, 2005).

The failure to deal with this type of power not only reinforces the existing dominant power structures and perpetuates inequality, but can also lead to exclusion and negative stereotypes that limit the participation of people from certain backgrounds (VeneKlasen \& Miller, 2002). As explained, women, particularly those with small children, have been largely excluded from participating in the LST programme. However, the workload of the wives of the male participants' may double within their family, because they not only have to care for their children and husband in the home, but also have to help their husband on their land. The double burden of women's work, 
thus, lends support to the feminist theorists, who call for the need to analyse power and address inequality in the familial or private spheres (VeneKlasen \& Miller, 2002, p. 51). In addition, the failure to deal with invisible power can prevent effective actions for change and reinforce hierarchical systems (Miller et al., 2006). As pointed out, due to a strong culture of filial piety within the local community, young people often experience subordination. Consequently, their roles and contribution become limited and less effective.

Furthermore, using the 'expression of power' framework, another negative form of power, that is power over can also be identified in the practices of the LST programme. This type of power was exercised by YTP and its staff, particularly in decision-making processes. By having the power to make important decisions about the programme, YTP and its staff has the power to control the local people (Dahl, 1961; Lukes, 2005). The minimal participation of the local people in decision-making processes, particularly in the initial stage of the programme, corresponds to what Gaventa (2006) calls the closed spaces of participation, where decision is made by the powerful actors with little involvement or consultation of the people that may be affected by those decisions.

\subsubsection{Empowerment of the Local People}

The positive expressions of power provide relevant insights into aspects of empowerment in participatory development. The power to dimension highlights the trained participants' ability to achieve financial empowerment. Although this is the main objective of the LST programme, as Muchtar, Overton, and Palomino-Schalscha (2019, p. 1054) point out, "Empowerment is not merely about economic empowerment because economic change is not sufficient to promote social transformation." Apart from financial empowerment, access to decision making and the personal development of the local people are also important aspects of empowerment (Rowlands, 1995). The power to dimension also highlights a sense of awareness of the trained participants' capability, not only to help themselves and their family, but also others in their community. More importantly, the power to dimension 
shows that the trained participants can make important decisions in relation to their agricultural work, based on their preference and situations.

Similarly, the power with dimension indicates greater awareness on the part of the trained participants of their situation. They understand their capacity and what their work involves, the benefits they can get by working collectively, and choose to do so. The act of choosing to work collectively with others in their community is in line with Freire's conscientisation, where the process of self-awareness leads them to take action to transform their situation (Freire, 2018).

In addition, the power within dimension shows the trained participants' potential and their individual abilities to make improvements both in their own lives and in those of others in their community. Having greater self-confidence also demonstrates a greater sense of agency (Gaventa \& Barrett, 2010). When combined, the three positive expressions of power can bring about change. As Gaventa (2019, p. 134) suggests, "Power within, power with, and power to, taken together, are necessary to challenge the power over in a transformative way."

However, the participation of the local people in the LST programme has not fully transformed them to be 'active participants' (Oakley, 1991). There may be aspects of empowerment, both financially and in their personal development, as have been described earlier. Nevertheless, they are still unable to gain control over some important aspects of the programme, such as in the decision-making process, the implementation of, and the monitoring and evaluation of the LST programme. Although the LST programme engages in transferring the power of knowledge and skills, this process has not transformed them to actively engage throughout the project cycle, let alone resulted in social transformation, where they can exercise their agency and re-negotiate their power within existing power relations (Oakley, 1991). It appears that YTP's staff have a lack of understanding of power, as well as its dynamics, potential, and implications. What seems to be clear, however, is that there was a lack of 'handing over the stick' (Chambers, 1997). The lack of 'handing over the stick', or the 
disempowerment of the more powerful group, as reflected through the top-down and paternalistic approaches in the LST programme, has more likely contributed to this situation (Chambers, 1997). Yet, it is probably premature to expect social transformation to happen as an outcome of the participation of the local people in the LST programme, since social transformation requires time and the LST programme was only started three years ago.

\subsubsection{Power Exercised through Conflictual and Consensual Mechanisms}

The exercise of power in the LST programme was done through conflictual and consensual mechanisms. The conflictual mechanism of power was demonstrated by YTP's domination of decision-making processes in the LST programme (Dahl, 1961). Consequently, it led to a condition in which existing power inequalities were sustained. Similarly, the conflictual mechanism of power was also reflected by the discriminative attitudes and behaviours toward women through the preference to choose men over women as the training participants, which was largely contributed by the ideological power that shapes values and beliefs of Indonesian society regarding gender roles and division of labour (Bachrach \& Baratz, 1962; Lukes, 2005). These practices reinforce social hierarchies between men and women and perpetuate power inequalities between genders.

However, power was not only exercised through conflicts in the LST programme. According to Parsons (1963), power does not always lead to conflicts since it may be generated through consent or legitimation from society. The consensual mechanism of power was reflected in the remarks made by the young female trainer, who seemed to be willing to adjust her social position when she delivered her training (Figure 22 overleaf). Although she had a more powerful position when teaching her training participants, she was willing to change her mindset and to adjust her position, either to be in an equal position with them or even to be in a less powerful position, in order to encourage greater participation of the local people. The attitudes and behaviours of 'power reversal' from the powerful ones are important for changing the unequal power relationship (Chambers, 1983, 1997). At the same time, the trained participants 
consensually gave her the power to lead them in the process of transferring the knowledge and skills in her training sessions, despite of the fact that she is a woman and younger than most them.

This analysis further illustrates the dynamics of power in the LST programme. It demonstrates the intersectionality and changing nature of power. As Miller, VeneKlasen, Reilly, and Clark (2006, p. 8) point out, one can "... experience privilege and subordination simultaneously. [...] In one setting, a person may be more powerful while in another setting, face discrimination." Moreover, the analysis confirms that conflictual and consensual mechanisms of power are not mutually exclusive and can occur in the same setting (Brennan \& Israel, 2013). More importantly, it shows that there is a potential to transform

Figure 22 An Outdoor Session Led by a Female Trainer

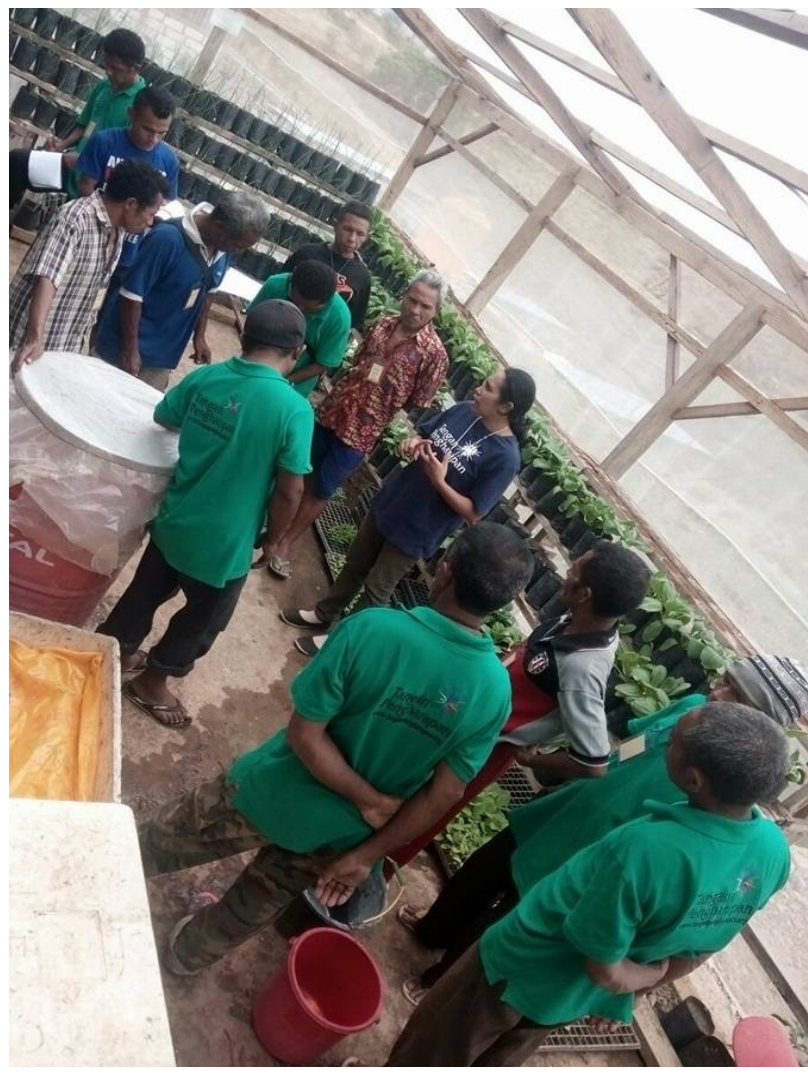

Location: Kupang Date: 31 Jul 2017

power to benefit those who are powerless, when the more powerful ones have a genuine interest in empowering the powerless (or less powerful ones) and have the required attitudes and behaviours to change the unequal power relations (Chambers, 1997).

\subsection{Summary}

This chapter has explored issues related to power in the LST programme, using the framework of 'faces of power' and 'expressions of power'. The two frameworks were used to show how power operates in society and how it affects a development 
programme, both negatively and positively. The analysis of the power dynamics in the LST programme can be summarised into three major findings. First, issues related to power, which are common in the practices of participatory development, can be identified in the LST programme. Second, local people were empowered to some extent. However, their participation in the LST programme has not fully transformed them to be 'active participants'. Third, although power was exercised both through conflictual and consensual means, opportunities for changing the unequal power relations to benefit the powerless still exist when there is a genuine interest in empowering the powerless and less powerful ones, and the willingness to 'hand over the stick' on the part of the powerful ones. 


\section{CHAPTER 7 \\ CONCLUSION}

\subsection{Introduction}

This chapter sets out a brief summary of the study, which includes information about the research objectives, questions, and methods. It also provides a summary of the key findings and the main thesis argument. It is then followed by a brief explanation of the significance of the study. Additionally, this chapter outlines the limitations of the study and provides a recommendation for further research. Finally, this chapter concludes with some lessons learnt and final reflections.

\subsection{Summary of the Study}

Although the participation of local, poor and marginalised people is important in the development process, their voices are often disregarded by those who have power. Against this backdrop, this study engages with two main themes: people's participation in a development programme, and the power asymmetry that can affect their participation. In addressing these issues, the study not only aims to draw insights for improvement in the practices of participatory development, but also to identify opportunities for transforming the negative forms of power to benefit those who are less powerful.

To help provide an in-depth understanding of the complexities and interconnectedness of the two issues, the Life Skills Training (LST) programme was chosen as a case study. This programme was designed and delivered by Yayasan Tangan Pengharapan (YTP), a local NGO in Indonesia, with the intention of empowering low-income people in rural and remote areas of Timor Island, East Nusa Tenggara, through the delivery of various training activities in agriculture. 
Three research questions were devised to help guide the study. The main question of the study is 'how are issues of power manifested in the Life Skills Training programme?' Then, two further questions were added to help answer the main question, they are:

1. What experiences, perceptions, and feelings of the participatory processes are held by the various stakeholders involved, particularly the targeted beneficiaries, in the Life Skills Training programme?

2. How does the application of a participatory process in the Life Skills Training programme relate to the needs, capacity, and livelihood of the local community?

The study used semi-structured interviews and observations (Chapter 4) in three different locations: Jakarta, Kupang, and Timor Tengah Selatan regency between June and July 2019. The interviews were conducted with 14 research participants, who were selected purposively from three different groups of people, who were involved in the programme, in order to recognise the diversity of perspectives. The three groups are members of the head office staff, members of the field staff or local trainers, and the local people, who participated in the programme or their spouse.

\subsection{Key Findings and Main Argument}

The study highlights several important points related to participation and power. In relation to participation, the experiences from various people involved in the programme show that top-down and paternalistic approaches were adopted in all stages of the programme, despite the use of the rhetoric of participation (Mosse, 2001, 2003). Starting from the programme initiative that came from a party outside of the community, the opportunities and availability of platforms for greater participation by the local people to make important decisions, or to monitor and evaluate the programme, ranged from lacking to almost non-existent.

Moreover, people's experiences from participating in the programme demonstrate that important differences within the local community and the physical contexts of the area 
where the local community lives, tended to be undervalued. This accords with much of the critical literature on participatory development (for example Cohen \& Uphoff, 1980; Kapoor, 2005; Mohan \& Stokke, 2000; Mosse, 2001; Shah \& Guijt, 1998a, 1998b). The tendency to overlook important differences in gender, age, and religion in the community was reflected in different ways. These ranged from the discounted impact of the physical workload for the older and female participants in some of the practical sessions of the training programme, to the over-representation of men and the underrepresentation of non-Christian participants in the programme.

In relation to the physical contexts of the region, the importance of climate, geography, and infrastructure of the region were also downplayed (Cohen \& Uphoff, 1980). The region is mountainous, has long periods of dry weather that often leads to drought, and a lack of infrastructure. All of these pose significant challenges for achieving success. However, the assistance provided in the programme still concentrated on training in agriculture and horticulture, which would require a continuous supply of water.

Another key finding from the experiences of the people involved in the programme is that people's attitudes and behaviours can both promote and hinder people's participation. Attitudes and behaviours that encourage self-reliance and stimulate greater participation of the local people are essential (Burkey, 1993). Likewise, intrinsic motivation on the part of the local people is fundamental for their participation in the programme (Burkey, 1993). By contrast, discriminative attitudes and biases can limit the participation of people from certain backgrounds (Chambers, 1983). In this study, these have resulted in a situation in which women have been largely excluded. On the part of the local people, attitudes and behaviours that expect financial rewards (as an exchange for their attendance in the training programme), and prejudice against YTP's background in terms of religion can significantly inhibit them from participating.

Concerning people's perceptions, the study highlights two important points. First, the study finds that the local people held a slightly different view of what they considered as the main problem of their community and what they need, than what YTP perceived 
as the local problems and needs. Most of the local people identified water as their main problem and that they need technology and infrastructure to help address this problem. However, YTP views poverty as the main problem of the local communities due to the lack of education, knowledge and skills. The discrepancy suggests that there is a lack of genuine levels of participation, and that the local people's participation was instrumental to achieve the pre-determined programme's objective (White, 1996).

Second, there is a general perception that the participation of local people in the programme contributed to an increased capacity of the local communities in agriculture and an improvement in the livelihoods of the trained participants. Aspects of empowerment that relate to personal development, such as increased selfconfidence, can be recognised from the trained participants (Marsden, 1994; Rowlands, 1995). They gained new knowledge, skills, and techniques in agriculture. Some of them shared their knowledge with others in their community, and others were able to increase the size of their land. They also had an increase in their income. However, these achievements were not demonstrated by all of them.

With regard to the feelings of participation in the programme, the people interviewed in the study, generally, had positive feelings. These positive feelings, on the part of those who were relatively more powerful in the programme, were contributed by a sense of agency, dignity, and self-worth (Gaventa \& Barrett, 2010). In comparison, although the local people were not invited to participate in the initial stage of designing the programme, they appeared to have positive feelings that were contributed by a greater sense of self-confidence and control over things that they were unable to do previously (Marsden, 1994). However, all the negative feelings that were expressed during the interviews can be linked to power and disempowerment.

In its analysis of power, the study finds that issues of power that are commonly found in the practices of participatory development were also at play in the LST programme. These issues were demonstrated through the reproduction of power inequality between YTP and the local people, particularly in the decision-making processes (Kapoor, 2005; Mosse, 2001, 2003). Moreover, important differences within the local 
community in gender, age, and religions, that can create and reinforce power inequalities were also downplayed (Kapoor, 2005; Mohan \& Stokke, 2000; Mosse, 2001; Shah \& Guijt, 1998a). For women, it resulted in the strengthening of the existing male-dominant culture, and the exclusion of a large number of women, not only from participating, but also from the agenda of empowerment (Rowlands, 1995). However, issues of power were also contributed by patriarchy and filial piety, two forms of power that are less visible and circulated through social norms and cultural practices within the local community and in Indonesia society (VeneKlasen \& Miller, 2002). Furthermore, the extent of the impact of patriarchy and filial piety on the LST programme are different. While the impact of patriarchy is clearly evident in the programme, the impact of filial piety is rather obscure.

Another key finding related to power is that aspects of empowerment of the local people, both in their economic and personal development, occur to some extent. However, the lack of decision-making power and active engagement in the programme hindered them from being 'active participants' and from progressing in their development process (Oakley, 1991).

The study also finds that although power was exercised through both conflictual and consensual means, the potential for changing power inequalities to benefit those who are powerless was present, when necessary conditions were met (Brennan \& Israel, 2013). These conditions require the powerful ones to have a genuine interest in empowering the powerless, and to have the willingness to 'hand over the stick' (Chambers, 1983, 1997).

Based on these key findings, I argue that issues related to inequalities of power in the Life Skills Training programme are manifested in the domination of YTP's leadership in the decision-making processes, and that these were also contributed to by patriarchy and filial piety, two socio-cultural norms within the local community and in Indonesian society in general. Additionally, unless these issues are addressed, people's participation in the programme is less likely lead to meaningful outcomes. 


\subsection{The Significance of the Study}

There have been numerous previous studies of participatory development. These have focussed on analysing its shortcomings and benefits, as well as looking for ways to improve it (Chambers \& Guijt, 1995; Cooke \& Kothari, 2001; Kapoor, 2002, 2005; Kindon et al., 2007; Parfitt, 2004). However, studies that explore and examine the experiences, perceptions, and feelings of the intended beneficiaries (as well as other stakeholders involved) about their participation in a development programme that has been delivered by an NGO from 'the South' are rare. Therefore, this thesis contributes to filling the gaps in the literature of participatory development (Chapter 2.5.) by drawing on a case study in Indonesia, and by offering the perspectives of the powerless or relatively less powerful people on their participation in the Life Skills Training Programme. By exploring the different perspectives of the stakeholders involved, the study shows that doing so will reveal important information required to deliver higher quality and more successful participatory development, with more meaningful impact.

This study helps reveal a number of important factors that can influence and sustain the participation of the local people in development programmes or projects in Indonesia. First, the socio-cultural aspects (which may include but are not limited to issues related to gender, age, and religion) and the physical contexts of the local community play a key role in ensuring and retaining the participation of the local people. Second, the identity and values of the aid agency can affect the decision of the local people to participate (or not) in the programme. Third, positive attitudes and behaviours, by development practitioners or professionals, that foster self-reliance and encourage greater participation, together with intrinsic motivation from the local people, are both fundamental. Additionally, approaches to participatory development that involve a careful attention to power differences and dynamics between different groups of people involved in the programme are necessary, not only to address the barriers to greater participation of the local people but also to transform power imbalances.

Much of the debate in the literature of participatory development regarding the causes of failure of participatory practices gravitates around the perpetuation of power 
inequality, either within the local communities, or between development practitioners (aid agencies) and their intended beneficiaries (local communities) (Cornwall, 2003; Hildyard et al., 2001; Mompati \& Prinsen, 2000; Mosse, 2003). In search of the answer as to why many development projects continue to fail, McKinnon (2007) focussed on the practices of development professionals as powerful actors in the development field. Drawing on her work in Thailand, McKinnon (2007) suggests that postdevelopment approaches and strategies can be useful to address the perpetual power imbalances in development practice.

However, the study considered in this thesis shows that, due to the complexity of power, development practitioners may not be fully aware of the existing various forms of power and their implications. Thus, I believe practitioners will benefit from this study because it provides a greater understanding of the convoluted power dynamics in participatory development. A greater understanding of power dynamics would be valuable, as it can assist practitioners to identify various drivers of inequalities and to find the potential to transform power imbalances (McGee \& Pettit, 2019).

\subsection{Limitations and Recommendation}

In attempts to gain insights into people's experiences and opinions from a diverse range of backgrounds, this study has limitations due to the difficulty in having access to people from a totally different religious background than those of YTP or the majority of the local communities. This was due to the fact that there was a very low number of non-Christian people that participated in the LST programme. Furthermore, most of them did not continue to participate after attending the training programme in Kupang. However, this limitation does not significantly undermine the results and conclusion of the study, as inferences of their experiences and opinions of the programme can also be drawn from the interviews with other research participants.

In conducting the interviews, I was also limited because I was not able to speak with my research participants from the local communities in Timor in their primary language. Although the risk of misinterpretation can be mitigated since most of them were able 
to speak the national language that I am fluent in, this limitation may impair the richness of the information that they provided during the interviews.

Finally, this study is limited by the over-representation of local men interviewed in this study. This limitation is attributed to the fact that only a small number of women participated in the LST programme. In this way, the study is insufficient in providing the voices of local women about their participation in the programme, particularly about the way inherent power relations in the programme, and social norms and cultural practices in Indonesian society, impacted their personal and familial domains. Therefore, further research to address these issues is recommended.

\subsection{Lessons Learnt and Final Reflections}

Five important lessons can be learned from this study by development practitioners for addressing power inequalities in participatory development. First, there is a need to pay greater attention to important differences within the local community when developing and delivering a programme (Cornwall, 2003; Mompati \& Prinsen, 2000). This requires practitioners to move away from viewing and treating a local community as a homogenous and harmonious entity, and make greater efforts to understand the heterogeneous reality (Guijt, 1994; Guijt \& Shah, 1993, as cited in Guijt \& Shah, 1998a, p. 8). Such differences, which may include gender, ethnic, age, and religious differences, can affect the lives of various segments of the community differently, and may lead them to have different needs and interests. Failing to take into account these important differences not only can impact on the success of development programmes, but also can lead to the perpetuation of inequalities.

As this study shows, a lack of attention to issues concerning gender, age, and religious differences within the local communities in Timor, had led to the perpetuation of inequalities. These inequalities were particularly apparent in relation to gender, where women and their interests were largely excluded, in spite of the roles they play within their families and communities. Regarding age differences, the downplaying of the significance of age differences had, sometimes, limited the role and participation of 
people from certain age groups. With regard to religion, a large number of nonChristians, who are the minority within the local communities in Timor, missed out on the benefits of participating in the LST programme. However, this situation can not strictly be attributed to the overlooking of religious differences on the part of the staff members of YTP, as the attitudes and perceptions of local people regarding the values and identity of YTP and its religious background have also contributed to this situation. Greater awareness of the significance of the religious issues would be beneficial for developing strategies to encourage the participation of people from the minority religion, and thus, reduce inequities between people of the majority and minority religions.

Second, there is a need to better understand the experiences, perceptions, and feelings of the intended beneficiaries (and other stakeholders involved) of development programmes. This study suggests that higher quality and more successful development programmes are more likely to result from explicitly seeking this information. Without doing this, useful information that can inform the discussions about the design, implementation, monitoring and evaluation of development programmes, will be missed. In turn, development programmes that make claims about participation and empowerment but do not seek the experiences, perceptions, and feelings of the intended beneficiaries, may be less effective and successful in achieving their transformative goals.

Third, despite the perception that the work of local NGOs is more 'grounded' in local communities, it cannot be assumed that the approaches they take will be more participatory than other agencies (such as government or international aid agencies). In international aid relations, working with local NGOs has been viewed as an effective way to increase local ownership and to promote sustainable development, as they are perceived to have better knowledge of the needs, constraints, and contextual situations of the local communities. Moreover, working with local NGOs can increase local acceptance in the delivery of development programme. However, this study shows that, due to a lack of local people's participation in the LST programme, there is an inconsistency between the local people's understanding of their needs and 
problems and YTP's understanding. Thus, it cannot be assumed that the work of local NGOs will be inherently more participatory than other agencies.

Fourth, there is a need for a better understanding of power, power relations and dynamics in the practices of participatory development. As power is complex, multidimensional, and dynamic, a great understanding of power is required (McGee \& Pettit, 2019; VeneKlasen \& Miller, 2002). This includes a deeper understanding and analysis of what power is, how it manifests and operates in different contexts, and the practical implications it brings for different people (McGee \& Pettit, 2019). A better understanding of power is fundamental to ensure good development practices that intend to address power imbalances in favour of the powerless, and to bring about meaningful change in society. As the study shows, power imbalances in the decisionmaking process of the LST programme have prevented its intended beneficiaries from achieving greater personal development, and the full benefits of empowerment. A broader understanding of power can assist YTP's staff (as well as development practitioners) to take more effective actions to better help those who are powerless. Greater effort can be made by YTP to assist the intended beneficiaries of the LST programme in developing their power within and power with.

A broader understanding of power can also assist practitioners to better understand the significance of 'power reversal' (Chambers, 1997). Practitioners will be able to reflect on their own power, including the less visible forms of power (e.g. gender norms), and to act in more transformative ways (Gaventa, 2019). As this study shows, attitudes and behaviours of 'power reversal', on the part of the local trainer who was more powerful in the training setting, were necessary to alter the power imbalances between the trainer and the local people.

Moreover, an increased understanding of various forms of power and their implications will be useful for development practitioners to exercise their power to make a difference. As hidden and invisible power, which operate through social norms and cultural practices within the society, can bring negative impacts for certain groups of people, practitioners can develop appropriate strategies to address and prevent these 
negative impacts. A critical analysis of power in this study points to three main areas for improvement in the delivery of the LST programme, which include greater awareness and understanding of power, participation, and gender.

Finally and most importantly, a deeper understanding of power should be followed by real actions to address power inequalities. These actions may include conducting a deeper analysis and identification of various factors that contribute to inequalities against those who are powerless and marginalised, building appropriate strategies to address issues of power, and identifying opportunities to transform the negative implications of power (McGee \& Pettit, 2019). As Rowlands (2019, p. 156) points out "Doing a thorough job of the power analysis can be immobilising if it does not include the essential process of strategic choice-making that takes it towards action." With increasing inequality worldwide, now is the time for mainstreaming power analysis in development practice, and making it integral to the process of assessing the effectiveness of development programmes.

To conclude, applying participatory approaches in development practice may be helpful to reduce power imbalances. However, without careful attention and critical approaches to power and its dynamics, these efforts will be inadequate. 


\section{BIBLIOGRAPHY}

Agarwal, B. (1997). Re-sounding the Alert: Gender, Resources and Community Action. World Development, 25, 1373-1380.

Arnstein, S. R. (1969). A Ladder of Citizen Participation. Journal of the American Institute of Planners, 35(4), 216-224. doi:10.1080/01944366908977225

Aspinall, E., \& Fealy, G. (2003). Local Power and Politics in Indonesia Decentralisation \& Democratisation. Singapore: Institute of South East Asian Studies.

Bachrach, P., \& Baratz, M. (1962). Two Faces of Power. The American Political Science Review (1927), 56(4), 947.

Badan Pusat Statistik (BPS). (2010). Penduduk Menurut Wilayah dan Agama yang Dianut Provinsi Nusa Tenggara Timur. Badan Pusat Statistik Retrieved from https://sp2010.bps.go.id/index.php/site/tabel?tid=321\&wid=5300000000

Badan Pusat Statistik (BPS). (2011). Kewarganegaraan, Suku Bangsa, Agama, dan Bahasa Sehari-hari Penduduk Indonesia. Badan Pusat Statistik Retrieved from https://www.bps.go.id/publication/download.html?nrbvfeve=NTVIY2EzOGI3 ZmUwODMwODMONjA1YjM1\&xzmn=aHROcHM6Ly93d3cuYnBzLmdvLmlkL3B 1YmxpY2FOaW9uLzIwMTIvMDUvMjMvNTVIY2EzOGI3ZmUwODMwODMONjA 1YjM1L2tld2FyZ2FuZWdhcmFhbi1zdWt1LWJhbmdzYS1hZ2FtYS1kYW4tYmFoY XNhLXNlaGFyaS1oYXJpLXBIbmR1ZHVrLWluZG9uZXNpYS5odG1s\&twoadfnoarf eauf=MjAxOSOxMiOxNyAxMjo1MjoxMQ\%3D\%3D

Badan Pusat Statistik (BPS). (2019a). Peringkat Indeks Pembangunan Manusia menurut Provinsi 2010-2018. Badan Pusat Statistik Retrieved from https://www.bps.go.id/dynamictable/2019/04/16/1615/peringkat-indekspembangunan-manusia-menurut-provinsi-2010-2018-metode-baru-.html

Badan Pusat Statistik (BPS). (2019b). Persentasi Masyarakat Miskin, Maret 2019. Badan Pusat Statistik Retrieved from https://www.bps.go.id/QuickMap?id=0000000000

Badan Pusat Statistik (BPS). (2019c). Statistik Indonesia 2019. Badan Pusat Statistik Retrieved from https://www.bps.go.id/publication/download.html?nrbvfeve=ZGFhYzFiYTE4Y 
2FIMWU5MDcwNmVINThh\&xzmn=aHROcHM6Ly93d3cuYnBzLmdvLmlkL3B1Y mxpY2F0aW9uLzIwMTkvMDcvMDQvZGFhYzFiYTE4Y2FIMWU5MDcwNmVINT hhL3NOYXRpc3Rpay1pbmRvbmVzaWEtMjAxOS5odG1s\&twoadfnoarfeauf=Mj AxOSOxMiOxOCAwNjoxMDozOQ\%3D\%3D

Badan Pusat Statistik (BPS) Kabupaten TTS. (2018). Kabupaten Timor Tengah Selatan Dalam Angka 2018. Badan Pusat Statistik Retrieved from https://timortengahselatankab.bps.go.id/publication/2018/08/16/0eef7f56e 29e6d653b6aa24a/kabupaten-timor-tengah-selatan-dalam-angka-2018.html Badan Pusat Statistik (BPS) Kabupaten TTS. (2019). Kabupaten Timor Tengah Selatan Dalam Angka 2019. Badan Pusat Statistik Retrieved from https://timortengahselatankab.bps.go.id/publication/2019/08/16/6414d2bd bdc5af3d28a80c0a/kabupaten-timor-tengah-selatan-dalam-angka-2019.html Badan Pusat Statistik (BPS) Provinsi NTT. (2018). Provinsi Nusa Tenggara Timur Dalam Angka 2018. Badan Pusat Statistik Retrieved from https://ntt.bps.go.id/publication/2018/08/16/d94e38a4fda352a452976ffb/p rovinsi-nusa-tenggara-timur-dalam-angka-2018.html

Banks, G., \& Scheyvens, R. (2014). Ethical Issues. In R. Scheyvens (Ed.), Development Fieldwork: a Practical Guide (2nd edition ed., pp. 160-187). London: SAGE Publications Ltd.

Bland, B. (2019). Indonesia: Look Beyond Quotas for Gender Representation.

Retrieved from https://www.lowyinstitute.org/the-interpreter/indonesialook-beyond-quotas-gender-representation

Bradley, A. (2019). Did we forget about power? In R. McGee \& J. Pettit (Eds.), Power, Empowerment and Social Change (1st ed., pp. 101-116). Abingdon, Oxon: Routledge.

Brennan, M. A., \& Israel, G. D. (2013). The Power of Community. In M. A. Brennan, J. C. Bridger, \& T. R. Alter (Eds.), Theory, Practice, and Community Development (First edition. ed., pp. 78 - 97). Abingdon, Oxon: Routledge.

Burkey, S. (1993). People First: a Guide to Self-reliant Participatory Rural Development. London: Zed Books. 
CartoGIS Services, T. A. N. U. A. (Cartographer). (2019). Nusa Tenggara Timur.

Retrieved from https://asiapacific.anu.edu.au/mapsonline/base-maps/nusatenggara-timur

Chambers, R. (1983). Rural Development: Putting the Last First. Burnt Mill, Harlow, Essex, England: Longman Scientific \& Technical.

Chambers, R. (1997). Whose Reality Counts? Putting the First Last. London: Intermediate Technology Publications.

Chambers, R. (2007). From PRA to PLA and pluralism: Practice and theory. The SAGE Handbook of Action Research: Participative Inquiry and Practice, 297.

Chambers, R., \& Guijt, I. (1995). PRA Five Years Later: Where are We Now? Forest, Trees and People Newsletter, April(26/27), 4-15.

Cleaver, F. (1999). Paradoxes of Participation: Questioning Participatory Approaches to Development. Journal of International Development, 11(4), 597-612. doi:10.1002/(SICI)1099-1328(199906)11:4<597::AID-JID610>3.0.CO2-Q

Cleaver, F. (2001). Institutions, Agency and the Limitations of Participatory Approaches to Development. In B. Cooke \& U. Kothari (Eds.), Participation: the new tyranny? (pp. 36-55). London: Zed Books.

CNN Indonesia. (2018). Konferensi Perempuan Timur, Menyuarakan Hak 'Warga Kelas Dua'. Retrieved from https://www.cnnindonesia.com/nasional/20181207155913-20351905/konferensi-perempuan-timur-menyuarakan-hak-warga-kelas-dua Cohen, J. M., \& Uphoff, N. T. (1977). Rural Development Participation: Concept and Measures for Project Design, Implementation and Evaluation. New York: Cornell University, Ithaca.

Cohen, J. M., \& Uphoff, N. T. (1980). Participation's Place in Rural Development: Seeking Clarity through Specificity. World Development, 8(3), 213-235. doi:10.1016/0305-750X(80)90011-X

Cooke, B., \& Kothari, U. (2001). Participation: the new tyranny? London: Zed Books. Cornwall, A. (2003). Whose Voices? Whose Choices? Reflections on Gender and Participatory Development. World Development, 31(8), 1325-1342. doi:10.1016/S0305-750X(03)00086-X 
Cornwall, A., \& Pratt, G. (2003). Pathways to Participation: Reflections on PRA. London: ITDG Publishing.

Creswell, J. W. (2014). Research Design: Qualitative, Quantitative, and Mixed Methods Approaches (4th ed.). Thousand Oaks: SAGE Publications.

Cupples, J., \& Kindon, S. (2014). Returning to University and Writing the Field. In R. Scheyvens (Ed.), Development Fieldwork: a Practical Guide (2nd edition ed., pp. 236-252). London: SAGE Publications Ltd.

Dahl, R. A. (1961). Who governs? Democracy and Power in an American city. New Haven: Yale University Press.

Dewan Ketahanan Pangan (DKP) Provinsi NTT, \& United-Nations World Food Programme (UN-WFP). Peta Ketahanan dan Kerentanan Pangan Nusa Tenggara Timur tahun 2015. Kupang: Dewan Ketahanan Pangan Provinsi NTT Retrieved from https://documents.wfp.org/stellent/groups/public/documents/ena/wfp2851 31.pdf?iframe

Ellicott, K., \& Gall, S. B. (2003). Indonesia. In K. Ellicott \& S. B. Gall (Eds.), Junior Worldmark Encyclopedia of Physical Geography (Vol. 3, pp. 1-6). Detroit, MI: UXL.

Eyben, R., Harris, C., \& Pettit, J. (2006). Introduction: Exploring Power for Change. IDS bulletin, 37(6), 1-10.

Foucault, M. (1980). Power/Knowledge: Selected Interviews and Other Writings, 1972-1977. Brighton, Sussex: Harvester Press.

Freire, P. (2018). Pedagogy of the Oppressed (50th anniversary ed.). New York: Bloomsbury Academic.

Friedmann, J. (1992). Empowerment: the Politics of Alternative Development. Cambridge, Massachusetts: Blackwell.

Friedmann, J., \& Weaver, C. (1979). Territory and Function: The Evolution of Regional Planning. London: E. Arnold.

Fuglesang, A. (1982). About Understanding: Ideas and Observations on Cross-cultural Communication. Uppsala: Dag Hammarskjold Foundation.

Gaventa, J. (2006). Finding the Spaces for Change: A Power Analysis. IDS bulletin, 37(6), 23-33. doi:10.1111/j.1759-5436.2006.tb00320.x 
Gaventa, J. (2019). Applying Power Analysis: Using the 'Powercube' to Explore Forms, Levels and Spaces. In R. McGee \& J. Pettit (Eds.), Power, Empowerment and Social Change (1st ed., pp. 117-138). Abingdon, Oxon: Routledge.

Gaventa, J., \& Barrett, G. (2010). So What Difference Does It Make? Mapping the Outcomes of Citizen Engagement. IDS Working Papers, 2010(347), 01-72.

Guijt, I. (1994). Making a Difference: Integrating Gender Analysis into PRA Training. RRA notes, 19, 49-55.

Guijt, I., \& Shah, M. K. (1993). The Trap of Community Averages: Report on a PRA and Gender Workshop. Agricultural Research and Extension Network Newsletter, 29, 24-27.

Hettne, B. (1990). Development Theory and the Three Worlds. Harlow, Essex, England: Longman Scientific \& Technical.

Hickey, S., \& Mohan, G. (2005). Relocating Participation within a Radical Politics of Development. Development and Change, 36(2), 237-262. doi:10.1111/j.0012$155 X .2005 .00410 . x$

Hildyard, N., Hegde, P., Wolvekamp, P., \& Reddy, S. (2001). Pluralism, Participation and Power: Joint Forest Management in India. In B. Cooke \& U. Kothari (Eds.), Participation: the new tyranny? (pp. 56-71). London: Zed Books.

Holland, J., \& Blackburn, J. (1998). Whose Voice? Participatory Research and Policy Change With a foreword by Robert Chambers: Practical Action Publishing. Hussein, K. (1995). Participatory Ideology and Practical Development: Agency Control in a Fisheries Project, Kariba Lake. In N. Nelson \& S. Wright (Eds.), Power and Participatory development: Theory and Practice (pp. 170-180). London: Intermediate Technology.

Indonesia Investments. (2017a, 5 Sep). Penduduk Indonesia. Retrieved from https://www.indonesia-investments.com/id/budaya/penduduk/item67 Indonesia Investments. (2017b, 12 Jan). Poverty in Indonesia. Retrieved from https://www.indonesia-investments.com/finance/macroeconomicindicators/poverty/item301?

Indonesia.go.id. (2019). Suku Bangsa. Retrieved from https://www.indonesia.go.id/profil/suku-bangsa 
Kapoor, I. (2002). The Devil's in the Theory: A Critical Assessment of Robert

Chambers' Work on Participatory Development. Third World Quarterly, 23(1), 101-117. doi:10.1080/01436590220108199

Kapoor, I. (2005). Participatory Development, Complicity and Desire. Third World Quarterly, 26(8), 1203-1220. doi:10.1080/01436590500336849

Kementrian Pendidikan dan Kebudayaan. (2018). Badan Bahasa Petakan 652 Bahasa Daerah di Indonesia. Retrieved from https://www.kemdikbud.go.id/main/blog/2018/07/badan-bahasa-petakan652-bahasa-daerah-di-indonesia

Kindon, S., Pain, R., \& Kesby, M. (2007). Participatory Action Research Approaches and Methods: Connecting People, Participation and Place. London: Routledge.

Kota, D. (2019, 27 Sep). Kelompok Tani Syalom Desa Nasi Lakukan Panen Raya, Raup Belasan Juta Rupiah. Pos Kupang. Retrieved from https://kupang.tribunnews.com/2019/09/27/kelompok-tani-syalom-desanasi-lakukan-panen-raya-raup-belasan-juta-rupiah

Kothari, U. (2001). Power, Knowledge and Social Control in Participatory Development. In B. Cooke \& U. Kothari (Eds.), Participation: the new tyranny? (pp. 139-152). London: Zed Books.

Lukes, S. (2005). Power: A Radical View (2nd ed.). New York: Palgrave Macmillan.

Marsden, D. (1994). Measuring the Process: Guidelines for Evaluating Social Development. Oxford: Intrac.

McArdle, J. (1989). Community Development: Tools of the Trade. Community Quarterly, 16, 47-54.

McGee, R., \& Pettit, J. (2019). Power, Empowerment and Social Change (1st ed.). Abingdon, Oxon: Routledge.

McKinnon, K. (2007). Postdevelopment, Professionalism, and the Politics of Participation. Annals of the Association of American Geographers, 97(4), 772785. doi:10.1111/j.1467-8306.2007.00582.x

Miller, V., VeneKlasen, L., Reilly, M., \& Clark, C. (2006) Making Change Happen 3: Power. In. Concepts for Revisioning Power for Justice, Equality, and Peace. Washington, DC: Just Associates. 
Mohan, G., \& Stokke, K. (2000). Participatory Development and Empowerment: The Dangers of Localism. Third World Quarterly, 21(2), 247-268. doi:10.1080/01436590050004346

Mohanty, R. (2002). Women's Participation in JFM in Uttaranchal Villages: Mimeo.

Mompati, T., \& Prinsen, G. (2000). Ethnicity and Participatory Development Methods in Botswana: Some Participants are to be Seen and Not Heard. Development in Practice, 10(5), 625-637. doi:10.1080/09614520020008805

Mosse, D. (1995). Authority, Gender and Knowledge: Theoretical Reflections on Participatory Rural Appraisal. Economic and Political Weekly, 30(11), 569-578.

Mosse, D. (2001). 'People's Knowledge', Participation and Patronage: Operations and Representations in Rural Development. In B. Cooke \& U. Kothari (Eds.), Participation: the new tyranny? (pp. 16-35). London: Zed Books.

Mosse, D. (2003). The Making and Marketing of Participatory Development. In P. Q. van Ufford \& A. K. Giri (Eds.), A Moral Critique of Development: In Search of Global Responsibilities (pp. 57-89): Routledge.

Mosse, D. (2005). Power Relations and Poverty Reduction. In R. Alsop (Ed.), Power, Rights, and Poverty: Concepts and Connections (pp. 51-67). Washington DC and London: The World Bank/DFID.

Muchtar, A. T., Overton, J., \& Palomino-Schalscha, M. (2019). Contextualising Empowerment: Highlighting Key Elements from Women's Stories of Empowerment. Development in Practice, 29(8), 1053-1063. doi:10.1080/09614524.2019.1609906

Nelson, N., \& Wright, S. (1995). Power and Participatory Development: Theory and Practice. London: Intermediate Technology.

Novianty, D. (2016). Kadis PU: Anggaran Pembangunan Infrastruktur NTT Meningkat Tajam. Retrieved from https://www.suara.com/bisnis/2016/08/08/101722/kadis-pu-anggaranpembangunan-infrastruktur-ntt-meningkat-tajam

Oakley, P. (1991). Projects with People: The Practice of Participation in Rural Development. Geneva: International Labour Office.

Onyx, J., \& Benton, P. (1995). Empowerment and Ageing: Toward Honoured Places for Crones and Sages. In G. Craig \& M. Mayo (Eds.), Community 
Empowerment: A Reader in Participation and Development (pp. 46-58). London: Zed Books.

Organisation for Economic Cooperation and Development (OECD). (1991). Development Assistance Committee Chairman's Report. Paris: OECD

Parfitt, T. (2004). The Ambiguity of Participation: A Qualified Defence of Participatory Development. Third World Quarterly, 25(3), 537-555.

Parsons, T. (1963). On the Concept of Political power. Proceedings of the American Philosophical Society, 107(3), 232-262.

Pemerintah Provinsi Nusa Tenggara Timur. (2019a). Informasi Ketenagakerjaan. Retrieved from http://nttprov.go.id/ntt/informasi-ketenaga-kerjaan/ Pemerintah Provinsi Nusa Tenggara Timur. (2019b). Kondisi Geografis. Retrieved from http://nttprov.go.id/ntt/kondisi-geografis/

Pretty, J. N. (1995). Participatory Learning for Sustainable Agriculture. World Development, 23(8), 1247-1263. doi:10.1016/0305-750X(95)00046-F

Rahnema, M. (2011). Participation. In W. Sachs (Ed.), The Development Dictionary: a Guide to Knowledge as Power (2nd ed.). London, UK: Zed Books.

Rowlands, J. (1995). Empowerment Examined. Development in Practice, 5(2), 101107. doi:10.1080/0961452951000157074

Rowlands, J. (2003). Development Methods and Approaches: Critical Reflections. Oxford: Oxfam

Rowlands, J. (2019). Finding the Right Power Tool(s) for the Job: Rendering the Invisible Visible. In R. McGee \& J. Pettit (Eds.), Power, Empowerment and Social Change (1st ed., pp. 152-165). Abingdon, Oxon: Routledge.

Sarin, M. (1998). Community Forest Management: Whose participation? In M. K. Shah \& I. Guijt (Eds.), The Myth of Community: Gender Issues in Participatory Development (pp. 121-130). London: Intermediate Technology Publications. Satriyo, H. (2003). Decentralisation and Women in Indonesia: One Step Back, Two Steps Forward? In E. Aspinall \& G. Fealy (Eds.), Local Power and Politics in Indonesia Decentralisation \& Democratisation (pp. 217-229). Singapore: Institute of South East Asian Studies.

Saxena, N. C. (2011). What is meant by people's participation? In A. Cornwall (Ed.), The Participation Reader (pp. 31-33). London: Zed Books. 
Shah, M. K., \& Guijt, I. (1998a). The Myth of Community: Gender Issues in Participatory Development. London: Intermediate Technology Publications.

Shah, M. K., \& Guijt, I. (1998b). Waking Up to Power, Conflict and Process. In M. K. Shah \& I. Guijt (Eds.), The Myth of Community: Gender Issues in Participatory Development (pp. 1-23). London: Intermediate Technology Publications.

Sultana, F. (2007). Reflexivity, Positionality and Participatory Ethics: Negotiating Fieldwork Dilemmas in International Research. ACME: An International Journal for Critical Geographies, 6(3), 374-385.

Sutiyo, \& Maharjan, K. L. (2017). Decentralization and Rural Development in Indonesia. Singapore: Springer.

Thomas-Slayter, B., \& Sodikoff, G. (2001). Sustainable Investments: Women's Contributions to Natural Resource Management Project in Africa. Development in Practice, 11(1), 45-61.

VeneKlasen, L., \& Miller, V. (2002). A New Weave of Power, People and Politics. Oklahoma City: World Neighbours.

White, S. C. (1996). Depoliticising Development: The Uses and Abuses of Participation. Development in Practice, 6(1), 6-15. doi:10.1080/0961452961000157564

Williams, G. (2004). Evaluating Participatory Development: Tyranny, Power and (Re) politicisation. Third World Quarterly, 25(3), 557-578.

Yayasan Tangan Pengharapan (YTP). (2018). Annual Report 2018 Yayasan Tangan Pengarapan. Retrieved from

Yayasan Tangan Pengharapan (YTP) (Producer). (2020, 4 Jul). Di Antara Karang, Kering \& Kurang - Timor Tengah Selatan - JTP Ep 10. Journey Tangan Pengharapan. [Video file] Retrieved from https://www.youtube.com/watch?v=un42VGYnSHI 


\section{APPENDICES}

Appendix A: Human Ethics Committee Approval

Appendix B: Sample of Information Sheets for Interviews

Appendix C: Sample of Consent Forms for Interviews

Appendix D: Interview Schedules

Appendix E: Sample of Information Sheets for Observations

Appendix F: Sample of Consent Form for Observations

Appendix G: The Life Skills Training Programme Proposal

Appendix H: Rules for the Life Skills Training Programme Participants 


\section{Appendix A: Human Ethics Committee Approval}

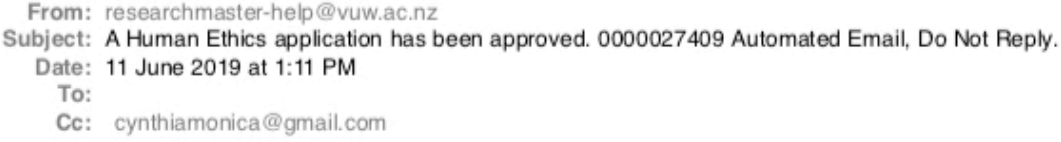

Dear Head of School or delegate,

A Human Ethics application has been approved for a researcher in your School. The application details are below. You have online access to this form through ResearchMaster here: https://rme6.vuw.ac.nz/RME6/.

Application ID: 0000027409

Application title: Exploring Issues of Power in Participatory Development: A Case Study of the 'Life Skills Training' Programme in Kupang, East Nusa Tenggara, Indonesia

Researcher: Cynthia Ecclestone

It is best to use either Internet Explorer or Safari to access the system.

Thank you

ResearchMaster

${ }^{\star \star \star \star \star}$ This is an automated email. Do not reply to this email address $S^{\star \star \star \star \star \star \star}$

Queries for the central Human Ethics Committee can be sent to ethicsadmin@vuw.ac.nz

Pipitea Ethics subcommittee queries can be sent to: pipitea-hec@vuw.ac.nz Psychology Ethics subcommittee queries can be sent to: louise.hamblin@vuw.ac.nz

Information Management subcommittee queries: vanessa.venter@vuw.ac.nz 


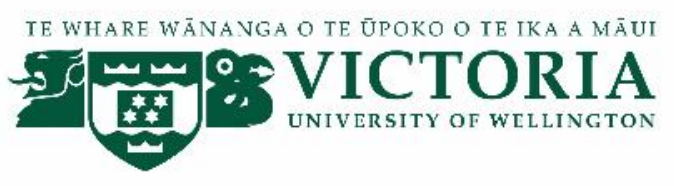

Exploring Local Perspectives on Participatory Development

\section{A Case Study of the 'Life Skills Training' programme in Kupang, East Nusa Tenggara, Indonesia}

\section{INFORMATION SHEET FOR INTERVIEWS}

(For: NGO Staff)

You are invited to take part in this research. Please read this information before deciding whether or not to take part. If you decide to participate, thank you. If you decide not to participate, thank you for considering this request.

\section{Who am I?}

My name is Cynthia Ecclestone and I am a Masters student in Development Studies at Victoria University of Wellington, New Zealand. This research project is work towards my thesis.

\section{What is the aim of the research project?}

This project seeks to explore people's perceptions, experiences, and feelings about their participation in the Life Skills Training programme, particularly those of the intended beneficiaries of the programme. In this research, I also want to learn more about the impact of interactions between various parties involved by conducting a series of interviews.

This research has been approved by the Victoria University of Wellington Human Ethics Committee [Application ID: 0000027409].

\section{How can you help?}

You have been invited to participate because you are one of Yayasan Tangan Pengharapan's staff members, who have been involved in the Life Skills Training programme. If you agree to take part, I will interview you in your office. I will ask you

\footnotetext{
13 The information sheets are tailored to the three groups of research participants (the head office staff, local trainer or field staff, and training participants).
} 
questions about the programme, and your experience and perception about your involvement in this programme. The interview will take roughly 1 hour. I will audio record the interview with your permission and write it up later. You can choose to not answer any question or stop the interview at any time, without giving a reason. You can withdraw from the study by contacting me at any time before 1 August 2019. If you withdraw, the information you provided will be destroyed or returned to you.

\section{What will happen to the information you give?}

This research is confidential. This means that the researcher named below will be aware of your identity, but the research data will be combined, and your identity will not be revealed in any reports, presentations, or public documentation. However, you should be aware that in small projects, your identity might be apparent to others in your community. Additionally, since this research looks at a particular programme that your organisation has delivered, you should also be aware that your organisation will be named.

Only my supervisor and I will read the notes or transcript of the interview. The interview transcripts, summaries and any recordings will be kept securely and destroyed on 1 June 2023.

\section{What will the project produce?}

The information from my research will be used in my Masters report and/or academic publications and conferences.

\section{If you accept this invitation, what are your rights as a research participant?}

You do not have to accept this invitation if you don't want to. If you do decide to participate, you have the right to:

- choose not to answer any question;

- ask for the recorder to be turned off at any time during the interview;

- withdraw from the study before 1 August 2019;

- ask any questions about the study at any time;

- read over and comment on a written summary of your interview;

- be able to read any reports of this research by emailing the researcher to request a copy.

\section{If you have any questions or problems, who can you contact?}

If you have any questions, either now or in the future, please feel free to contact [either/me]: 
Student:

Name: Cynthia Ecclestone

University email address:

ecclescynt@vuw.ac.nz

\section{Supervisor:}

Name: Professor John Overton

Role: Programme Director, Development Studies

School: Geography, Environment, and Earth Sciences

Phone: +64 44635281

john.overton@vuw.ac.nz

\section{Human Ethics Committee information}

If you have any concerns about the ethical conduct of the research you may contact the Victoria University HEC Convenor: Dr Judith Loveridge. Email hec@vuw.ac.nz or telephone +64-4-463 6028 . 


\title{
Menggali Perspektif Lokal tentang Pembangunan Partisipatif Sebuah Studi Kasus dari Program 'Pelatihan Ketrampilan' di Kupang, Nusa Tenggara Timur, Indonesia
}

\section{LEMBAR INFORMASI UNTUK WAWANCARA}

(Untuk: Staff YTP)

\begin{abstract}
Bapak/lbu/Saudara diundang untuk mengambil bagian dalam penelitian ini. Harap membaca informasi ini terlebih dahulu sebelum memutuskan untuk mengikuti penelitian ini. Jika Bapak/lbu/Saudara memutuskan untuk berpartisipasi, pertama-tama saya ucapkan terima kasih. Jika tidak, terima kasih telah mempertimbangkan permintaan ini.
\end{abstract}

\section{Siapa saya?}

Nama saya Cynthia Ecclestone dan saya seorang mahasiswa Strata 2 (S2/Master) jurusan Studi Pembangunan di Universitas Victoria, Wellington, Selandia Baru. Penelitian ini adalah bagian dari studi dan penulisan tesis $\mathrm{S} 2$ saya.

\section{Apa tujuan dari penelitian ini?}

Penelitian ini bertujuan untuk menggali persepsi, reaksi, dan pengalaman tentang keterlibatan orang-orang yang terkait dalam program 'Pelatihan Ketrampilan' (Life Skills Training) di Kupang, Nusa Tenggara Timur, terutama persepsi, reaksi, dan pengalaman mereka yang menjadi sasaran penerima manfaat dari program ini. Penelitian ini juga bertujuan untuk memahami dampak dari interaksi antara berbagai pihak terkait.

Penelitian ini telah disetujui oleh Komite Etik Penelitian Sosial dari Universitas Victoria, Wellington, Selandia Baru [No Aplikasi: 0000027409].

\section{Bagaimana Anda dapat membantu penelitian ini?}

Bapak/Ibu/Saudara diundang untuk berpartisipasi karena Bapak/Ibu/Saudara adalah salah satu staff (anggota) dari Yayasan Tangan Pengharapan, yang telah terlibat dalam program 'Pelatihan Ketrampilan'. Jika Bapak/Ibu/Saudara setuju untuk berpartisipasi dalam penelitian ini, saya akan mewawancarai Bapak/lbu/Saudara di kantor Yayasan Tangan Pengharapan. Saya akan menanyakan pertanyaan mengenai program 'Pelatihan Ketrampilan' ini, dan menggali pengalaman maupun persepsi Bapak/lbu/Saudara atas keterlibatan Bapak/lbu/Saudara di program ini. Wawancara akan memakan waktu kurang lebih 1 jam. Saya juga akan merekam (audio) jalannya wawancara ini dengan izin Bapak/lbu/Saudara, dan menuliskan ringkasan dari hasil wawancara tersebut. Bapak/Ibu/Saudara dapat memilih untuk tidak menjawab pertanyaan saya atau menghentikan wawancara setiap saat, tanpa memberikan alasan. Bapak/Ibu/Saudara juga dapat memutuskan untuk 
menarik diri dari penelitian ini dengan memberitahu saya setiap saat sebelum tanggal 1 Agustus 2019. Jika Bapak/Ibu/Saudara memutuskan untuk menarik diri dari penelitian ini, informasi yang telah Bapak/lbu/Saudara berikan akan saya musnahkan atau kembalikan.

\section{Apa yang terjadi pada informasi yang Anda berikan?}

Penelitian ini bersifat rahasia. Artinya peneliti yang disebutkan di bawah ini akan mengetahui identitas Bapak/lbu/Saudara, tetapi data penelitian akan digabungkan, dan identitas Bapak/lbu/Saudara tidak akan terungkap dalam laporan, presentasi, atau dokumentasi publik apa pun. Namun, perlu diketahui bahwa dalam proyek-proyek kecil, identitas Bapak/lbu/Saudara dapat diketahui oleh orang lain di lingkungan Bapak/lbu/Saudara. Selain itu, karena penelitian ini melihat pada program tertentu yang dilakukan oleh Yayasan Tangan Pengharapan, perlu diketahui juga bahwa nama organisasi Bapak/lbu/Saudara akan disebutkan dalam laporan, publikasi maupun presentasi akademik.

Hanya dosen pengawas dan peneliti yang akan membaca catatan atau transkrip wawancara. Transkrip wawancara, ringkasan, dan rekaman apa pun akan disimpan dengan aman dan dihancurkan pada 1 Juni 2023.

\section{Apa yang akan dihasilkan dari penelitian ini?}

Informasi dari penelitian ini akan digunakan untuk bahan laporan studi (tesis S2/Master) peneliti, dan/atau publikasi serta konferensi akademik.

Jika Anda bersedia berpartisipasi dalam penelitian ini, hak-hak apa yang Anda punya sebagai peserta penelitian?

Bapak/Ibu/Saudara tidak harus berpartisipasi dalam penelitian ini jika tidak bersedia. Jika Bapak/Ibu/Saudara memutuskan untuk berpartisipasi, Bapak/lbu/Saudara memiliki hak untuk:

- Memilih untuk tidak menjawab pertanyaan yang diberikan;

- Meminta alat perekam dimatikan kapan saja saat diwawancara;

- Menarik diri dari penelitian sebelum tanggal 1 Agustus 2019;

- Mengajukan pertanyaan tentang penelitian ini kapan saja;

- Membaca kembali dan mengomentari ringkasan tertulis dari wawancara Anda;

- Membaca laporan penelitian ini dengan mengirimkan email kepada peneliti untuk mendapatkan salinan dari laporan penelitian.

Jika Anda memiliki pertanyaan atau masalah, siapa yang dapat Anda hubungi? Jika Bapak/lbu/Saudara memiliki pertanyaan tentang penelitian ini, saat ini maupun di waktu mendatang, dapat menghubungi [salah satu di bawah ini ataupun saya sendiri]: 
Mahasiswa:

Nama: Cynthia Ecclestone

Alamat email universitas:

ecclescynt@vuw.ac.nz
Dosen Pengawas:

Nama: Profesor John Overton

Jabatan: Direktur Program, Studi

Pembangunan

Sekolah: Geografi, Lingkungan, dan IImu

Bumi

Telepon : +64 44635281

john.overton@vuw.ac.nz

\section{Informasi Komite Etik Penelitian Sosial}

Jika Bapak/lbu/Saudara mempunyai kekhawatiran atas hal-hal yang berkaitan dengan etika dari pelaksanaan penelitian ini, Bapak/lbu/Saudara dapat menghubungi Victoria University HEC Convenor: Dr Judith Loveridge. Email hec@vuw.ac.nz atau telepon + 644-463 6028. 


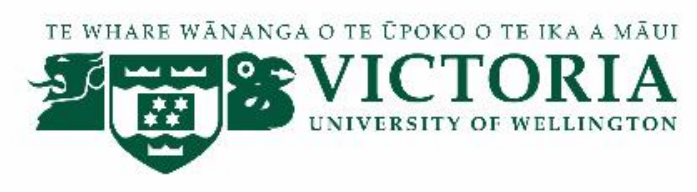

Exploring Local Perspectives on Participatory Development

\author{
A Case Study of the 'Life Skills Training' programme in Kupang, \\ East Nusa Tenggara, Indonesia \\ CONSENT TO INTERVIEW \\ (For: NGO Staff)
}

This consent form will be held for 5 years.

Researcher: Cynthia Ecclestone, School of Geography, Environment, and Earth Sciences, Victoria University of Wellington, New Zealand.

- I have read the Information Sheet and the project has been explained to me. My questions have been answered to my satisfaction. I understand that I can ask further questions at any time.

- I agree to take part in an audio recorded interview.

I understand that:

- I may withdraw from this study at any point before 1 August 2019, and any information that I have provided will be returned to me or destroyed.

- $\quad$ The identifiable information I have provided will be destroyed on 1 June 2023.

- $\quad$ Any information I provide will be kept confidential to the researcher and the supervisor.

- I understand that the results will be used for a Masters report and/or academic publications and/or presented to conferences.

- I can read over and comment on a written summary of your interview.

- I consent to information or opinions that I have given being attributed to my organisation in any reports on this research Yes $\square$ No $\square$ and have the authority to agree to this on behalf of the organisation:

- I would like a summary of my interview: $\quad$ Yes $\square$ No $\square$

- I would like to receive a copy of the final report and have $\quad$ Yes $\square$ No $\square$ added my email address below.

Signature of participant: Name of participant:

\footnotetext{
${ }^{14}$ The consent forms are tailored to the three groups of research participants (the head office staff, local trainer or field staff, and training participants).
} 
Date:

Contact details: 


\section{FORMULIR PERSETUJUAN WAWANCARA}

(Untuk: Staff YTP)

Formulir persetujuan ini akan disimpan selama 5 tahun.

Peneliti: Cynthia Ecclestone, Sekolah Geografi, Lingkungan, dan Ilmu Bumi, Universitas Victoria, Wellington, Selandia Baru.

- Saya telah membaca Lembar Informasi, dan penelitian ini telah dijelaskan kepada saya. Pertanyaan yang saya ajukan tentang penelitian ini telah dijawab oleh peneliti. Saya mengerti bahwa saya dapat mengajukan pertanyaan lebih lanjut tentang penelitian ini kapan saja.

- Saya setuju untuk ikut serta dalam wawancara yang juga akan direkam (audio).

Saya mengerti bahwa:

- Saya dapat menarik diri dari studi ini kapan saja sebelum 1 Agustus 2019, dan informasi apa pun yang saya berikan akan dikembalikan kepada saya atau dimusnahkan.

- Informasi yang telah saya berikan dan dapat membuka identitas saya akan dimusnahkan pada 1 Juni 2023.

- Setiap informasi yang saya berikan akan dirahasiakan, dan hanya dapat diakses oleh peneliti dan dosen pengawas peneliti.

- Hasil penelitian ini akan digunakan untuk laporan studi (tesis S2/Master) peneliti, dan/atau publikasi serta konferensi akademik.

- Membaca kembali dan mengomentari ringkasan tertulis dari wawancara Anda

- Saya menyetujui bahwa informasi yang saya berikan dalam laporan penelitian ini juga mewakili pendapat dari organisasi $\quad$ Ya $\square \quad$ Tidak $\square$ saya, dan saya mempunyai kewenangan atas hal ini atas nama organisasi saya :

- Saya ingin mendapatkan ringkasan dari hasil wawancara Ya $\square \quad$ Tidak $\square$ saya:

- Saya ingin mendapatkan satu salinan laporan akhir dan telah $\quad$ Ya $\square \quad$ Tidak memberikan alamat email saya di bawah ini. 
Tanda tangan peserta:

Nama peserta:

Tanggal:

Rincian kontak: 


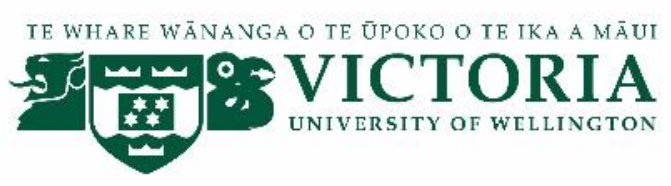

\section{Exploring Local Perspectives on Participatory Development}

\section{A Case Study of the 'Life Skills Training' programme in Kupang, East Nusa Tenggara, Indonesia}

\section{INTERVIEW SCHEDULE (NGO Staff)}

I. Opening

1. Personal identity of research participants (name, age, family size, occupation, education)

II. Participation in the programme

1. Role \& responsibility of the organisation

2. Role \& responsibility of the research participant

III. Information about the Life Skills Training programme

1. Objective, expected outcomes, activities, targeted beneficiaries, time period, frequency of the activities, and (if any) restrictions of participating in the programme.

2. Experience of planning, implementation, monitoring and evaluation of the programme (good and bad)

IV. Perceptions \& Feelings of research participants in relation to

1. Their experience and opportunities in participating in the programme (planning, implementation, monitoring and evaluation)

2. Challenges they face

3. Coordination and communication with both Yayasan Tangan Pengharapan's local partner and training participants

4. The needs (expectation) of the local community

5. The capacity and livelihood of the local people

V. Closing

1. Information about the follow-up action after the interview 


\section{Exploring Local Perspectives on Participatory Development}

\section{A Case Study of the 'Life Skills Training' programme in Kupang, East Nusa Tenggara, Indonesia}

\section{INTERVIEW SCHEDULE (NGO's Local Partners \& Training Participants)}

I. Opening

1. Personal identity of research participants (name, age, family size, occupation, education)

II. Participation in the programme

1. Role

2. Experience in the planning, implementing, monitoring and evaluation of the programme (good and bad)

III. Perceptions \& Feelings of research participants in relation to

1. Their experience and opportunities in participating in the programme (planning, implementation, monitoring and evaluation)

2. Challenges they face

3. Coordination and communication

4. The needs (expectation) of the local community

5. The capacity and livelihood of the local people

IV. Closing

1. Information about the follow-up action after the interview 


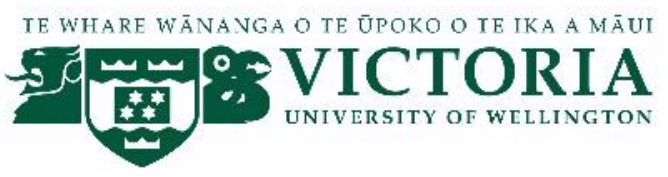

Menggali Perspektif Lokal tentang Pembangunan Partisipatif

Sebuah Studi Kasus dari Program 'Pelatihan Ketrampilan' di Kupang, Nusa Tenggara Timur, Indonesia

\section{TOPIK ULASAN WAWANCARA \\ (Untuk Staff YTP)}

I. Pembukaan

1. Identitas pribadi peserta penelitian (nama, umur, jumlah anggota keluarga, pekerjaan, pendidikan)

II. Partisipasi dalam program

1. Peran \& tanggung jawab organisasi

2. Peran \& tanggung jawab peserta wawancara

III. Informasi tentang program 'Pelatihan Ketrampilan' (the Life Skills Training programme)

Tujuan, hasil yang diharapkan, kegiatan yang dilakukan, target penerima

manfaat, periode program, frekuensi kegiatan, dan (jika ada) persyaratan

untuk berpartisipasi dalam program.

IV. Pengalaman, Persepsi \& Perasaan peserta wawancara sehubungan dengan

1. Perencanaan, pelaksanaan, pemantauan dan evaluasi program (baik dan buruk)

2. Peluang untuk berpartisipasi dalam program (perencanaan, pelaksanaan, pemantauan dan evaluasi)

V. Persepsi Umum peserta wawancara sehubungan dengan:

1. Keterlibatan dan partisipasi pihak-pihak terkait

2. Hasil/Dampak/Perubahan dari hasil program Pelatihan Ketrampilan sehubungan dengan kapasitas dan mata pencaharian masyarakat setempat

3. Tantangan yang mereka hadapi

4. Koordinasi dan komunikasi dengan mitra lokal dan peserta program 'Pelatihan Ketrampilan'

VI. Penutup

1. Informasi tentang tindakan tindak lanjut setelah wawancara 


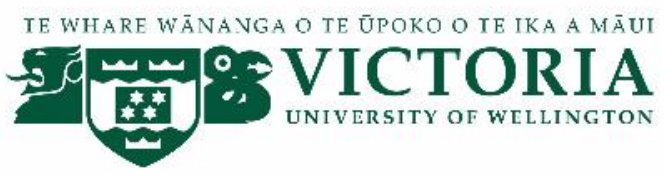

Menggali Perspektif Lokal tentang Pembangunan Partisipatif

Sebuah Studi Kasus dari Program 'Pelatihan Ketrampilan' di Kupang, Nusa Tenggara Timur, Indonesia

TOPIK ULASAN WAWANCARA

(Untuk: Mitra Lokal YTP \& Peserta Program 'Pelatihan Ketrampilan')

I. Pembukaan

1. Identitas pribadi peserta penelitian (nama, umur, jumlah anggota keluarga, pekerjaan, pendidikan)

2. Peran \& tanggung jawab peserta wawancara dalam program 'Pelatihan Ketrampilan'

II. Informasi Umum tentang Masyarakat Setempat

1. Masalah atau problem utama masyarakat setempat (di daerah tsb)

2. Kebutuhan utama masyarakat setempat

III. Informasi Umum tentang program 'Pelatihan Ketrampilan'

IV. Pengalaman, Persepsi \& Perasaan peserta wawancara sehubungan dengan

1. Perencanaan, pelaksanaan, pemantauan dan evaluasi program (baik dan buruk)

2. Pengalaman dan peluang mereka untuk berpartisipasi dalam program (perencanaan, pelaksanaan, pemantauan dan evaluasi)

3. Tantangan yang mereka hadapi (di masing-masing tahap)

V. Persepsi Umum peserta wawancara sehubungan dengan:

1. Keterlibatan dan partisipasi pihak-pihak terkait

2. Hasil/Dampak/Perubahan dari hasil program Pelatihan Ketrampilan sehubungan dengan kapasitas dan mata pencaharian masyarakat setempat

3. Tantangan yang mereka hadapi

4. Koordinasi dan komunikasi dengan mitra lokal dan peserta program 'Pelatihan Ketrampilan'

VI. Penutup

1. Informasi tentang tindakan tindak lanjut setelah wawancara 


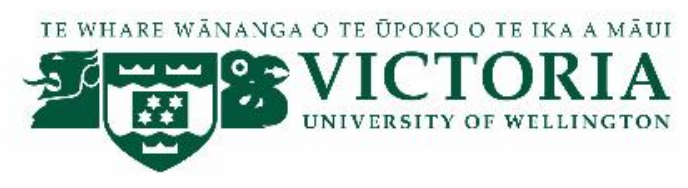

\section{Exploring Local Perspectives on Participatory Development}

\section{A Case Study of the 'Life Skills Training' programme in Kupang, East Nusa Tenggara, Indonesia}

\section{INFORMATION SHEET FOR OBSERVATION \\ (For: Training Participants)}

You are invited to take part in this research. Please read this information before deciding whether or not to take part. If you decide to participate, thank you. If you decide not to participate, thank you for considering this request.

\section{Who am I?}

My name is Cynthia Ecclestone and I am a Masters student in Development Studies at Victoria University of Wellington, New Zealand. This research project is work towards my thesis.

\section{What is the aim of the research project?}

This project seeks to explore people's perceptions, experiences, and feelings about their participation in the Life Skills Training programme, particularly those of the intended beneficiaries of the programme. In this research, we want to learn more about the impact of interactions between various parties involved by observing how the training programme is delivered to participants.

This research has been approved by the Victoria University of Wellington Human Ethics Committee [Application ID: 0000027409].

\section{How can you help?}

You have been invited to participate because you are one the participants of the Life Skills Training programme that is supported by Yayasan Tangan Pengharapan in Kupang. If you agree to take part, your participation and interactions with each other

\footnotetext{
15 The information sheets are tailored to the three groups of research participants (the head office staff, local trainer or field staff, and training participants).
} 
during the training sessions will be observed. I may take photographs during my observation with your permission. You do not have to consent to being photographed. You can withdraw from the study by contacting me before 1 August 2019. If you withdraw, the information you provided will be destroyed or returned to you. If you do not agree to take part, this will not adversely affect you in any way.

\section{What will happen to the information gathered?}

This research is confidential. This means that the researcher named below will be aware of your identity, but the research data will be combined, and your name and other identifying factors will not be revealed in any reports, presentations, or public documentation.

Only my supervisor and I will read the notes of the observation. The notes will be kept securely and destroyed on 1 June 2023

However, as I may take photographs during my observation, your identity might be apparent to others in your community from the final report. At the end of the observation, you will be able to review the photos I have taken. If you are not happy about appearing in the photos, you can decline the use of particular image(s) of yourself, and/or you can request that your face will be made obscure in any photo used in the research report and related academic publication or conference presentation. All the original and unused photos will be kept securely and destroyed on 1 June 2023.

\section{What will the project produce?}

The information from my research will be used in my Masters report and/or academic publications and conferences.

\section{If you accept this invitation, what are your rights as a research participant?}

You do not have to accept this invitation if you don't want to. If you do decide to participate, you have the right to:

- withdraw from the study before 1 August 2019;

- ask any questions about the study at any time;

- be able to read any reports of this research by emailing the researcher to request a copy. If access to email is not available, the researcher can provide the research summaries and findings via an alternative means.

- be able to review the observation photos, decline the use of particular image(s) of yourself, and decide whether you want your face blurred out or not. 
If you have any questions or problems, who can you contact?

If you have any questions, either now or in the future, please feel free to contact [either/me]:

\section{Student:}

Name: Cynthia Ecclestone

University email address:

ecclescynt@vuw.ac.nz

\section{Supervisor:}

Name: Professor John Overton

Role: Programme Director, Development

Studies

School: Geography, Environment, and Earth

Sciences

Phone: +64 44635281

john.overton@vuw.ac.nz

If access to email is not available, you can contact me via an alternative means (a local phone number will be provided).

\section{Human Ethics Committee information}

If you have any concerns about the ethical conduct of the research you may contact the Victoria University HEC Convenor: Dr Judith Loveridge. Email hec@vuw.ac.nz or telephone +64-4-463 6028 . 


\title{
Menggali Perspektif Lokal tentang Pembangunan Partisipatif Sebuah Studi Kasus dari Program 'Pelatihan Ketrampilan' di Kupang, Nusa Tenggara Timur, Indonesia
}

\section{LEMBAR INFORMASI UNTUK OBSERVASI (Untuk: Peserta Pelatihan)}

\begin{abstract}
Bapak/lbu/Saudara diundang untuk mengambil bagian dalam penelitian ini. Harap membaca informasi ini terlebih dahulu sebelum memutuskan untuk mengikuti penelitian ini. Jika Bapak/lbu/Saudara memutuskan untuk berpartisipasi, pertama-tama saya ucapkan terima kasih. Jika tidak, terima kasih telah mempertimbangkan permintaan ini.
\end{abstract}

\section{Siapa saya?}

Nama saya Cynthia Ecclestone dan saya seorang mahasiswa Strata 2 (S2/Master) jurusan Studi Pembangunan di Universitas Victoria, Wellington, Selandia Baru. Penelitian ini adalah bagian dari studi dan penulisan tesis $\mathrm{S} 2$ saya.

\section{Apa tujuan dari penelitian ini?}

Penelitian ini bertujuan untuk menggali persepsi, reaksi, dan pengalaman tentang keterlibatan orang-orang yang terkait dalam program 'Pelatihan Ketrampilan' (Life Skills Training) di Kupang, Nusa Tenggara Timur, terutama persepsi, reaksi, dan pengalaman mereka yang menjadi sasaran penerima manfaat dari program ini. Penelitian ini juga bertujuan untuk memahami dampak dari interaksi antara berbagai pihak terkait melalui observasi lapangan.

Penelitian ini telah disetujui oleh Komite Etik Penelitian Sosial dari Universitas Victoria, Wellington, Selandia Baru [No Aplikasi: 0000027409].

\section{Bagaimana Anda dapat membantu penelitian ini?}

Bapak/Ibu/Saudara diundang untuk berpartisipasi karena Bapak/Ibu/Saudara adalah salah satu peserta pelatihan program 'Pelatihan Ketrampilan' di Kupang. Jika Bapak/Ibu/Saudara setuju untuk berpartisipasi dalam penelitian ini, saya akan mengamati partisipasi Bapak/lbu/Saudara di program ini, dan interaksi antara berbagai pihak selama sesi pelatihan berlangsung. Saya juga akan mengambil beberapa foto, dengan ijin dari Bapak/lbu/Saudara, pada saat pelatihan berlangsung. Bapak/lbu/Saudara tidak harus memberikan persetujuan untuk difoto, jika Bapak/Ibu/Saudara tidak bersedia difoto. Bapak/Ibu/Saudara dapat memutuskan untuk menarik diri dari penelitian ini dengan memberitahu saya setiap saat sebelum tanggal 1 Agustus 2019. Jika Bapak/lbu/Saudara memutuskan untuk menarik diri dari penelitian ini, informasi yang telah Bapak/lbu/Saudara berikan akan saya musnahkan atau 
kembalikan. Jika Bapak/lbu/Saudara tidak bersedia untuk berpartisipasi dalam studi ini, hal ini tidak akan berdampak negatif terhadap Bapak/lbu/Saudara.

\section{Apa yang terjadi pada informasi yang Anda berikan?}

Penelitian ini bersifat rahasia. Artinya peneliti yang disebutkan di bawah ini akan mengetahui identitas Bapak/lbu/Saudara, tetapi data penelitian

akan digabungkan, dan identitas Bapak/Ibu/Saudara tidak akan terungkap dalam laporan, presentasi, atau dokumentasi publik apa pun. Hanya dosen pengawas dan peneliti yang akan membaca catatan observasi yang saya lakukan. Catatan tersebut akan disimpan dengan aman dan dihancurkan pada 1 Juni 2023.

Namun, karena saya akan mengambil foto saat melakukan observasi, identitas Bapak/lbu/Saudara dapat diketahui oleh orang lain di komunitas Bapak/Ibu/Saudara. Oleh karena itu, Bapak/lbu/Saudara dapat melihat foto-foto observasi yang saya ambil pada akhir observasi saya. Jika Bapak/lbu/Saudara tidak ingin terlihat di foto-foto tsb, Bapak/lbu/Saudara dapat menolak penggunaaan foto-foto tertentu yang menampilkan wajah Bapak/Ibu/Saudara, dan/atau meminta agar wajah Bapak/Ibu/Saudara dikaburkan dalam laporan, presentasi, atau dokumentasi publik apa pun. Semua foto asli dan yang tidak digunakan akan disimpan dengan aman dan dihancurkan pada 1 Juni 2023.

\section{Apa yang akan dihasilkan dari penelitian ini?}

Informasi dari penelitian ini akan digunakan untuk bahan laporan studi (tesis S2/Master) peneliti, dan/atau publikasi serta konferensi akademik.

Jika Anda bersedia berpartisipasi dalam penelitian ini, hak-hak apa yang Anda punya sebagai peserta penelitian?

Bapak/Ibu/Saudara tidak harus berpartisipasi dalam penelitian ini jika tidak bersedia. Jika Bapak/lbu/Saudara memutuskan untuk berpartisipasi, Bapak/lbu/Saudara memiliki hak untuk:

- Menarik diri dari penelitian sebelum tanggal 1 Agustus 2019;

- Mengajukan pertanyaan tentang penelitian ini kapan saja;

- Membaca laporan penelitian ini dengan mengirimkan email kepada peneliti untuk mendapatkan salinan dari laporan penelitian. Jika akses untuk mengirimkan email tidak tersedia, peneliti dapat menyediakan ringkasan penelitian dan temuan melalui cara lain.

- Dapat melihat foto-foto observasi, menolak penggunaaan foto-foto tertentu yang menampilkan wajah saya, dan memutuskan apakah saya ingin wajah saya dikaburkan dalam foto-foto tsb.

\section{Jika Anda memiliki pertanyaan atau masalah, siapa yang dapat Anda hubungi?}

Jika Bapak/lbu/Saudara memiliki pertanyaan tentang penelitian ini, saat ini maupun di waktu mendatang, dapat menghubungi [salah satu di bawah ini ataupun saya sendiri]: 
Mahasiswa:

Nama: Cynthia Ecclestone

Alamat email universitas:

ecclescynt@vuw.ac.nz
Dosen Pengawas:

Nama: Profesor John Overton

Jabatan: Direktur Program, Studi

Pembangunan

Sekolah: Geografi, Lingkungan, dan IImu

Bumi

Telepon : +64 44635281

john.overton@vuw.ac.nz

Jika akses untuk mengirimkan email tidak tersedia, saya dapat dihubungi dengan cara

lain (nomor telepon lokal akan diberikan).

\section{Informasi Komite Etik Penelitian Sosial}

Jika Bapak/Ibu/Saudara mempunyai kekhawatiran atas hal-hal yang berkaitan dengan etika dari pelaksanaan penelitian ini, Bapak/lbu/Saudara dapat menghubungi Victoria University HEC Convenor: Dr Judith Loveridge. Email hec@vuw.ac.nz atau telepon + 644-463 6028. 


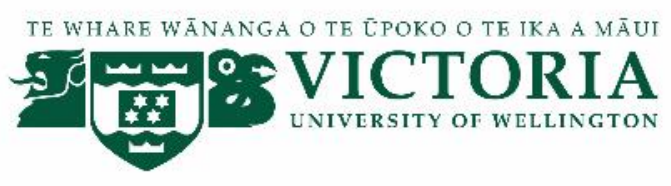

\section{Exploring Local Perspectives on Participatory Development}

\section{A Case Study of the 'Life Skills Training' programme in Kupang, East Nusa Tenggara, Indonesia}

\section{CONSENT FORM FOR OBSERVATION \\ (For: Training Participants)}

This consent form will be held for 5 years.

Researcher: Cynthia Ecclestone, School of Geography, Environment, and Earth Sciences, Victoria University of Wellington, New Zealand.

- I have read the Information Sheet and the project has been explained to me. My questions have been answered to my satisfaction. I understand that I can ask further questions at any time.

- I agree to take part in this observational study.

I understand that:

- I may withdraw from this study at any point before 1 August 2019, and any information generated from this observation that relates specifically to me will be destroyed.

- $\quad$ The identifiable information I have provided will be destroyed on 1 June 2023.

- Any information gathered will be kept confidential to the researcher and the supervisor.

- I understand that the results will be used for a Masters report, and/or academic publications, and/or presented to conference.

- My name will not be used in reports.

- I can review the observation photos and decline the use of particular image(s) of myself.

- I consent to be photographed during the observation. $\quad$ Yes $\square$ No $\square$

- I would like my face to be made obscure in these $\quad$ Yes $\square$ No photographs.

- I would like to receive a copy of the final report. If access Yes $\square \quad$ No to email is not available, the report will be provided via an alternative means.

\footnotetext{
${ }^{16}$ The consent forms are tailored to the three groups of research participants (the head office staff, local trainer or field staff, and training participants).
} 
- My preferred method of communication

Email Phone

Other

Signature of participant:

Name of participant:

Date:

Contact details: 


\section{FORMULIR PERSETUJUAN OBSERVASI}

(Untuk: Peserta Pelatihan)

Formulir persetujuan ini akan disimpan selama 5 tahun.

Peneliti: Cynthia Ecclestone, Sekolah Geografi, Lingkungan, dan Ilmu Bumi, Universitas Victoria, Wellington, Selandia Baru.

- Saya telah membaca Lembar Informasi, dan penelitian ini telah dijelaskan kepada saya. Pertanyaan yang saya ajukan tentang penelitian ini telah dijawab oleh peneliti. Saya mengerti bahwa saya dapat mengajukan pertanyaan lebih lanjut tentang penelitian ini kapan saja.

- Saya setuju untuk ikut serta dalam penelitian observasi lapangan ini.

Saya mengerti bahwa:

- Saya dapat menarik diri dari studi ini kapan saja sebelum 1 Agustus 2019, dan informasi apa pun yang saya berikan akan dikembalikan kepada saya atau dimusnahkan.

- Informasi yang telah saya berikan dan dapat membuka identitas saya akan dimusnahkan pada 1 Juni 2023.

- Setiap informasi yang saya berikan akan dirahasiakan, dan hanya dapat diakses oleh peneliti dan dosen pengawas peneliti.

- Saya memahami bahwa hasil penelitian ini akan digunakan untuk laporan studi (tesis S2/Master) peneliti, dan/atau publikasi serta konferensi akademik.

- Nama saya tidak akan digunakan di dalam laporan penelitian.

- Saya dapat melihat foto-foto observasi yang diambil oleh peneliti dan menolak penggunaan foto-foto tertentu yang menampilkan wajah saya.

- Saya bersedia dan setuju untuk difoto selama observasi Ya $\square$ Tidak lapangan dilakukan

- Saya ingin wajah saya dikaburkan di foto-foto ini. $\quad$ Ya $\square \quad$ Tidak $\square$

- Saya ingin mendapatkan satu salinan laporan akhir. Jika Ya $\square \quad$ Tidak $\square$ akses untuk mengirimkan email tidak tersedia, peneliti akan menyediakan ringkasan dan temuan penelitian melalui cara lain.

- Metode komunikasi yang saya pilih. $\quad$ Email $\square$ Telp $\square$ Lainnya (Saya telah mengisi kontak detail saya di bawah ini) 
Tanda tangan peserta:

Nama peserta:

Tanggal:

Rincian kontak: 


\section{Appendix G: The Life Skills Training Programme Proposal}

\section{LATAR BELAKANG}

Sekolah Lapangan Yayasan Tangan Pengharapan (Life Training Center) telah diresmikan pada tanggal 22 November 2016, oleh Bapak Drs. Frans Lebu Raya, selaku Gubernur Nusa Tenggara Timur. Life Training Center merupakan suatu program pelatihan singkat, yang lahir dari mimpi dan kepedulian terhadap masyarakat pedalaman yang ada di Nusa Tenggara Timur untuk menjawab kebutuhan masyarakat di pedalaman dalam bidang teknologi air tepat guna, pertanian terpadu, peternakan dan perikanan, serta teknologi tepat guna lainnya, dengan harapan dapat meningkatkan sumberdaya manusia yang lebih baik serta menjadi solusi bagi masyarakat atas persoalan-persoalan dalam bidang perairan, pertanian, peternakan, dan perikanan.

\section{TUJUAN DAN SASARAN}

\section{A. TUJUAN}

1. Melatih masyarakat untuk meningkatkan sumber daya manusia.

2. Meningkatkan ekonomi masyarakat menjadi lebih baik.

3. Meningkatkan pola hidup masyarakat menjadi lebih baik.

4. Mampu melihat peluang usaha yang bisa dikembangkan oleh masyarakat baik untuk kepentingan individu maupun kelompok.

5. Meningkatkan budaya gotong-royong, memberi dan menolong orang lain yang membutuhkannya.

\section{B. SASARAN}

1. Masyarakat lokal

2. Kelompok Tani

\section{MANFAAT}

1. Masyarakat mampu memahami teknologi tepat guna dalam bidang perairan.

2. Masyarakat mampu memahami teknik pertanian terpadu.

3. Masyarakat mampu memahami teknik peternakan dan teknologi terpadu lainnya. 
4. Masyarakat dibangun mentalitas dan karakternya yang baik.

5. Masyarakat mampu menolong dirinya sendiri serta mampu menolong orang lain.

\section{SYARAT \& KETENTUAN}

Setiap Desa yang diundang untuk mengikuti pelatihan, bisa mengirimkan perwakilannya untuk mengikuti pelatihan di Sekolah Lapangan Yayasan Tangan Pengharapan dengan mengutus minimal 2 orang peserta dan maksimal 5 orang peserta dengan syarat sebagai berikut:

1. Pria/ Wanita berusia antara 25 - 48 tahun.

2. Mempunyai kemauan yang tinggi untuk belajar.

3. Siap untuk dibina dan mau berhasil untuk memperbaiki hidup menjadi lebih baik.

4. Rajin dan pekerja keras.

5. Ingin membangun Desa menjadi lebih baik.

6. Tidak membawa benda berbahaya dan minuman keras pada saat pelatihan.

7. Tidak pulang selama pelatihan berlangsung kecuali ada kedukaan dan hal hal lain yang dianggap penting.

\section{JENIS-JENIS PELATIHAN}

1. Teknologi Tepat Guna Perairan, meliputi:
a. Pembuatan tangki air (Ferrocement Water Tank) di atas tanah,
b. Pembuatan tangki air (Ferrocement Water Tank) di dalam tanah,
c. Pembuatan penyaringan air kotor,
d. Pembuatan pompa air Rus Pamp, dan
e. Pembuatan Closet.

2. Pertanian Terpadu, meliputi:
a. Teknik persemaian menggunakan poly bag, tri dan menanam langsung di bedeng,
b. Teknik budidaya sayuran,
c. Teknik pembuatan bedeng,
d. Teknik Olah lubang dan poly bag,
e. Teknik pemasangan mulsa plastik dengan system tetesan, 

f. Teknik pemupukan dan pengamatan,
g. Teknik penyemprotan,
h. Teknik pengendalian hama terpadu,
i. Teknik pembuatan pupuk bokhasi cair maupun bokhasi padat,
j. Teknik pembuatan pestisida alami,
k. Teknik pembuatan perangkap lalat buah, dan
I. Rumah sayur organik (RSO)

3. Budidaya Ikan Air Tawar (Lele).

4. Teknik Pemeliharaan Ayam Pedaging (Broiler).
5. Pengenalan Pembangkit Listrik Tenaga Surya (PLTS) Solar Home System.

6. Teknik Penggemukan Sapi Yang Alami Dan Pembuatan Pakan Ternak.

7. Manajemen Kesehatan Hewan (sapi, babi dan ayam)

\section{WAKTU \& TEMPAT PELATIHAN}

Estimasi waktu pelatihan: 7 Hari pelatihan, Teori 20\% dan 80\% Praktek.

Tempat Pelatihan: Sekolah Lapangan Yayasan Tangan Pengharapan, Jalan Perumahan Sejahtera Land, RT.30/RW.10, Dusun 05, Desa Penfui Timur, Kecamatan Kupang Tengah, Kabupaten Kupang, Nusa Tenggara Timur.

PENUTUP: Kami berharap pelatihan dari Sekolah Lapangan Yayasan Tangan Pengharapan bagi masyarakat desa di pedalaman Nusa Tenggara Timur ini dapat membantu meningkatkan potensi sumber daya masyarakat serta meningkatkan ekonomi masyarakat setempat. 


\section{BACKGROUND}

Yayasan Tangan Pengharapan's Life Training Centre was inaugurated on November 22, 2016, by Governor Frans Lebu Raya. The Life Skills Training programme is a short training programme, which was born out of the dreams of and concerns for rural communities in East Nusa Tenggara. It intends to answer the needs of rural communities in the area of water technology, integrated agriculture, animal husbandry and fisheries, and other relevant technologies. The programme also aims to improve the quality of human resources of the community and to be a solution for the community's problems in these areas.

\section{PURPOSE AND TARGETS}

\section{A. PURPOSE}

1. To train the community and to improve their skills.

2. To improve the community's economy

3. To improving the community's lifestyle

4. To assist the community in the development of economic opportunities, as an individual or collective

5. To spread the culture of helping others who need it

\section{B. TARGETS}

1. Local people

2. Farmer Group

\section{BENEFITS}

1. Communities are able to understand the appropriate water technology

2. Communities are able to understand integrated farming techniques

3. Communities able to understand various animal husbandry techniques and other integrated technologies

4. Participants are trained to have good character and mentality.

5. Participants are able to help themselves and others

\section{TERMS AND CONDITIONS}

Each village is invited to join the training programme and to send representatives (a minimum of 2 participants and a maximum of 5 participants) 
to attend the training programme at the Training Centre, with the following conditions:

1. Male/Female aged between 25 - 48 years

2. Participants have high willingness to learn

3. Participants want to succeed and to improve their life

4. Diligent and hardworking

5. Participants have the willingness to improve their village

6. Participants are not allowed to bring dangerous objects and alcohol during training sessions

7. Participants are not allowed to go home during the training sessions unless for important reasons

\section{TYPES OF TRAINING}

1. Technology in Water, Irrigation, and Sanitation, including:
a. Ferro-cement Water Tank (on the ground)
b. Ferro-cement Water Tank (in the ground)
c. Water filter
d. Rush Pump, and
e. Closet Making

2. Integrated Agriculture, including:
a. Nursery techniques
b. Vegetable cultivation techniques
C. Raised bed making technique
d. Processing holes and poly bags
e. Plastic mulch installation (a drip system)
f. Fertilization and plant observation techniques
g. Spraying technique
h. Integrated pest control
i. Liquid and solid bokashi fertilizer
j. Natural pesticides
k. Fruit fly traps
I. Organic vegetable

3. Freshwater Aquaculture

4. Chicken Broiler 
5. Introduction to Home Solar System

6. Cattle Farming and Fodder

7. Animal Health Management (cattle, pigs, and chickens)

\section{TIME \& PLACE OF TRAINING}

Estimated training time: 7 days training, 20\% theory and 80\% practice.

Venue: Tangan Pengharapan Life Training Centre, Jalan Perumahan Sejahtera Land, RT.30 / RW.10, Dusun 05, Penfui Timur Village, Kupang Tengah District, Kupang Regency, East Nusa Tenggara.

\section{CLOSING}

We hope that the training programme can help increase the potential of community's skills and improve the economy of the local community 


\section{Appendix H: Rules for the Life Skills Training Programme Participants}

\section{Lampiran 1}

Dalam melaksanakan pelatihan di Sekolah Lapangan Yayasan Tangan Pengharapan, kami memiliki ketentuan-ketentuan dalam pelaksanaannya untuk diikuti dan dipatuhi oleh setiap utusan dari desa-desa peserta pelatihan, yaitu sebagai berikut:

1. Dalam kegiatan pelatihan yang dilaksanakan oleh Sekolah Lapangan Yayasan Tangan Pengharapan tidak mengenal uang duduk dan atau tidak ada uang saku.

2. Setiap desa undangan, maksimum jumlah utusan untuk mengikuti pelatihan di Sekolah Lapangan Yayasan Tangan Pengharapan tidak dibatasi, namun harus dikoordinasikan dengan tim sosialisasi dari Tangan Pengharapan terlebih dahulu.

3. Setiap peserta diwajibkan untuk menanggung semua transportasi pulangpergi (PP) dari desa masing-masing ke titik penjemputan dan pengantaran yang telah ditetapkan oleh Sekolah Lapangan Yayasan Tangan Pengharapan.

4. Apabila ada peserta datang tidak tepat waktu pada saat penjemputan, maka segala resiko yang ada diluar tanggung jawab Sekolah Lapangan Yayasan Tangan Pengharapan

5. Apabila ada peserta berangkat ke tempat pelatihan Sekolah Lapangan Yayasan Tangan Pengharapan, tanpa ada konfirmasi terlebih dahulu kepada Sekolah Lapangan Yayasan Tangan Pengharapan, maka segala biaya transportasi dan resiko yang ada, diluar tanggung jawab Sekolah Lapangan Yayasan Tangan Pengharapan.

6. Bagi peserta perempuan, tidak diperbolehkan membawa anak kecil ke tempat pelatihan Sekolah Lapangan Yayasan Tangan Pengharapan.

7. Dilarang membawa minum-minuman keras dan atau benda tajam lainnya pada saat penjemputan dan selama pelatihan di Sekolah Lapangan Yayasan Tangan Pengharapan berlangsung.

8. Segala Akomodasi peserta pelatihan seperti transportasi pulang-pergi (PP) dari Sekolah Lapangan Yayasan Tangan Pengharapan ke titik Penjemputan 
dan Pengantaran, makan-minum disepanjang perjalanan, makan-minum selama pelatihan berlangsung, keperluan ATK dan perlengkapan mandi selama pelatihan berlangsung ditanggung oleh Sekolah Lapangan Yayasan Tangan Pengharapan. Peserta pelatihan juga akan mendapatkan T-Shirt (Kaos Berkerak) Tangan Pengharapan.

9. Diakhir dari pelatihan yang dilaksanakan oleh Sekolah Lapangan Yayasan Tangan Pengharapan, setiap peserta akan dibekali dan atau diberikan segala materi pelatihan, dibekali dan atau diberikan modal awal pertanian berupa pacul dan bibit-bibit sayur-sayuran, serta setiap peserta pelatihan akan mendapatkan Sertifikat pelatihan dari Sekolah Lapangan Yayasan Tangan Pengharapan.

10. Setiap peserta pelatihan wajib mematuhi segala peraturan dan tata tertib yang telah ditetapkan oleh Sekolah Lapangan Yayasan Tangan Pengharapan. 


\section{Attachment 1}

In carrying out the training programme, there are a number of rules to be followed and obeyed by each delegate from the participating villages, as follows:

1. Tangan Pengharapan will not provide any financial incentive for attending the training programme.

2. For each invited village, the maximum number of delegates to attend is not limited, but must first be coordinated with the socialization team from Tangan Pengharapan.

3. Participants are required to cover all round-trip transportation from their respective villages to the pick-up and drop-off point near their villages.

4. Tangan Pengharapan is not responsible if participants do not arrive on time at the pick-up point at an agreed time.

5. Tangan Pengharapan is not responsible for the cost of transportation for participants who arrive at the training centre without prior confirmation

6. For female participants, it is not permitted to bring small children to the training centre.

7. Participants are not allowed to bring alcoholic drinks or other sharp objects to the training centre.

8. Tangan Pengharapan will cover all costs for accommodation, transportation, and meals for participants. Trainees will also get a t-shirt.

9. At the end of the training sessions, each participant will be provided with the training materials, hoe and vegetable seeds. Each participant will also receive a training certificate.

10. Each participant must comply with all rules and regulations set by Tangan Pengharapan. 